\title{
PAPERS OF PROFESSOR TETSUJI KAMETANI
}

1. Studies on the Synthesis of Emetine and Related Compounds. VI. A Synthesis

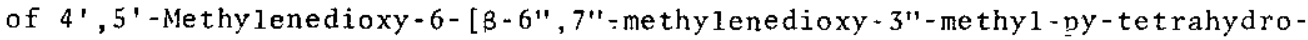
isoquinoly1-1"')-ethyl]-4-methy $1-3,4,5,6,7,8$-hexahydro- $\left(1^{\prime}, 2^{\prime}: 1,2\right.$-benzoquino1izine): S. Sugasawa and T. Kametani, Yakugaku Zasshi, 65, $372-373$ (1945).

2. Syntheses of Imidazoisoquinoline Derivatives. I. Syntheiss of 9,10-Dimethoxy-3-(p-aminopheny1)-5,6-dihydrobenzoglyoxalocoline: T. Kametani and H. Iida, Yakugaku Zasshi, 70, 258-261 (1950).

3. Syntheses of Imidazoisoquinoline Derivatives. II. Synthesis of 9,10-Dimethoxy-3-veratry1-5,6-dihydrobenzog1yoxalocoline: T. Kametani and H. Iwakata, Yakugaku Zasshi, $70,261-263$ (1950).

4. Syntheses of Imidazoisoquinoline Derivatives. III. Synthesis of 9,10-Dimethoxy-3-safry1-5,6-dihydrobenzoglyoxalocoline: T. Kametani and H. Iwakata, Yakugaku Zasshi, 70, $263-265$ (1950).

5. Syntheses of Papaverine Derivatives. I. Synthesis of 1-(3'-Methoxy-4"-hydroxypheny1)-3-methyl-6,7-methylenedioxyisoquinoline: T. Kametani, Yakugaku Zasshi, $\underline{71}, 322-324$ (1951).

6. Syntheses of Imidazoisoquinoline Derivatives. IV. Syntheses of 9,10-Methy1enedioxy-3-(4'-nitropheny1)-5-me thy 1-5,6-dihydrobenzoglyoxalocoline, 9,10le thylenedioxy-3-(3',4'-dimethoxyphenyl)-5-methylbenzoglyoxalocoline and $9,10-$ Me thylenedioxy-3-(3',4'-me thylenedioxypheny1)-5-methy1-5,6-dihydrobenzoglyoxalocoline: T. Kametani, H. Iida, and H. Iwakata, Yakugaku Zasshi, 71, 325 - 329 (1951).

7. Studies on the Syntheses of Aminoisoquinoline Derivatives. I. Saponification of Benzy1 1-Pheny1-6,7-dimethoxyisoquinolyl-3-carbamate: T. Kametani, Yakugaku Zasshi, $71,329-331$ (1951).

8. Studies on the Syntheses of Aminoisoquinoline Derivatives. II. A Synthesis of 1-Pheny 1-3,4-dihydro-4-amino-6,7-dimethoxyisoquinoline Derivatives: T. Kametani, Yakugaku Zasshi, 71,332 - 335 (1951).

9. Syntheses of Imidazoisoquinoline Derivatives. V. Synthesis of 9,10-Dimethoxy-3-nicotinyl-5,6-dihydrobenzoglyoxalocoline: T. Kametani and H. Iida, Yakugaku Zasshi, 71, 995 - 998 (1951).

10. Syntheses of Imidazoisoquinoline Derivatives. VI. Synthesis of 9,10-Dimetho- 
xy-3-isonicotınyl-5,7-dihydrobenzoglyoxalocoline: T. Kametani and H. Iida, Yakugaku Zasshi, 71, 998 - 1000 (1951).

11. Syntheses of Imidazoisoquinoline Derivatives. VIL. Synthesis of 9,10-Dimethoxy-3-picolinyl-5,6-dihydrobenzoglyoxalocoline: T. Kametani and H. Iida, Yakugaku Zasshi, 71, $1000-1002$ (1951).

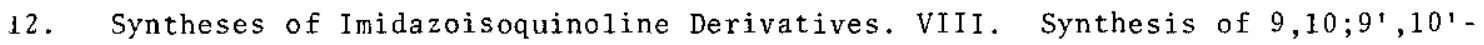
bis-Dimethoxy-3,3'-(5,6-dihydrobenzog1yoxalocoline): T. Kametani and H. Iwakata, Yakugaku Zasshi, 71, 1002 - 1004 (1951).

13. Syntheses of Imidazoisoquinoline Derivatives. IX. Synthesis of 9,10-Dimethoxy-3-(cinchony1)-5,6-dihydrobenzoglyoxalocoline: T. Kametani and H. Iida, Yakugaku Zasshi, 71, $1004-1006$ (1951).

14. Syntheses of Pyrimidinoisoquinoline Derivatives. I. Syntheses of (2'-Pheny1$4^{\prime}$-hydropyrimidino $) 1^{\prime}, 6^{\prime} ; 1,2-(3,4$-dihydro-6,7-dimethoxy isoquinoline): T. Kametani and S. Kano, Yakugaku Zasshi, 71, 1007 - 1009 (1951).

15. Syntheses of Aminoisoquinoline Derivatives. III. Synthesis of 1-Pheny1-3,4dihydro-4-(4'-dimethylaminopheny1)-6,7-dimethoxyisoquinoline: T. Kametani and T. Oda, Yakugaku Zasshi, 71, 1009 - 1011 (1951).

16. Studies on the Syntheses of Isoquinoline Derivatives. XV. Syntheses of Some Nitro Compounds as Synthetic Materials for Isoquinoline Derivatives: $T$. Kametani and Y. Masuda, Yakugaku Zasshi, $72,81-85$ (1952).

17. Studies on the Syntheses of Isoquinoline Derivatives. XVI. Synthesis of 1Pheny1-3-veratry1-6,7-dimethoxyisoquinoline: T. Kametani, Yakugaku Zasshi, $\underline{72}, 85-87(1952)$.

18. Studies on the Antibacterial Substances. I. Antibacterial Activities of Isonicotinic Acid Hydrazide and Isonicotinylglycine Hydrazide: 2 . Horii, $T$. Kametani, and Y. Yamamura, Yakugaku Zasshi, 72, 971 - 972 (1952).

19. Syntheses of Isoquinoline Derivatives. XVII. Studies on the Syntheses of Papaverine Derivatives. (2). Syntheses of $1-\left(2^{\prime}, 4^{\prime}-\right.$ Dihydroxypheny 1$)$ - and 1 (3',4'-Dihydroxypheny1)-3-methy1-6,7-methylenedioxyisoquinoline (Benzylation of B-Resorcyclic Acid): T. Kametani and S. Kano, Yakugaku Zasshi, 72, 1081 $1084(1952)$.

20. Studies on the Syntheses of Isoquinoline Derivatives. XVIII. Syntheses of Papaverine Derivatives. (3). Synthesis of 1-( $3^{\prime}$-Methoxy-4'-hydroxybenzy1)3-methy1-6,7-methylenedioxy isoquinoline: T. Kametani and J. Serizawa, Yakugaku Zasshi, 22, $1084-1087$ (1952). 
21. Studies on the Syntheses of Isoquinoline Derivatives. XIX. Synthesis of 1Phenyl-3-benzylisoquinoline: T. Kametani, K. Ninomiya, H. Iida, and J. Serizawa, Yakugaku Zasshi, 72, 1087 - 1090 (1952).

22. Studies on the Syntheses of Isoquinoline Derivatives. XX. A New Method for the Preparation of Isoquinoline Derivatives (1). Reaction of Safrol on Acid AmIde in the Presence of $\mathrm{POCl}_{3}$ : T. Kametani, Yakugaku Zasshi, $\underline{72}, 1090$ - 1093 (1952).

23. Studies on Antibacterial Substances. II. Antibacterial Activities of Various Hydrazides for M. tuberculosis in vitro: T. Kametani, Y. Yamamura, and $H$. Uchida, Yakugaku Zasshi, 22, 1093 - 1096 (1952).

24. Studies on the Syntheses of Isoquinoline Derivatives. XXI. A New Method for the Preparation of Isoquinoline Derivatives (2). Reaction of MethyleugenoI on Acid Amide in the Presence of POCl 3 : T. Kametani, Yakugaku Zasshi, $\underline{72}$, $1537-1539$ (1952).

25. Studies on the Syntheses of Isoquinoline Derivatives. XXII. A New Method for the Preparation of Isoquinoline Derivatives. (3). Condensation Agents, Mechanism of New Syntheses, and a Synthesis of 3,4-Dihydroneupaverine: T. Kametani and K. Ninomiya, Yakugaku Zasshi, 72, 1539 - 1541 (1952).

26. Studies on the Syntheses of Isoquinoline Derivatives. XXIII. A New Method for the Preparation of Isoquinoline Derivatives. (4). Reaction of Ally1benzene Derivatives and Oximes: T. Kametani, Yakugaku Zasshi, 73, $12-15$ (1953).

27. Syntheses of Thiophene Derivatives. I. Modified Synthesis of 3-Dimethylamino1,1-di-(2'-thieny1)butene-1: T. Kametani and Y. Akazawa, Yakugaku Zasshi, $\underline{73}$, $649-650(1953)$.

28. Studies on the Syntheses of Isoquinoline Derivatives. XXIV. Migration of the Double Bond of Isoquinoline Derivatives. (1): T. Kametani and H. Iida, Yakugaku Zasshi, $73,677-680$ (1953).

29. Studies on the Syntheses of Isoquinoline Derivatives. XXV. Migration of the Double Bond of Isoquinoline Derivatives. (2): T. Kametani and K. Ninomiya, Yakugaku Zasshi, 23, 681 - 685 (1953).

30. Studies on the Syntheses of Isoquinoline Derivatives. XXVI. A New Method for the Preparation of Isoquinoline Derivatives. (5). Reaction of Various Allylbenzene Derivatives and Aldoximes or Acid Amides: T. Kametani and K. Otsuki, Yakugaku Zasshi, $\underline{73}, 685-687$ (1953).

31. Studies on the Syntheses of Isoquinoline Derivatives XXVII. Synthesis of 
3-Methy1-6,7-methylenedioxy-3,4-dihydroisoquinoly1-1-carboxylic Acid Ethyl Ester: T. Kametani, Yakugaku Kenkyu, 25, 451 - 453 (1953).

32. Studies on the Syntheses of Isoquinoline Derivatives. XXVIII. Synthesis of Papaverine Derivatives. (5): T. Kametani and M. Inagaki, Yakugaku Zasshi, 74, $417-419(1954)$.

33. Studies on the Syntheses of Isoquinoline Derivatives. XXIX. Synthesis of Papaverine Derivatives. (6): T. Kametani and K. Ohtsuki, Yakugaku Zasshi, $\underline{74}$, $621-625(1954)$.

34. Studies on the Syntheses of Isoquinoline Derivatives. XXX. Synthesis of Papaverine Derivatives. (7): T. Kametani and M. Inagaki, Yakugaku Zasshi, $74,1040-1041(1954)$.

35. Studies on the Syntheses of Isoquinoline Derivatives. XXXI. Synthesis of Furo[3,2-c] ]pyridine Derivatives: T. Kametani, Y. Ito, and H. Isaka, Yakugaku Zassh1, 74, $1298-1299$ (1954).

36. Studies on the Syntheses of Isoquinoline Derivatives. XXXII. Synthesis of Thieno[3,2-c]pyridine Derivatives and Their Pharmacological Action: $T$. Kametani, Y. Ito, and S. Aonuma, Yakugaku Zasshi, 74, 1301 - 1304 (1954).

37. Studies on the Syntheses of Synthetic Analgesics and Antispasmodics. II. Synthesis of Procaine Amide Analogs: T. Kametani, T. Katagi, T. Fujiwara, and Y. Akasawa, Yakugaku Kenkyu, 26, $544-548$ (1954).

38. Studies on the Syntheses of Isoquinoline Derivatives and Their Analogs. XXXIII. Mechanism of the Cyclization of 3-Phenylisoquinoline Derivatives: T. Kametani and $\mathrm{K}$. Ohtsuki, Yakugaku Zasshi, $\underline{75}$, 705 - 709 (1955).

39. Studies on the Syntheses of Isoquinoline Derivatives and Their Analogs. XXXIV. Pyrimidinoisoquinoline Derivatives. (2): T. Kametani and T. Katagi, Yakugaku Zasshi, $\underline{75}, 709-713(1955)$.

40. The Effects of Benzylamine Derivatives on Bloodvessel and Heart: $S$, Aonuma, T. Hama, and T. Kametani, Yakugaku Kenkyu, 27, $607-611$ (1955).

41. Studies on the Syntheses of Heterocyclic Compounds. XLII. Synthesis of Imidazoisoquinoline Derivatives. X: H. Iida and T. Kametani, Yakugaku Kenkyu, $27,774-778(1955)$.

42. Studies on the Syntheses of Isoquinoline Derivatives and Their Analogs. XXXV. Migration of the Double Bond of Pyrimidinoisoquinolines and Presumption of Their Structures by the Infrared Absorption Spectra: $\mathrm{T}$. Kametani and $\mathrm{T}$. Katagi, Pharm. Bull. (Japan), 3, 253-259 (1955). 
43. Studies on the Syntheses of Isoquinoline Derivatives and Their Analogs. XXXVI. Deamination of $2^{\prime}$-(p-Aminophenyl)pyrimidinoisoquinoline Derivatives: T. Kametani and T. Katagi, Pharm. Bu1l. (Japan), 3, 259- 262 (1955).

44. Studies on the Syntheses of Isoquinoline Derivatives and Their Analogs. XXXVII. A New Method for the Preparation of 1-Substituted 3-Methyl-3,4dihydroisoquinoline Derivatives by the Reaction of Allylbenzene and Heterocyclic Acıd Amide or Oxime: T. Kametani, K. Ohtsuki, and M. Fukui, Pharm. Bu11. (Japan), 3, $263-266$ (1955).

45. Studies on the Syntheses of Heterocyc1ic Compounds. LXIII. Syntheses of Furan Derivatives. (2). Synthesis of Furo[2,3-c] $]$ pyridine Derivative and Its Related Compounds: T. Kametani, Y. Nomura, and K. Morita, Yakugaku 2asshi, 76, $652-654(1956)$.

46. Studies on the Syntheses of Heterocyc1ic Compounds. LXIV. Syntheses of Furan Derivatives. (3). Synthesis of $N$-Substituted $\beta$-2-Furylethylamine Derivatives: T. Kametani and Y. Nomura, Yakugaku Zasshi, 76, 753 - 754 (1956).

47. Studies on the Syntheses of Heterocyclic Compounds. LXIX. The Mechanism of Bischler-Napieralski Reaction (The Ring-closure of a Tertiary Acid Amide): T. Kametani, T. Katagi, and Y. Nomura, Yakugaku Kenkyu, 30, $185-193$ (1958).

48. Studies on the Syntheses of Heterocylic Compounds. L. A Synthesis of 6Methoxytryptamine: T. Kametani and T. Katagi, Yakugaku Kenkyu, 30, 194 $196(1958)$.

49. Hydrolytic Products of 2-Methy)- or 2-Pheny1-4-(2'-nitro-3'-methoxy-4'acetoxybenza1)-5-oxazolone and Their Related Compounds: T. Kametani and K. Fukumoto, Yakugaku Kenkyu, $\underline{30}, 412-419$ (1958).

50. Studies on the Syntheses of Heterocyclic Compounds. XLV. Synthesis of the Methyl Derivatives of Heterocyclic Compounds by the Hydrogenolysis of Their Phenylurethans from Primary Alcohol: T. Kametani, K. Fukumoto, and Y. Nomura, Chem. and Pharm. Bull. (Japan), $\underline{6}, 467-472$ (1958).

51. Synthesis of $\alpha$-Substituted Glutarimides via'Michael Condensation: $T$. Kametani, W. Taub, and D. Ginsburg, Bu11. Chem. Soc. Japan, 31, $857-859$ (1958).

52. Synthesis of 3,3-Disubstituted 2-Piperizinones: T. Kametani, W. Taub, and D. Ginsburg, Bu11. Chem. Soc. Japan, 31, $860-861$ (1958).

53. Studies on Anticancer Agents. (1). Synthesis of Varlous Alkyl Thiolsulfinates and Their Tumor Inhibiting Effects: T. Kametani, K. Fukumoto, and 0. Umezawa, Yakugaku Kenkyu, 31, 60 - 74 (1959). 
54. Studies on Anticancer Agents. (II). A Synthesis of Heterocyclic Disulfides and Their Oxidation Products: T. Kametani, K. Fukumoto, and O. Umezawa, Yakugaku Kenkyu, 31, 132 - 139 (1959).

55. Studies on Antibacterial Derivatives. (III). Antibacterial and Antifungal Activities of Various Thiolsulfinates: T. Kametani and O. Umezawa, Yakugaku Kenkyu, 31, $158-161$ (1959).

56. Studies on the Syntheses of Benzoquinolizine Derivatives. II. The Formation of 2-Quinolone and 1-Isoquinolone by Alkali Treatment of Their Corresponding Chloro Derivatives: T. Kametani, Y. Nomura, and K. Fukumoto: Yakugaku Kenkyu, 31, $673-677$ (1959).

57. Studies on the Syntheses of Benzoquinolizine Derivatives. III. The Condensation of Ethy 1 Crotonate with Ethyl Cyanoacetate, Reesterification during Its Michael Condensation and Synthesis of 4-Methy1-5-carboethoxy-2-piperidone: T. Kametani and Y. Nomura, Yakugaku Kenkyu, 31, $678-689$ (1959).

58. Studies on the Syntheses of Heterocyclic Compounds. LII. The EschweilerClarke and Pictet-Spengler Reaction with $\beta$-Methoxysafrylamine: T. Kametani, K. Fukumoto, and T. Katagi, Chem. and Pharm. Bu11. (Japan), 7, $567-572$ (1959).

59. Studies on the Syntheses of Heterocyclic Compounds. LIII. The Formation of Vanillide and Polyvanillide: T. Kametani, K. Fukumoto, and Y. Nomura, Chem. and Pharm. Bull. (Japan), 7, $641-644$ (1959).

60. Studies on the Syntheses of Heterocyclic Compounds. LXI. Syntheses of Imidazoisoquínoline Derivatives. (11). Syntheses of 8,9-Dimethoxy-3-(2-furfuryl)and -(2-furylethy1)-5,6-dihydroimidazo[5,1-a $]$ isoquinoline: H. Iida (T. Kametani), Yakugaku Zasshi, 80, $1127-1130$ (1960).

61. Studies on the Synthesis of Heterocyclic Compounds. LIX. Studies on the Polyester. (2). The Formation of Polymer from $\mathrm{p}$-Hydroxy- or $\mathrm{p}$-Benzyloxybenzoic Acid and the Character of Thionyl Chloride: T. Kametani and K. Fukumoto, Yakugaku Zasshi, $80,1188-1192(1960)$.

62. Studies on the Syntheses of Heterocyclic Compounds. LX. 1,2-Dihydroisoquino1ine Derivatives: T. Kametani and K. Fukumoto, Yakugaku Zasshi, 80, 1288 $1290(1960)$.

63. Synthesis of rac-Tetrahydrorotundine: T. Kametani and Y. Nomura, Chem. and Pharm. Bul1. (Japan), $\underline{8}, 658-660(1960)$.

64. Studies on the Syntheses of Heterocyclic Compounds. LIV. Formation of $\mathrm{N}$ Alky1-2-pyridone by Alkali Treatment of N-Alky1-2-chloropyridinium Salt: T. Kametani and Y. Nomura, Chem. and Pharm. Bu11. (Japan), 8, $741-744$ (1960). 
65. Anti-cancer Agents. IV. Desulfurization by Hydrazine Hydrate. (1). The Reaction of $\underline{o}^{-}, \underline{m}^{-}$, and $\mathrm{p}-\mathrm{Nitrobenzyl}$ Disulfide with Hydrazine Hydrate: T. Kametani, K. Fukumoto, Y. Takayanagi, T. Teshigawara, and O. Umezawa, Chem. and Pharm. Bu11. (Japan), $\underline{8}, 995$ - 998 (1960).

66. Studies on Anti-Cancer Agents. V. Desulfurization by Hydrazine Hydrate. II. The Reaction of Benzyl and Piperonyl Disulfide with Hydrazine: T. Kametani, K. Fukumoto, Y. Satoh, T. Teshigawara, and O. Umezawa, Bu11. Chem. Soc. Japan, $\underline{33}, 1678-1680(1960)$.

67. Studies on the Anti-cancer Agents. VI. The Mechanism of Desulfurization Reaction of Bis (p-nitrobenzy 1) Disulfide with Hydrazine Hydrate and the Reaction of Disulfide with Varıous Amines: T. Kametani, S. Takano, K. Fukumoto, and Y. Takayanagi, Yakugaku Zasshi, 81, $83-88$ (1961).

68. A Modified Synthesis of Tryptamine (Studies on the Syntheses of Heterocyc1ic Compounds. LXIII): T. Kametani and K. Fukumoto, Yakugaku Kenkyu, $\underline{33}, 83$ 86 (1961).

69. Studies on the Syntheses of Benzoquinolizine Derivatives. IV. Syntheses of B-Phenethyl Alcohols by the Diazotisation Reaction: T. Kametani and Y. Nomura, Yakugaku Kenkyu, $\underline{33}, 87-91$ (1961).

70. Studies on the Syntheses of Benzoquinolizine Derivatives. V. Condensation of Drethyl $\alpha$-Cyano- $\beta$-methylglutarate with Homoveratrylamine by Catalytic Reduction in a Higher Pressure: T. Kametani and Y. Nomura: Yakugaku Kenkyu, $\underline{33}, 92-98(1961)$.

71. Studies on the Syntheses of Pyrimidoisoquinoline Derivatives. V. Synthesis of 4-(3',4'-Dimethoxyphenyl)- and 4-(3',4'-Methylenedioxypheny1)-6,7-dihydro9,10-dimethoxy-2H-pyrimido[4,3-a] isoquinoline: T. Kametani, H. Iida, and S. Kano, Yakugaku Kenkyu, 33, 223 - 227 (1961).

72. Studies on the Syntheses of Heterocyclic Compounds. LXVII. Synthesis of Dibenzochinanthridine Derivatives: T. Kametani and Y. Satoh, Yakugaku Kenkyu, $\underline{33}, 228-233(1961)$.

73. Studies on the Syntheses of Heterocyclic Compounds. LXIX. Syntheses of Chinarthridine Derivatives. 2. A Synthesis of 2,3,10,11-Tetramethoxy-5,6, 13,14-tetrahydrodibenzo [므, $\underline{\text { ] }}]$ chinanthridine: T. Kametani and Y. Satoh, Yakugaku Kenkyu, 33, 803 - 809 (1961).

74. Studies on the Syntheses of Heterocyclic Compounds, LXX. A Synthesis of 1Ethoxyme thy 1-6,7-dime thoxy-1,2,3,4-tetrahydroisoquinoline: T. Kametani, S. Ihara, and Y. Satoh, Yakugaku Kenkyu, 33, $810-812$ (1961). 
75. Studies on the Syntheses of Heterocyclic Compounds. LxII. Synthesis of racTetrahydrorotundine: T. Kametani and Y. Nomura, Chem. and Pharm. Bul1., 9, $139-145$ (1961).

76. Studies on the Syntheses of Heterocyclic Compounds. LXVIII. Synthesis of Papaverine Derivatives. (8). Synthesis of 1-(2,5-Dihydroxypheny1)-3-methy16,7-methylenedioxyisoquinoline and Supplement on Synthesis of 1-(3,4-Dihydroxypheny 1)isoquinoline Derivative: T. Kametani and S. Kano, Yakugaku $\underline{\text { Zasshi, }} \underline{82}, 731-733$ (1962).

77. Studies on the Syntheses of Heterocyclic Compounds. LXXIII. Synthesis of 2Methy 1-9,10-dime thoxy-1,2,3,4,6,7-hexahydro-11bH-benzo[a]quinolizine: T. Kametani, T. Hayasaka, S. Takano, and S. Akaboshi, Yakugaku Zasshi, 82, y56 959 (1962).

78. Synthesis of Papaverine Derivatives. (9). A Synthesis of 1-(3,5-Dihydroxypheny1)-3-methyl-6,7-methylenedioxyisoquinoline and the Supplement on the Synthesis of 1-(2,4-Dihydroxyphenyl)isoquinoline Derivative (Studies on the Syntheses of Heterocyclic Compounds. LXXI): T. Kametani and S. Kano, Yakugaku Zasshi, 82, 1059 - 1062 (1962).

79. Studies on the Syntheses of Heterocyclic Compounds. LXXII. Syntheses of Imidazoisoquinoline Derivatives. (12). The Mechanism of Ring Closure of Imidazoisoquinoline Derivatives: H. Iida (T. Kametani), Yakugaku Zasshi, $\underline{82}$, 1063 - 1065 (1962).

80. Studies on the Syntheses of Heterocyclic Compounds. Lxxiv. The Condensation of Polybasic Acid Esters with Amines. (1). The Condensation Products by Fusion of Diethyl 2-Ethoxycarbonyl-3-methylg1utarate with Homoveratrylamine: T. Kametani and R. Yanase, Yakugaku Zasshi, 82, 1303 - 1306 (1962).

81. Studies on the Syntheses of Cularine Derivatives. I. A Synthesis of Dipheny1 Ether by Ullmann Reaction and the Formation of oxepine Nucleus: T. Kametani, K. Fukumoto, and T. Nakano, Yakugaku Zasshi, 82, 1308 - 1311 (1962).

82. Studies on the Syntheses of Heterocyclic Compounds. LXXVI. Synthesis of 4 Methylpyridine Derivatives: T. Kametani and M. Satoh, Yakugaku Kenkyu, $\underline{34}$, 117 - 124 (1962).

83. The Condensation of Polybasic Acid Esters with Amines. (2). The Condensation Products by Fusion of Diethyl 2-Cyano-3-methylglutarate with Homoveratrylamine (Studies on the Syntheses of Heterocyclic Compounds. LXXVII): T. Kametani, R. Yanase, and R. Kobayashi, Yakugaku Zasshi, 83, 171 - 174 (1963).

84. Synthesis of 1-(5-Nitro-2-thienyl)-6,7-dialkoxyisoquinoline Derivatives and Antibacterial or Antifungal Actrvity of 2 -Substituted 5 -Nitrothiophene Deriva- 
tives (Studies on the Syntheses of Heterocyclic Compounds. LXXVIII): T. Kametani, O. Umezawa, M, Satoh, and R. Kobayashi, Yakugaku Zasshi, $\underline{83}, 174$ $179(1963)$.

85. Synthesis of Cularine and Related Compounds. (2). The Products of N-[3-(2Formy 1-4,5-dimethoxyphenoxy)-4-methoxyphenethyl」acetamide by Pictet-Spengler Reaction (A Synthesis of C-nor-Cularine) (Studies on the Syntheses of Heterocyclic Compounds. LXXIX): I. Kametani, K. Fukumoto, and K. Ogasawara, Yakugaku Zasshi, 83, $180-184$ (1963).

86. Studies on the Syntheses of Heterocyclic Compounds. LXXX. Synthesis of Papaverine Derivatives. (10). Synthesis of 1-(2,3-Dihydroxypheny 1)- and 1-(2,6-Dihydroxypheny1)-3-methyl-6,7-methylenedioxyisoquinoline and Its Related Compounds: T. Kametani and S. Kano, Yakugaku Zasshi, $\underline{83}, 356-360$ (1963).

87. Studies on the Syntheses of Heterocyclic Compounds. LXXXI. Synthesis of Papaverine Derivatives. (11). Synthesis of 6,7-Methylenedioxy-3,4-dihydroand 1,2,3,4-tetrahydroisoquinoline Derivatives Possessing a Thiophene Nucleus in 1-Position: T. Kametani and H. Sugahara, Yakugaku Zasshi, $\underline{83}, 360-364$ $(1963)$.

88. Synthesis of 2-Halogeno-4,5-dialkoxyphenylfatty Acid Hydrazide and Its Re1ated Compounds and Their Anti-cancer Activity: T. Kametani, O. Umezawa, Y. Satoh, K. Ugasawara, S. Shibuya, M. Ishiguro, and D. Mizuno, Yakugaku Zasshi, $\underline{83}$, $838-844(1963)$.

89. The Reaction of (2-Bromo-4,5-dimethoxypheny1)acetic Acid Hydrazide with Various Carbonyl Compounds and Their Anticancer Activity (Studies on Anticancer Agents. VIII): T. Kametani, O. Umezawa, H. Yagi, M. Ishiguro, and D. Mizuno, Yakugaku_Zasshi, $83,844-847$ (1963).

90. Bromination of (2-Bromo-4,5-dimethoxyphenyl)acetic Acid Hydrazide Derivatives (Studies on Anti-cancer Agents. IX): T. Kametani and O. Umezawa, Yakugaku $\underline{\text { ZasshI }}, \underline{83}, 847-850(1963)$.

91. Synthesis of 2-Nitro-4,5-dimethoxyphenylfatty Acid Hydrazide and Its Related Compounds and lheir Anti-cancer Activity: T. Kametani, O. Umezawa, S. Shibuya, K. Ogasawara, M. Ishiguro, and D. Mizuno, Yakugaku Zasshi, $\underline{83}, 851$ 855 (1963).

92. Synthesis of Papaverine Derivatives. (12). Oxidation of Methylene Group of 1-(3,4-Dimethoxybenzy 1)-6,7-dimethoxy-3,4-dihydro (and 1,2,3,4-tetrahydro)isoquinoline by Alumina-Chromatography (Studies on the Syntheses of Heterocyclic Compounds. LXXXVI): T. Kametani and K. Fukumoto, Yakugaku Zasshi, $\underline{83}$, $1031-1035$ (1963). 
93. A Simplified Synthesis of 3-Methoxy-4-hydroxy- and 3-Methoxy-4-tosyloxyphenethylamine (Studies on the Syntheses of Heterocyclic Compounds. LXXXVII): T. Kametani, S. Takano, and E. Karibe, Yakugaku Zasshi, 83, 1035 - 1039 (1963).

94. Ring Closure Reaction of N-Substituted Imide Derivatives (Studies on the Syntheses of Heterocyclic Compounds. LXXXVIII): T. Kametani and R. Yanase, Yakugaku Zasshi, $\underline{83}, 1039-1042$ (1963).

95. Studies on the Syntheses of Heterocyclic Compounds. LXXIX. Mechanism of the Formation of 2H-Pyrjmido[4,3-a]isoquinoline Derivatives: T. Kametani and $S$. Kano, Yakugaku Zasshi, $\underline{83}, 1043$ - 1047 (1963).

96. Synthesis of Papaverine Derivatives. (13). Synthesis of 6,7-Dimethoxy-3,4dihydro-, 1,2,3,4-l'etrahydro- and 3-Methy1-6,7-dimethoxy-3,4-dihydro-, 3Methy 1-6,7-methylenedioxy-3,4-dihydroisoquinoline Derivatives Possessing a Thiophene Nucleus in 1-Position (Studies on the Syntheses of Heterocyc1ic Compounds. XC): T. Kametani and H. Sugahara, Yakugaku Zasshi, 83, 1048 $1052(1963)$.

97. Synthesis of cularine and Related Compounds. VII. The Formation of Indole Derivatives (Studies on the Syntheses of Heterocyclic Compounds. XCI): T. Kametani, K. Fukumoto, and K. Masuko, Yakugaku Zasshi, 83, 1052 - 1055 (1963).

98. Antimicrobial Effect of 2-Substituted 5-Nitrothiophene Derivatives: 0. Umezawa, F. Kobayashı, and T. Kametani, Yakugaku Kenkyu, 35, 256 - 263 (1963).

99. The Synthesis of Natural Products by Phenol Oxidation: $\mathrm{T}$. Kametani and $\mathrm{K}$. Fukumoto, Yakugaku Kenkyu, 35, 426 - 447 (1963).

100. Cularıne and Related Compounds. V. Investigation of the Ullmann Reaction Products of Methyl (2-Bromo-4,5-dimethoxypheny1)acetate with Phenolic Compounds, and an Approach to the Total Synthesis of Cularine: T. Kametani, K. Fukumoto, S. Shibuya, and T. Nakano, Chem. and Pharm. Bull. (Japan), 11, 1299 - 1305 (1963).

101. Cularine and Related Compounds. IV. The oximination and Reduction of 2,3,6Trimethoxydibenzo[b,f] oxepin-10(11H)-one: T. Kametani and K. Fukumoto, Chem. and Pharm. Bu11. (Japan), 11, 1322 - 1325 (1963).

102. Total Synthesis of $( \pm)$-Cularine: T. Kametani and K. Fukumoto, Chem. and Ind. , 1963,291 .

103. Cularine and Related Compounds. Part VI. A Total Synthesis of ( \pm )-Cularine: T. Kametani and K. Fukumoto, J. Chem. Soc., 1963, $4289-4296$.

104. Studies on the Syntheses of Heterocyclic Compounds, XCII. Synthesis of 1- 
Benzylcotarnine Derivatives: T. Kametani, S. Takano, and T. Nakano, Yakugaku Zasshi, 84, $314-317(1964)$.

105. Studies on Anti-cancer Agents. XI. Synthesis of Methanesulfonate of Various Carbinols and Phenolic Compounds and Their Pharmacological Activity: T. Kametani, O. Umezawa, K. Sekine, T. Oda, M. Ishiguro, and D. Mizuno, Yakugaku Zasshi, $84,237-246$ (1964).

106. Syntheses of Indene Related Comounds. I. A New Synthesis of 2-Indanamine: T. Kametani and H. Sugahara, Yakugaku Zasshi, 84, $399-402$ (1964).

107. Syntheses of Indene Related Compounds. II. Synthesis of 2-Indanamine Derivatives and Their Pharmacological Activity: K. Kigasawa, M. Hirragi, T. Hayasaka, H. Sugahara, and T. Kametan 1, Yakugaku Zasshi, 84, $402-404$ (1964).

108. Syntheses of Analgesics. III. Syntheses of Azabenzomorphans. (1). Synthesis of 3,4,5,6-Tetrahydro-2ㅍ-1,5-methanobenzo[e][1,4]diazocine: T. Kametani, K. Kıgasawa, M. Hiiragi, T. Hayasaka, and T. Iwata, Yakugaku Zasshi, 84, 405 $411(1964)$.

109. Studies on the Syntheses of Heterocyclic Compounds. XCVIII. A Synthesis of 1Substituted Benzo[a] quinolizine Derivatives: T. Kametani and H. Yagi, Yakugaku 2asshi, $\underline{84}, 412-415$ (1964).

110. Syntheses of Bisbenzylisoquinoline Alkaloids. I. Synthesis of d1-3-Amino-3'methoxy-4,4'-bis (2-methy 1-6,7-dimethoxy-1,2,3,4-tet rahydro-1-isoquinoly1methy1)diphenyl Ether (Studies on the Syntheses of Heterocyclic Compounds. CI): T. Kametani, K. Fukumoto, and M. Ro, Yakugaku Zasshi, 84, 532 - 537 (1964).

111. Cularine and Re1ated Compounds. XI. A Synthesis of 10-Amino-10,11-dxhydro2,3-dimethoxydibenzo[b,f]oxepine (Studies on the Syntheses of Heterocyclic Compounds. CII): T. Kametani and C. Kibayashi, Yakugaku Zasshi, 84, 642 $646(1964)$.

112. Indene and Related Compounds. Part III. Ring Expansion of 2-Nitro-1-indanone Oxime to Isocarbostyril Derivatives: H. Kametani and H. Sugahara, J. Chem. Soc., 1964, $3856-3859$.

113. Cularine and Related Compounds. Part VIII. A Modified Total Synthesis of ( \pm )Cularine Methiodide: T. Kametani and K. Ogasawara, J. Chem. Soc., 1964, 4142 - 4146 .

114. Cularine and Related Compounds. Part X. A Total Synthesis of ( \pm )-Cularimine: T. Kametani, S. Shibuya, S. Seino, and K. Fukumoto, J. Chem. Soc, 1964, 4146 - 4150 . 
115. Bisbenzylisoquinoline Alkaloids and Related Compounds. Part IV, A Total Synthesis of ( \pm )-Dauricine: J'. Kametani and K. Fukumoto, J. Chem. Soc., 1964, $6141-6146$.

116. A Total Synthesis of ( \pm )-Cularimine: T. Kametani, S. Shibuya, S. Seino, and K. Fukumoto, Tetrahedron Letters, 1964, $25-28$.

117. Total Synthesis of ( \pm -Dauricine: T. Kametani and K. Fukumoto, Tetrahedron Letters, $\underline{1964}, 2771-2775$.

118. Coclaurine and Related Compounds. I. Syntheses of d1-Coclaurine and d1-0Benzyl-N-methylcoclaurine (Studies on the Syntheses of Heterocyclic Compounds. CIII): T. Kametani, S. Takano, K. Masuko, and S. Kuribara, Yakugaku Zasshi, $\underline{85}, 166-168(1965)$.

119. Synthesis of Papaverine Derivatives. XIV. Synthesis of 1-Dihydroxybenzy1-6,7dimethoxy-3,4-dihydroisoquinolines (Studies on the Syntheses of Heterocyclic Compounds. CIX): T. Kametani and S. Kano, Yakugaku Zasshi, 85, $256-261$ (1965).

120. Syntheses of Bisbenzylisoquinoline Alkaloids. II. A Synthesis of 1,1'-(3,3'-

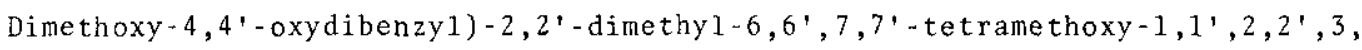
3',4,4'-octahydrodiisoquinoline (Studies on the Syntheses of Heterocyclic Compounds. CV); T. Kametani, M. Ro, and Y. Iwabuchi, Yakugaku Zasshi, 85, 355 $358(1965)$.

121. A Novel Dehydrazination Reaction. IV. The Reaction of Heterocyclic Carboxylic Acid Hydrazides with Chlora1: T. Kametani, O. Umezawa, H. Yagi, and S. Asagi, Yakugaku Zasshí, $\underline{85}, 518$ - 520 (1965).

122. Cularine and Related Compounds. XII. Reduction Products of 2-Ketocularimine (Studies on the Syntheses of Heterocylcic Compounds. CXIII): T. Kametani, S. Shibuya, and I. Noguchi, Yakugaku Zasshi, 85, $667-673$ (1965).

123. Azabenzomorphan and Related Compounds. IV. Synthesis of 2-Substituted 4Quinolineacetic Acid Derivatives (Studies on the Syntheses of Heterocyclic Compounds. CXVIJ: T. Kametani, M. Hiiragi, and K. Kigasawa, Yakugaku Zasshi, $85,830-839(1965)$.

124. Azabenzomorphan and Related Compounds. V. Cyanation of 4-Bromomethylcarbostyril and Syntheses of 4 -Substituted Carbostyril Derivatives: T. Kametani, M. Hi iragi, and K. Kigasawa, Yakugaku Zasshi, $85,867-870$ (1965).

125. Azabenzomorphan and Related Compounds. VI. Synthesis of 3-Methyl-1,2,3,4,5, 6-hexahydro-2,6-methanobenzold] [1,3]diazocine (Studies on the Syntheses of Heterocyclic Compounds. CXIX): T. Kametani, K. Kigasawa, and M. Hiiragi, 
Yakugaku Zasshi, $85,871-875$ (1965).

126. Papaverine and Related Compounds. XV. A Synthesis of 1-Benzy1-2-methy1-6methoxy-1,2,3,4-tetrahydroisoquinolin-7-o1 (Studies on the Syntheses of Heterocyc1ic Compounds. CXXIV): I. Kametani, K. Wakisaka, and K. Fukumoto, Yakugaku Zasshi, 85, 956 - 959 (1965).

127. Papaverine and Related Compounds. XVI. A Synthesis of 1-Phenyl-2-methyl-6methoxy-1,2,3,4-tetrahydroisoquinolin-7-ol: T. Kametani, M. Shio, and K. Fukumoto: Yakugaku Zasshi $, \underline{85}, 960-962$ (1965).

128. Streptonigrin and Related Compounds. I. Syntheses of 5,6,8-Trimethoxy-7dimethylaminoquinoline and 7-Amino-6-hydroxy-5,8-quinolinedione (Studies on the Syntheses of Heterocyclic Compounds. CXXVI): T. Kametani and K. Ogasawara, Yakugaku Zasshi, $85,985 * 990$ (1965).

129. A Synthesis of 2-Methy1-9,10-dimethoxy-1,2,3,4,6,7-hexahydro-11bh-benzo[a]quinolizine-3-methanol Phenylcarbamate (Studies on the Syntheses of Heterocyclic Compounds. CXXVIII): T. Kametani, Y. Nomura, and K. Ohkubo, Yakugaku Zasshi, $\underline{85}, 1087-1089$ (1965).

130. Azabenzomorphan and Related Compounds. II. A Synthesis of 1,2,3,4-Tetrahydro-6ㅂ-1,5-methanobenzo[f] $[1,4]$ diazocine: T. Kametani, K. Kigasawa, M. Hiiragi, and H. 1shimaru, Chem. and Pharm. Bull. (Japan), 13, $295-299$ (1965).

131. Azabenzomorphan and Related Compounds. III. A Synthesis of $1,2,3,4,5,6$ Hexahydro-2,0-methanobenzo[e]f1,4]diazocine: T. Kametani, K. Kigasawa, and T. Hayasaka, Chem. and Pharm. Bull. (Japan), 13, $300-303$ (1965).

132. Azabenzomorphan and Related Compounds. VII. Synthesis of $1,2,3,4,5,6-$ Hexahydro-2,6-methanobenzo[d] $[1,3]$ diazocine Derivatives: $T$. Kametani, $K$. Kigasawa, and M. Hiiragi, Chem, and Pharm. Bul1. (Japan), 13, $1220-1224$ (1965).

133. Azabenzomorphan and Re1ated Compounds. VIII. A Synthesis of 4-Benzy1-2,3,4, 6-tetrahydro-1ㅁ-2,6-methanobenzo[e] $][1,3]$ diazocine: T. Kametani, K. Kigasawa, and $\mathrm{T}$. Hayasaka, Chem. and Pharm. Bull. (Japan'), 13, $1225-1230$ (1965).

134. Cularine and Related Compounds. Part XIII. l'otal Synthesis of (+)-Cularimine and (+)-Cularine: T. Kametani and S. Shibuya, J.Chem. Soc., 1965, 5565 5566 .

135. A Total Synthesis of the Stereoisomeric Mixture of Magnolamine: T. Kametani and H. Yagi, Tetrahedron Letters, 1965, $953-958$.

136. A Novel Methylation of Tertiary Amines with Methyl Salicylate: T. Kametani, 
K. Kigasawa, M. Hiiragi, H. Sugahara, T. Hayasaka, T. Iwata, and H. Ishimaru, Tetrahedron Letters, $1965,1817-1822$.

137. Total Syntheses of (+)-Cularimine and (+)-Cularine: T, Kametani and S. Shibuya, Tetrahedron Letters, 1965, 1897 - 1899.

138. The Structure of Corpaverine: T. Kametani, K. Ohkubo, I. Noguchi, and R. H. F. Manske, Tetrahedron Letters, 1965, 3345 - 3349.

139. The Structure of Sendaverine and Its Tota1 Synthesis: T. Kametani and K. Ohkubo, Tetrahedron Letters, 1965, 4317 - 4326 .

140. Papaverine and Related Compounds. XVII. Synthesis of 1-Pheny1-2-methyl-6hydroxy-7-methoxy-1,2,3,4-tetrahydroisoquinoline: T. Kametani and M. Shio, J. Heterocyclic Chem., 2, $222-223$ (1965).

141. An Abnormal Product in the Chichibabin Reaction of Quinoline: T. Kametani, K. Kigasawa, Y. Iwabuchi, and T. Hayasaka, J. Heterocyclic Chem., 2, 330 (1965).

142. Streptonigrin and Related Compounds. II. Syntheses of 7-Aminoquinoline Derivatives from Hexachlorocyclohexane: T. Kametani and K. Ogasawara, Yakugaku Zasshi, $86,55-58$ (1966).

143. Synthesis of 1-Methyl-3-acety1-6,7-dimethoxyisoquinoline (Studies on the Syntheses of Heterocyclic Compounds. CXXXI): T. Kametani, L.-L. Ling, S. and S. Shibuya, Yakugaku Zasshi, $86,72-74$ (1966).

144. Reaction of Several Polyfunctional Compounds Containing Amino, Hydroxyl, or Carboxyl Groups with Mesyl Chloride (Studies on the Syntheses of Heterocyclic Compounds. CXXXVII): T. Kametani, S. Asagi, S. Nakamura, M. Satoh, N. Wagatsuma, and S. Takano, Yakugaku Zasshi, 86, $107-109$ (1966).

145. Corpaverine and Related Compounds. I. A Synthesis of 1-(p-Hydroxybenzy1)-2methyl-6,7,8-trimethoxy-1,2,3,4-tetrahydrolsoquinoline (Studies on the Syntheses of Heterocyclic Compounds. CXXXIX): T. Kametani, S. Kano, and Y. Watanabe, Yakugaku Zasshi, $86,417-422$ (1966).

146. Corpaverine and Related Compounds. II. Synthesis of 1-(p-Methoxybenzy1)-2methyl-6,8-dimethoxy-1,2,3,4-tetrahydroisoquinolin-7-ol (Studies on the Syntheses of Heterocyclic Compounds. CXL): T. Kametani, S. Kano, and T. Kikuchi, Yakugaku Zasshi, $86,423-426$ (1966).

147. Streptonigrin and Related Compounds. III. Syntheses of 4-Phenylnyridine Derivatives (Studies on the Syntheses of Heterocyclic Compounds. CXLVIII): T. Kametani, K. Ogasawara, and M. Shio, Yakugaku Zasshi, 86, $809-815$ (1966). 
148. Streptonigrin and Related Compounds. IV. Syntheses of 4-(3,4-Methylenedioxypheny 1) - and 4-(3,4-Dimethoxypheny 1)-3-cyano-5-ethoxycarbony 1-6-methy 1-2quinolylpyridine (Studies on the Syntheses of Heterocyclic Compounds. CXLIX): T. Kametani, K. Ogasawara, and A. Kozuka, Yakugaku Zasshi, 86, $815-822$ (1966).

149. A Nove1 Dehydrazination Reaction. VI. The Formation of Various Amides from Heterocyclic Carboxylic Acid Hydrazides in the Presence of Chloral (Studies on the Syntheses of Heterocyclic Compounds. CL): T. Kametani, S. Takano, 0 . Umezawa, H. Agui, K. Kanno, Y. Konno, F. Satoh, H. Nemoto, and K. Yamaki, Yakugaku Zasshi, $86,823-828(1966)$.

150. Studies on the Syntheses of Heterocyclic Compounds. CLI. Selective Demethylation of 3,4-Dihydro-6,7,8-trimethoxyisoquinoline and Modified Total Synthesis of Anhalamine: T. Kametani, N. Wagatsuma, and F. Sasaki, Yakugaku Zasshi, $\underline{86}$, $913-918(1966)$.

151. Studies on the Syntheses of Heterocyclic Compounds. CLII. Synthesis of 1Acety 1-6,7-dimethoxyisoquinoline: T. Kametani, S. Shibuya, and L.-L. Lin, Yakugaku Zasshi, 86, 973 - 975 (1966).

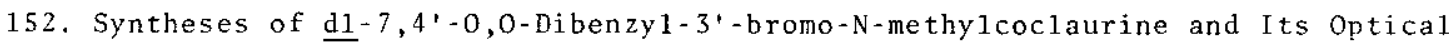
Resolution (Studies on the Syntheses of Heterocyclic Compounds. CLIII): T. Kametani, S. Takano, and K. Masuka, Yakugaku Zassh1 $, \underline{86}, 976-979$ (1966).

153. A Synthesis of 3,4-Dihydro-7-methoxy-1-(4-methoxybenzy 1)-6,8-isoqurnolinediol (Studies on the Syntheses of Heterocyclic Compounds. CLV): T. Kametani, S. Kano, and T. Kikuchi, Yakugaku Zasshi, 86, $979-983$ (1966).

154. Cepharanthine and Related Compounds. I. A Synthesis of 1-(D-Benzyloxybenzy 1$)$ 8-bromo-2-methyl-6,7-methylenedioxy-1,2,3,4-tetrahydroisoquinoline (Studies on the Syntheses of Heterocyclic Compounds. CLVI): T. Kametani and K. Wakisaka, Yakugaku Zasshi, $86,984-988$ (1966).

155. Formation and Ring Closure of $\mathrm{N}$-Substituted Imides (Studies on the Syntheses of Heterocyclic Compounds. CXLI): T. Kametani, R. Yanase, and S. Takano, Yakugaku Kenkyu, 37, 23 - 31 (1966).

156. Bisbenzylisoquinoline Alkaloids and Related Compounds. V. A Total Synthesis of Diastereoisomeric Mixture of Liensinine: T. Kametani, S. Takano, K. Masuko, and F. Sasaki, Chem. and Pharm. Bull. (Japan), 14, $67-72$ (1966).

157. Bisbenzylisoquinoline Alkaloids and Related Compounds. VI. A Modified Total Synthesis of the Stereoisomeric Mixture of Dauricine: T. Kametani, S. Takano, R. Yanase, C. Kibayashi, H. Iida, S. Kano, and K. Sakurai, Chem. and Pharm. Bull. (Japan), 14, $73-77$ (1966). 
158. Bisbenzylisoquinoline Alkaloids and Related Compounds. VII. A Total Synthesis of the Stereoisomeric Mixture of Magnolamine: T. Kametani and $H$. Yagi, Chem, and Pharm. Bull. (Japan), 14, 78 - 82 (1966).

159. Azabenzomorphan and Related Compounds. IX. A Synthesis of 3-Benzyl-3,4,5,6tetrahydro-2 $\mathrm{H}-1,5-m e t h a n o b e n z o l d][1,3]$ diazocine (Studies on the Syntheses of Heterocyclic Compounds. CXLI): T. Kametani and K. Kigasawa, Chem. and Pharm. Bull. (Japan), 14, 566 - 571 (1966).

160. Bisbenzylisoquinoline Alkaloids and Related Combounds. IX. A Modified Total Synthesis of Stereoisomeric Mixture of Magnolamine (Studies on the Syntheses of Heterocyclic Compounds. CXLV): T. Kametani, H. Yagi, and S. Kaneda, Chem. and Pharm. Bull. (Japan), 14, 974 - 980 (1966).

161. Studies on the Syntheses of Heterocyclic Compounds. CLIX. The Reaction of 2-Nitro-1-indanone Oxime with Formalin and Hydrochloric Acid: T. Kametani, H. Sugahara, and S. Asagi, Chem, and Pharm. Bull. (Japan), 14, 1408 - 1413 (1966).

162. Studies on the Syntheses of Heterocyclic Compounds. Part Cxxxv. The Structure of Cornaverine: T. Kametani, K. Ohkubo, and I. Noguchi, J. Chem. Soc. (C) $, \underline{1966}, 715-717$.

163. Studies on the Syntheses of Heterocyclic Compounds. Part CXXXVI. Rearrangement of 2-Nitro-1-tetralone Oxime with Polyphosphoric Acid: T. Kametani, H. Sugahara, and H. Yagi, J. Chem. Soc. (C), 1966, $717-722$.

164. Coreximine and Related Compounds. Part IV. A Total Synthesis of ( \pm )-Coreximine: T. Kametani and M. Ihara, J. Chem. Soc. (C), 1966, $2010-2011$.

165. The Nature of Corpaverine: T. Kametani and K. Ohkubo, Tetrahedron Letters, 1966, $985-988$.

166. The Structure of Cularidine: T. Kametani, S. Shibuya, and C. Kibayashi, Tetrahedron Letters, $1966,3215-3219$.

167. The Structure of a Yellow Substance Formed by Mild Oxidation of Aminopyrine: T. Kametani, K. Kigasawa, M. Ikari, T. Iwata, and M. Saito, Tetrahedron Letters, $1966,4849-4853$.

168. Novel Methylation. III. Methylation of Tertiary Amines such as Pyridine and Isoquinoline with Alkyl Carboxylates: T. Kametani, K. Kigasawa, T. Hayasaka, M. Hiiragi, H. Ishimaru, and S. Asagi, J. Heterocyclic Chem., 3 , $129-135$ (1966).

' 169. Total Synthesis of Stereoisomeric Mixture of Magnoline: T. Kametani, R. 
Yanase, S. Kano, and K. Sakurai, J. Heterocyclic Chem., 3 , $239-240$ (1966).

170. A Total Synthesıs of ( \pm - Isoliensinine: T. Kametani, S. Takano, and K. Satoh, J. Heterocyclic Chem., $\underline{3}, 546-547$ (1966).

171. Coreximine and Related Compounds. I. A Synthesis of O-Demethylcoreximine under Eschweiler-Clarke's Conditions (Studies on the Syntheses of Heterocyc1ic Compounds. CLXII). T. Kametani, I. Noguchi, S. Nakamura, and Y. Konno, Yakugaku Zasshi, 87, 168-173(1967).

172. Coreximine and Related Compounds. II. A Synthesis of $\{ \pm\}$-Coreximine under Eschweiler-Clarke's Conditions (Studies on the Syntheses of Heterocvclic Compounds. CLXIII): T. Kametani and M. Ihara, Yakugaku Zasshi , 87, 174 $178(1967)$.

173. Coreximine and Related Compounds. III. The Formation of Coreximine Isomers under Eschweller-Clarke's Conditions (Studies on the Syntheses of Heterocyclic Compounds. CLXIV): T. Kametani and M. Satoh, Yakugaku ZasshI, 87, $179-184(1967)$.

174. Selective Demethylation of 1-Substituted 6,7-Dimethoxy-3,4-dihydroisoquino1ine Derivatives and Modified Total Synthesis of ( \pm )-Salsoline (Studies on the Syntheses of Heterocyclic Compounds. CLXV): T. Kametani, S. Takano, and F. Sasaki, Yakugaku Zasshi, 87, 191 - 195 (1967).

175. Cularine and Related Compounds. XIV. Optical Resolution of ( \pm )-Cularimine and Synthesis of Related Compounds of Cularimine (Studies on the Syntheses of Heterocyclic Compounds. CLXVI): T. Kametani and S. Shibuya: Yakugaku Zasshi, 87, $196-198(1967)$.

176. Cularine and Related Compounds. XV. Demethylation of Cularine and Cularimine (Studies on the Syntheses of Heterocyclic Compounds. CLXVII): T. Kametanı, S. Shibuya, and S. Sasaki, Yakugaku Zasshi, 87, $198-201$ (1967).

177. Cularicine and Related Compounds. I. Synthesis of 2-(2-Benzyloxy-5-carboxymethylphenoxy)-4,5-methylenedioxyphenylacetic Acid and Its Attempted Cyclization (Studies on the Syntheses of Heterocyclic Compounds. CLXVIII): T. Kametani, S. Shibuya, and H. Ueno, Yakugaku Zasshi, 87, $238-242$ (1967).

178. Streptonigrin and Related Compounds. V. Syntheses of the Comnounds Having Streptonigrin-type Structure (Studies on the Syntheses of Heterocyc1ic Compounds. CLXIX): T. Kametani, K. Ogasawara, A. Kozuka, and M. Shıo: Yakugaku Zasshi, 87, $254-259$ (1967).

179. Streptonigrin and Related Compounds. VI. The NMR Spectra of 4-(2,3,4-Trimethoxyphenyl)-2,3-dimethylpyridine Derivatives (Studies on the Syntheses of 
Heterocyclic Compounds. CLXX): T, Kametani, K. Ogasawara, M. Shio, and A. Kozuka, YakugakuZzasshi, 87, $260-265$ (1967).

180. A Novel Alkylation. IV. N-Alkylation of Secondary Amines with Methy Salicylate (Studies on the Syntheses of Heterocyclic Compounds. CLXXI): T. Kametani, K. Kigasawa, and T. Hayasaka, Yakugaku Zasshi, 87, $265-270$ (1967).

181. Indene and Related Compounds. V. Ring Expansion of 2-Nitro-l-indanone Oxime with Polyphosphoric Acid (Studies on the Syntheses of Heterocyclic Compounds. CLXXIII): T. Kametani, H. Sugahara, and K. Kanno, Yakugaku Zasshi, 87, 309 - 314 (1967).

182. Studies on the Syntheses of Heterocyclic Compounds. CLXXV. A Synthesis of $1-(\alpha-H y d r o x y-4-m e$ thoxybenzy 1$)-2$-methy $1-1,2,3,4$ - te trahydroisoquinol in-5-ol: T. Kametani, S. Kano, Y. Watanabe, and T. Kikuchi, Yakugaku Zasshi, 87, 406 - $409(1967)$.

183. Reductive Oxygenation. I. A Synthesis of 3-Methyl-2,3,4,5,6,7-hexahydro-8 $\underline{H}^{-}$ 2,6-methanobenzo[d]-1,3-oxazocine (Studies on the Syntheses of Heterocyclic Compounds. CLXXX): T. Kametani, K. Kigasawa, and M. Hiiragi, Yakugaku Zasshi, 87, $558-562(1967)$.

184. Studies on the Syntheses of Heterocyclic Compounds. CLXXVII. Syntheses of Sendaverine Derivatives and Investigation of Their IR and NMR Spectra: T. Kametani, K. Ohkubo, and S. Takano, Yakugaku Zasshi, 87, 563 - 569 (1967).

185. Studies on the Syntheses of Heterocyclic Compounds. CLXXXI. NMR Spectra of 1-( $\alpha$-Hydroxybenzy 1$)-2-m e t h y 1-1,2,3,4-$ tetrahydroisoquinoline Derivatives: T. Kametani and T. Kikuchi, Yakugaku Zasshi, 87, $682-686$ (1967).

186. Cepharanthine and Related Compounds. II. A Synthes is of 1-(3-Bromo-4-methoxybenzy1)-1,2,3,4-tetrahydro-6-methoxy-2-methyl-7-isoquinolinol (Stuides on the Syntheses of Heterocyclic Compounds. CLXXXIII): T. Kametani, H. Yagi, S. Asagi, K. Kanno, and K. Wakisaka, Yakugaku Zasshi, 87, $749-752$ (1967).

187. Aztequine and Related Compounds. III. Synthesis of d1-1-(4-Bromo-3-hydroxybenzy1)-1,2,3,4-tetrahydro-6-methoxy-2-methyl-7-isoquinolinol (Studies on the Syntheses of Heterocyclic Compounds. CLXXXIV): T. Kametani, M. Shinbo, T. Fujikura, A. Kano, and H. Iida, Yakugaku Zasshi, 87, 753 - 756 (1967).

188. Coclaurine and Related Compounds. II. Syntheses of 7-Benzyloxy-1,2,3,4tetrahydro-1-(p-hydroxypheny 1)-6-methoxy-2-methylisoquinoline and 7-Benzyloxy1,2,3,4-tetrahydro-1-(p-hydroxybenzy1)-6-methoxy-2-methylisoquinoline (Studies on the Syntheses of Heterocyclic Compounds. CLXXXV): T. Kametani, S. Takano, and K. Satoh, Yakugaku Zasshi, 87, 757 - 760 (1967). 
189. Studies on the Syntheses of Heterocyclic Compounds. CLXXXVII. Ont1cal Resolution of dl-7-0-Benzylcoclaurine: T. Kametani, K. Sakurai, S. Kano, and H. Iida, Yakugaku Zasshi, $87,822-825$ (1967).

190. Dioxolanone and Related Compounds. I. Synthesis of 3-Ary1oxy-1,2-propanediol Derivaitves (Studies on the Syntheses of Heterocyclic Compounds. CLXXXIX): T. Kametani, T. Suzuki, K. Kigasawa, and M. Hi ragi, Yakugaku Zasshi, 87, 967 - $972(1967)$.

191. A Synthesis of 8-Aza-6-oxa-8-methy1-3,4-benzbicyclo[3.2.1]octane (Studies on the Syntheses of Heterocyclic Compounds, CXC): T. Kametani, K. Kigasawa, M. Hiiragi, and S. Asagi, Yakugaku Zasshi, 87, 973 - 979 (1967).

192. Synthesis of Related Compounds of Calycotomine (Studies on the Syntheses of Heterocyclic Compounds. CXCI\}: T. Kametani and S. Shibuya, Yakugaku Zasshi, 87, $1028-1031$ (1967).

193. Studies on the Syntheses of Heterocyclic Compounds. CXCIII. Synthesis of 7 , 8-Disubstituted Isoquinoline Derivatives: T. Kametani, M. Sato, and S. Shibuya, Yakugaku Zasshi, 87, 1063 - 1069 (1967).

194. Coreximine and Related Compounds. V. Total Synthesis of $( \pm)$-Tetrahydropalmatrne and Abnormal Reaction of Halogen Substitution (Studies on the Syntheses of Heterocyclic Compounds. CXCIV): T. Kametani and S. Kaneda, Yakugaku Zasshi, 87, $1070-1075$ (1967).

195. Streptonigrin and Related Compounds. VII. Synthesis of Streptonigrin Nucleus by the Formation of Pyridine Ring (Studies on the Syntheses of Heterocyclic Compounds. CXCVII): T. Kametani, K. Ogasawara, A. Kozuka, and K. Nyu, Yakugaku Zasshí, 87, 1189 - 1194 (1967).

196. Streptonigrin and Related Compounds. VIII. Hydrolysis and Hofmann Reaction of Ethyl 3-Cyano-4-(3,4-dime thoxypheny1)-6-methy1-2-auinoly1-5-pyridinecarboxylate (Studies on the Syntheses of Heterocyclic Compounds. CXCIX): T. Kametani, K. Ogasawara, and A. Kozuka, Yakugaku Zasshi, 87, 1195 - 1202 (1967).

197. A Novel Alkylation. V. Nove1 Methylation with Carboxylic Acid Ester. NMethylation of Secondary Amines with Methyl Carboxylate (Studies on the Syntheses of Heterocyclic Compounds. CC): T. Kametani, T. Hayasaka, and K. Kigasawa, Yakugaku Zasshi, 87, $1298-1303^{\prime}(1967)$.

198. Mitomycin and Related Compounds. I. Synthesis of 2,3-Dihydro-6-methyl-1Hpyrrolo[1,2-a $]$ indol-1-one (Studies on the Syntheses of Heterocyclic Compounds CCI): T. Kametani, T. Yamanaka, and M. Satoh, Yakugaku Zasshi, 87, 1407 1410 (1967). 
199. Dioxolanone and Related Compounds. II. Synthesis of 7-(2,3-Dihydroxypropy1)theophyline Derivatives (Studies on the Syntheses of Heterocyclic Compounds. CCII): T. Kametani, T. Suzuki, and K. Kigasawa, Yakugaku Zasshi, 87, 1411 $1413(1967)$.

200. Bisbenzylisoquinoline Alkaloids and Related Compounds. XI. Total Synthesis of Stereoisomeric Mixture of Magnoline: T. Kametani, R. Yanase, S. Kano, and K. Sakurai, Chem. and Pharm. Bull. (Japan), 15, 56-60 (1967).

201. The Structure of Sendaverine and $i t s$ Total Synthesis: T. Kametani and $K$. Ohkubo, Chem. and Pharm. Bu11. (Japan), 15, 608-612 (1967).

202. Novel Methylation. Methylation of Tertiary Amines with Alkyl Salicylate: T. Kametani, K. Kigasawa, H, Sugahara, M. Hiiragi, T. Hayasaka, T. Iwata, and H. Ishimaru, Chem. and Pharm. Bul1. (Japan), 15, $613-618$ (1967).

203. Azabenzomorphan and Related Compounds. X. A Synthesis of 1-Methyl-3-aminoisoquinoline (Studies on the Syntheses of Heterocyclic Compounds. CLXXX):

T. Kametani, K. Kigasawa, and M. Hi ragi, Chem. and Pharm. Bu11. (Japan), 15, $704-707(1967)$.

204. Studies on the Syntheses of Heterocyclic Compounds. CLXXXII. A Modified Synthesis of So-called Corpaverine: T. Kametani and T. Kikuchi, Chem. and Pharm. Bul1. (Japan), 15, $879-883$ (1967).

205. Magnolamine and Related Compounds. IV. An A1ternative Synthesis of D(-)-

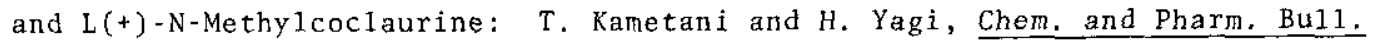
(Japan), 15, $1283-1286$ (1967).

206. Studies on the Syntheses of Heterocyclic Compounds. CXCV. The Structure of a Yellow Substance Formed by Mild Oxidation of Aninopyrine: T. Kametani, K. Kigasawa, N. Ikari, T. Iwata, M. Saito, and H. Yagi, Chem, and Pharm. Bu11. (Japan), 15, $1305-1309$ (1967).

207. Chichibabin Reaction. II. Chichibabin Reaction of 8-Methylquinoline and Migration of the Methyl Group in the Synthesis of 3,4-Dihydro-8-methylcarbostyril by Friedel-Crafts Reaction (Studies on the Syntheses of Heterocyclic Compounds, CCIII): T. Kametani and H. Nemoto, Chem. and Pharm. Bu11. (Japan), $15,1910-1015(1967)$.

208. Studies on the Syntheses of Heterocyclic Compounds. CCIV. Ring Contraction in the Catalytic Hydrogenation of 3-oximino-4-oxoisocarbostyril: T. Kametani, H. Sugahara, and K. Kanno, Chem. and Pharm. Bu11. (Janan), 15, 1916- 1921 $(1967)$.

209. An Alternative Total Synthesis of $( \pm)$-Scoulerine and $( \pm)$-Tetrahydropalmatine: 
T. Kametani and M. Ihara, J. Chem. Soc. (C), 1967, $530-532$.

210. Total Synthesis of $( \pm)-G$ aucine Methopicrate by Phenolic Oxidative Coupling:

T. Kametani and I. Noguchi, J. Chem. Soc. (C), 1967, $1440-1443$.

211. Total Syntheses of $( \pm)$-Glaziovine and ( \pm )-Pronuciferine by Phenolic Oxıdative Coupling: T. Kametani and H. Yagi, J. Chem. Soc. (C), 1967, $2182-2184$.

212. Benzyne Reaction. Part I. Total Synthesis of ( \pm )-Cryptaustoline and ( \pm ) Cryptowoline by the Benzyne Reaction: T. Kametani and K. Ogasawara, J. Chem. Soc. (C), 1967, $2208-2212$.

213. A Total Synthesis of ( \pm )-Glaziovine by Phenolic Oxidative Coupling: T. Kametani and H. Yagi, J.C.S. Chem. Comm., 1967, $366-367$.

214. Biogenetzc Synthesis of Cularine-type Compounds: T. Kametani, T. Kikuchi, and K. Fukumoto, J. C.S. Chem. Comm., 1967, $546-547$.

215. Syntheses of Homoaporphine-type Compounds by Phenolic oxidative Coupling: $T$. Kametani, K. Fukumoto, H. Yagi, and F. Satoh, J. C. S. Chem. Comm, , 1967, 878 - 879 .

216. Novel Rearrangement of Homoproaporphine and the Configuration of Two Isomeric Homoproaporphines: T. Kametani, F. Satoh, H. Yagi, and K. Fukumoto, J. C. S. Chem. Somm., 1967, $1103-1105$.

217. Total Synthesis of Stebisimine: T. Kametani, O. Kusama, and K. Fukumoto, J. C. S. Chem. Comm., 1967, 1212 - 1214 .

218. Studies on the Syntheses of Heterocyclic Compounds. ClXXIV. An Approach to the Synthesis of Oxyacanthine and Berbamine: T. Kametani, H. Iida, S. Kano, S. Tanaka, K. Fukumoto, S. Shibuya, and H. Yagi, J. Heterocyclic Chem., 4 , $85-92(1967)$.

219. By-Product in the Preparation of Homoveratrylamine by Catalytic Hydrogenation of 3,4-Dimethoxybenzyl Cyanide and Its Derivation to 2-Phenethylisoquinoline Derivatives: T. Kametani, K. Ogasawara, and T. Harada, Yakugaku Zasshi, $\underline{88}$, 163 - 165 (1968).

220. Novel Methylation. VI. N-Methylation of Primary Amines and Secondary Amines with Methyl Salicylate and Oxalate (Studies on the Syntheses of Heterocyclic Compounds. CCXXIII): T. Kametani, K. Kigasawa, and T. Hayasaka, Yakugaku Zasshi, $\underline{88}, 445-452(1968)$.

221. Chichibabin Reaction. IV. Chichibabin Reaction of 5- and 6-Methylquinolines (Studies on the Syntheses of Heterocyclic Compounds. CCXXIV): T. Kametani, 
H. Nemoto, and S. Takano, Yakugaku Zasshi, 88, $453-459$ (1968).

222. Synthesis of 8-Bromo-1,2,3,4-tetrahydro-1-[p-(5-hydroxymethy 1-2-methoxynhenoxy)benzyl]-6,7-methylenedioxyisoquinoline (Studies on the Syntheses of Heterocyclic Compounds. CCXXV): T. Kametani and K. Wakisaka, Yakugaku Zasshi, 88 , $483-487(1968)$.

223. Synthesis of 4-oxa-9-aza-9-methyl-6,7-benzobicyclo[3.3.1]nonane and Attempts to Cyclize the Piperidone Derivatıves by Reductive Cyclization (Studies on the Syntheses of Heterocyclic Compounds. CCXXVII): T. Kametani, K. Kigasawa, M. Hiiragi, and S. Asagi, Yakugaku Zasshi, $\underline{88}, 573$ - 582 (1968).

224. Syntheses of 1-(3-Hydroxy-4-methoxyphenethy1)-7-methoxy-2-methyl-1,2,3,4tetrahydroisoquinolin-6-ol and 1-(3-Hydroxy-4-methoxybenzy 1)-7-methoxy-2methy 1-1,2,3,4-tetrahydroisoquinoline-6,8-diol and Attempt to Cyclize the Isoquinoline Derivatives by Phenol Oxidation (Studies on the Syntheses of Heterocyclic Compounds. CCXXVIII): T. Kametani and S. Shibuya, Yakugaku $\underline{\text { Zasshi }}, \underline{88}, 583-588(1968)$.

225. Reduction Products of 2'-Nitropapaveraldine (Studies on the Syntheses of Heterocyclic Compounds. CCXXXIV): T. Kametani, T. Kobari, and S. Takano, Yakugaku Zasshi, $\underline{88}, 774-778(1968)$.

226. Synthesis of 2-Amınomethy1-1,1-diphenylbut-1-ene (Studies on the Syntheses of Heterocyclic Compounds. CCXXXIX): T. Kametani and I. Noguchi, Yakugaku Zasshi, 88, $911-914(1968)$.

227. Syntheses of 1-(3- and 4-Ch1orobenzy 1)-1,2,3,4-tetrahydro-6,7-dimethoxyisoquinoline and Cyclized Compounds by Benzyne Reaction (Studies on the Syntheses of Heterocyclic Compounds. CCXLI): T. Kametani, T. Terui, and K. Fukumoto, Yakugaku Zasshi, 88, 915 - 918 (1968).

228. Attempted Cyclization of 5-Substituted 2-(5-Carboxymethy1-2-methoxyphenoxy)-4methoxyphenylacetic Acid with Polyphophoric Acid (Studies on the Syntheses of Heterocyclic Compounds. CCXLII): H. Iida, C. Kibayashi, and T. Kametani, Yakugaku Zasshi, 88,937 - 841 (1968).

229. Ochotensine and Related Compounds. I. Syntheses of Ochotensine Related Compounds (Studies on the Syntheses of Heterocyclic Compounds. CCLI): T. Kametani, S. Takano, and S. Hibino, Yakugaku Zasshi, 88, 1123 - 1127 (1968).

230. Total Syntheses of Berbamunine and Its Diastereoisomer (Studies on the Syntheses of Heterocyclic Compounds. CCLIV): T. Kametani, K. Sakurai, and H. Iida, Yakugaku Zasshi, 88, 1163 - 1167 (1968).

231. Studies on the Syntheses of Heterocyclic Compounds. CCLV. Syntheses of 
Stepharotine and Related Compounds: T. Kametani, H. Iida, and T. Kikuchi, Yakugaku Zasshi, 88, $1185-1188$ (1968).

232. Studies on the Syntheses of Heterocyclic Compounds. CCLIX. Synthesis of 1(m-Ch1orophenethy 1)-1,2,3,4-tetrahydro-6,7-dimethoxyisoquinoline and Cyclized Product by Benzyne Reaction: T. Kametani, T. Terui, and K. Fukumoto, Yakugaku Zasshi, 88, 1388 - 1392 (1968).

233. Capaurimine and Related Compounds. IV. Syntheses of 1,10-Dihydroxy-2,3,11trimethoxy- and 3,10-Dihydroxy-1,2,11-trimethoxy-5,6,13,13a-tetrahydro-8Hdibenzo[a,g]quinolizine (Studies on the Syntheses of Heterocyclic Compounds. CCLXI1): T. Kametani, K. Fukumoto, H. Iida, and T. Kikuchi, Yakugaku Zasshi, $\underline{88}, 1482-1486(1968)$.

234. Studies on the Syntheses of Heterocyclic Compounds. CCIX. Total Syntheses of $( \pm)$-Isococlaurine and (-)-Lotusine: T. Kametani, S. Takano, F. Sasaki, and K. Yamaki, Chem. and Pharm. Bull. (Japan), 16, $20-24$ (1968).

235. Studies on the Syntheses of Heterocyclic Compounds. CCX. The Mass Spectra of 10-Subst1tuted Dibenz [므, $\underline{]}]$ oxepine Derivatives: T. Kametani, S. Shibuya, and C. Kibayashi, Chem. and Pharm. Bull. (Japan), 16, $34-38$ (1968).

236. Azamorphinan and Related Compounds. I. A Synthesis of 3-Hydroxy-N-methyl9-azamorphinan (Stuides on the Syntheses of Heterocyclic Compounds. CCXIV):

T. Kametani, K. Kigasawa, M. Hiiragi, and N. Wagatsuma, Chem. and Pharm. Bul1. (Japan), 16, $296-303(1968)$.

237. Chichibabin Reaction. III. Chichibabin Reaction of 7-Methylquinoline and Migration of the Methyl Group in Friedel-Carfts Reaction of N-(m-Toly1)- and $N$ - (p-Toly1)-B-chloropropionamide (Studies on the Syntheses of Heterocyclic Compounds. CCXV): T. Kametani, H. Nemoto, and S. Takano, Chem. and Pharm. Bu11. (Japan), 16, $367-370$ (1968).

238. Synthesis of Melanthioidine Derivative by Double Ullmann Reaction (Studies on the Syntheses of Heterocyclic Compounds. CCXXVI): T. Kametani, S. Takano, and K. Haga, Chem. and Pharm. Bull. (Japan), 16, 663 - 667 (1968).

239. Bisbenzylisoquinoline Alkaloids and Related Compounds. Part XII. Synthesis of Stereoisomeric Mixture of Cuspidaline (Studies on the Syntheses of Heterocyclic Compounds. CCXXIX): T. Kametani and F. Satoh, Chem. and Pharm. Bu11. (Japan), 16, $773-777$ (1968).

240. An Alternative Synthesis of So-called Corpaverine (Studies on the Syntheses of Heterocyclic Compounds. CCXXXI): T. Kametani and K. Ohkubo, Chem. and Pharm. Bull. (Japan), 16, $909-913$ (1968). 
241. Aztequine and Related Compounds. IV. A Synthesis of 2,2'-Dihydroxy-4,4'bis ( 7-hydroxy-6-methoxy-2-methy 1-1,2,3,4-tetrahydro-1-isoquinolylmethyl) diphenyl Ether (Studies on the Syntheses of Heterocyc1ic Compounds. (CCXXX): T. Kametani, H. Iida, M. Shinbo, and T. Endo, Chem. and Pharm. Bull. (Japan), 16, $949-952(1968)$.

242. Phenolic Cyclization. II. Syntheses of 6-Hydroxy- and 8-Hydroxy-1,2,3,4tetrahydroisoquinoline Derivatives (Studies on the Syntheses of Heterocyclic Compounds. CCXXXII): T. Kametani, S. Shibuya, and M. Satoh, Chem. and Pharm. Bu11. (Japan), $\underline{16}, 953-957$ (1968).

243. Synthesis of Cularine Type Compounds (Studies on the Syntheses of Heterocyclic Compounds. CCXXXVI): T. Kametani, T. Kikuchi, and K. Fukumoto, Chem. and Pharm. Bull. (Japan), 16, $1003-1008$ (1968).

244. Electrolytic Oxidation. I. Phenolic Oxidation of p-Cresol by Electrolysis (Studies on the Syntheses of Heterocyclic Compounds. CCxxxviI): T. Kametani, K. Ohkubo, and S. Takano, Chem. and Pharm. Bull. (Japan), 16, 1095 - 1097 (1968).

245. Studies on the Syntheses of Heterocyclic Compounds. CCxxxVIII. A Modified Synthesis of Pummerer's Ketone: T. Kametani and K. Ogasawara, Chem. and Pharm. Bull. (Japan), 16, 1138 - 1139 (1968).

246. Phenolic Cyclization. III. One Step Synthesis of cis- and trans-16-Hydroxy15-methoxyerythrinanone by Phenolic Cyclization (Studies on the Syntheses of Heterocyclic Compounds. CCXLIV): T. Kametani, H. Agui, and K. Fukumoto, Chem. and Pharm. Bu11. (Japan), 16, 1285 - 1287 (1968).

247. Studies on the Syntheses of Heterocyclic Compounds. CCXLV. The Mass Spectra of Cryptaustoline Type Alkaloids: T. Kametani and K. Ogasawara, Chem. and Pharm. Bu11. (Japan), 16, $1498-1502$ (1968).

248. Benzyne Reaction. II. Syntheses of Benzyl Cyanide Derivatives by Benzyne Reaction (Studies on the Syntheses of Heterocyclic Compounds. CCXLVII): T. Kametani, K. Ogasawara, T. Terui, K. Yamaki, and K. Fukumoto, Chem. and Pharm. Bul1. (Japan), 16, $1584-1588$ (1968).

249. A1ternative Synthesis of Stereoisomeric Mixture of Magnoline by U1lmann Reaction (Studies on the Syntheses of Heterocyclic Compounds. CCXLVIII): T. KametanI, H. Iida, and K. Sakurai, Chem. and Pharm. Bul1. (Japan), 16, $1623-1625$ (1968).

250. Synthesis of Stereoisomeric Mixture of Daurinoline (Studies on the Syntheses of Heterocyclic Compounds. CCXLIX): T. Kametani, S. Takano, T. Kobari, H. Iida, and M. Shinbo, Chem. and Pharm. Bull. (Japan), 16, 1625-1628 (1968). 
251. The Mechanism of the Formation of an Abnormal Products in the Chichibabin Reaction of Quinoline (Studies on the Syntheses of Heterocyc1ic Compounds. CCLIII): T. Kametani and H. Nemoto, Chem. and Pharm. Bul1. (Japan), $1696-1699(1968)$.

252. The Oxidation of p-Toluidine with Potassium Ferricyanide in Liquid Ammonia: T. Kametani and K. Ogasawara, Chem. and Pharm. Bul1. (Japan), 16, $1843-1845$ (1968).

253. The Acid Catalyzed Rearrangement of Homoproaporphine under Two Different Conditions: T. Kametani, H. Yagi, K. Fukumoto, and F. Satoh, Chem. and Pharm. Bu11. (Japan), 16, $2297-2298$ (1968).

254. Phenolic 0xidative Coupling Reaction of 1,2,3,4-Tetrahydro-7-hydroxy-1-(2hydroxy-4,5-methylenedioxybenzy 1)-6-methoxy-2-methylisoquinoline with Ferric Chloride (Studies on the Syntheses of Heterocyclic Compounds. CCLXV): T. Kametani and I. Noguchi, Chem, and Pharm. Bul1. (Japan), 16, $2451-2455$ $(1968)$.

255. Deoxygenation of Ascaridole with Triethyl phosphite: $T$. Kametani and K. Ogasawara, Chem. and Ind., 1968, 1772 .

256. Phenolic Cyclization. Part I. Novel Synthesis of 1-Substituted Isoauinoline and Spìro[cycloalkane-1,1'-isoquinoline] Derivatives and Its Application to the Total Syntheses of Isoquinoline Alkaloids: T. Kametani, K. Fukumoto, H. Agui, H. Yagi, K. Kigasawa, H. Sugahara, M. Hiiragi, T. Hayasaka, and H. Ishimaru, J. Chem. Soc. (C) $\underline{1968,112-118 .}$

257. Racemisation. Part I. Racemisation of Protoberberines under the Conditions of Catalytic Hydrogenation: T. Kametani and M. Ihara, J. Chem. Soc. (C) $1968,191-193$.

258. The Synthesis of Homoproaporphine-type Compounds by Phenolic Oxidative Coupling: T. Kametani, H. Yagi, F. Satoh, and K. Fukumoto, J. Chem, Soc. (C), $\underline{1968}, 271-275$.

259. Abnormal Products from Phenolic Oxidation of a Dihydroxy-1-benzyl-1,2,3,4tetrahydroisoquinoline: T. Kametani and I. Noguchi, J. Chem. Soc. (C), 1968, $447-451$.

260. Rearrangement and Novel Enol-ether Addition in Homoproaporphines: T. Kametani, F. Satoh, H. Yagi, and K. Fukümoto, J. Chem. Soc. (C), 1968, $1003-1005$.

261. Nitrenes. Part I. Modified Syntheses of B-Carboline Derivatives through Nitrene Intermediates: T. Kametani, K. Ogasawara, and T. Yamanaka, J. Chem. 
Soc. (C),$\underline{1968,1006-1007 .}$

262. The Structure of Capaurimine: T. Kametani, K. Fukumoto, H. Yagi, H. Iida, and T. Kikuchi, J. Chem. Soc. (C), 1968, $1178-1180$.

263. The Circular Dichroism and Optical Rotatory Dispersion of Protoberberines:

T. Kametani and M. Ihara, J. Chem. Soc. (C), 1968, 1305-1319.

264. Racemisation. Part II. Racemisation of 1 -Benzyltetrahydroisoquinolines under the Conditions of Catalytic Hydrogenation: T. Kametani, M. Ihara, and K. Shima, J. Chem. Soc. (C) $1968,1619-1620$.

265. Total Synthesis of Stebisimine: T. Kametani, O. Kusama, and K. Fukumoto, J. Chem. Soc. (C), 1968, $1798-1800$.

266. Synthesis of Homoerythrinadienone by Phenolic Oxidative Coupling: T. Kametani and K. Fukumoto, J. Chem. Soc. (C), 1968, $2156-2159$.

267. Phenolic Oxidative Coupling of a 1-Phenylpropylisoquinoline Derivative: T. Kametani, T. Satoh, H. Yagi, H. Iida, and S. Tanaka, J. Chem. Soc. (C), 1968, $2234-2237$.

268. The Conformation and Rearrangement Reaction of Derivatives of 10,11-Dihydrodibenzoxepin: T. Kametani, S. Shrbuya, and W. D. 011is, J. Chem. Soc. (C) , $1968,2877-2883$.

269. Potassium Ferricyanide Oxidation of $\mathrm{N}$-Methy1trototamine in Liquid Ammonia:

T. Kametani, T. Suzuki, and K. Ogasawara, J. Chem. Soc. (C), 1968, $2965-2968$.

270. One-Step Synthesis of an Androcymbine-type Compound: T. Kametani, K. Fukumoto, F. Satoh, and H. Yagi, J. Chem. Soc. (C), 1968, $3084-3088$.

271. Synthesis of "Homoerythrinadienone" by Phenolic Oxidative Coupling: T. Kametani and K. Fukumoto, J. C. S. Chem. Comm., 1968, 26.

272. Phenolic Oxidative Coupling of 1-(3-Phenylpronyl)isoquinoline Derivatives:

T. Kametani, T. Satoh, H. Yagi, H. Iida, and S. Tanaka, J. C. S. Chem. Comm., $\underline{1968}, 224-225$.

273. Novel Synthesis of Benzo[a]carbazole and Oxazolo[5,4-b ]quinoline Ring System from Aromatic Nitro-compounds with Triethy1 Phosphite: T. Kametani, Y. Yamanaka, and K. Ogasawara, J.C. S. Chem. Comm., 1968, $786-787$.

274. The Reaction of 4-o-Nitrophenylpyridine Derivatives with Triethyl Phosphite:

T. Kametani, T. Yamanaka, and K. Ogasawara, J. C. S. Chem. Comm., 1968, 996. 
275. One-step Synthesis of an Androcymbine-like Compound: T. Kametani, K. Fukumoto, F. Satoh, and H. Yagi, J. C. S. Chem. Comm, 1968, $1001-1002$.

276. One-step Synthesis of Morphinandienone-type Compounds: T. Kametani, K. Fukumoto, F. Satoh, and H. Yagi, J.C. S. Chem. Comm., 1968, 1398 .

277. Biogenetic Synthesis of an Androcymbine-type Compound: T. Kametani, K. Fukumoto, M. Koizumi, and A. Kozuka, J. C. S. Chem. Comm., 1968, $1605-1606$.

278. Syntheses of Diastereoisomeric Racemates of Melanthioidine for Determination of Its Structure by Mass Spectrometry: T. Kametani and S. Takano, Tetrahedron Letters, $1968,121-124$.

279. Structural Determination of Capaurimine and Capaurine: T. Kametani, M. Ihara, K. Fukumoto, H. Yagi, H. Shimanouchi, and Y. Sasada, Tetrahedron Letters, $1968,4251-4254$.

280 Head to Tail Coupling of 1-(4-Hydroxyphenethy 1)-7-hydroxy-6-methoxy-2-methy11,2,3,4-tetrahydroisoquinoline by Enzymic Phenolic Oxidation: T. Kametani, S. Takano, and T. Kobari, Tetrahedron Letters, 1968, $4565-4568$.

281. Total Synthesis of Amurine: T. Kametani, K. Fukumoto, and T. Sugahara, Tetrahedron Letters, 1968, 5459 - 5462 .

282. The Syntheses of Homoproaporphines by Phenolic Oxidative Coupling. II. Separation of Two Isomeric Dienones of Homoproaporphines: T. Kametani, F. Satoh, H. Yagi, and K. Fukumoto, J. Org. Chem., 33, 690-694 (1968).

283. Nitrene. II. Novel Conversion of 1-(2-Nitrobenzyl)isoquinoline Derivatives into Benz[a] carbazoles through Nitrene: T. Kametani, T. Yamanaka, and $K$. Ogasawara, J. Org. Chem., 33, $4446-4447$ (1968).

284. A Modified Synthesis of Codamine under Eschweiler-clarke Conditions: T. Kametani, T. Terui, H. Agui, and K. Fukumoto, J. Heterocyclic Chem., 5,753 - $755(1968)$.

285. Studies on the Syntheses of Heterocyclic Compounds. Part CCLXXIII. Synthesis of C-Nordihydrocorynantheol and Its Related Compounds: $T$. Kametani, M. Ihara, T. Suzuki, and K. Shima, J. Heterocyclic Chem,, 5, $799-804$ (1968).

286. Reaction Products by Treatment of 6-Bromoveratraldehyde and Its Acetal with . Sodium Amide in Liquid Ammonia (Studies on the Syntheses of Heterocyclic Compounds. CCLXXXIII): T. Kametani, K. Yamaki, and K. Ogasawara, Yakugaku Zasshi, 89, $154-157$ (1969).

287. Synthesis of Homomelanthioidine by Double U1lmann Reaction (Studies on the 
Syntheses of Heterocyclic Compounds. CCLXXXIV): T. Kametani, H. Iida, and S. Tanaka, Yakugaku Zasshi, $89,230-234$ (1969).

288. Capaurimine and Related Compounds. III. Syntheses of d1-5,6,13,13a-Tetrahydro-1,2,3,10,11-pentamethoxy-8ㅁ-dibenzo[a, g]quinolizine and d1 -5,6,13,13aTetrahydro-2,3,10,11,12-pentame thoxy-8-dibenzo $[a, g]$ quinolizine (Studies on the Syntheses of Heterocyclic Compounds. CCLXXXVI): T. Kametani and K. Ohkubo, Yakugaku Zasshi, 89, $279-282$ (1969).

289. Reduction Products of 3-0ximino-4-oxoisocarbostyril (Studies on the Syntheses of Heterocyclic Compounds. CCXCIII): T. Kametani, K. Kigasawa, H. Sugahara, M. Hiiragi, and K. Kanno, Yakugaku Zasshi, 89, $418-421$ (1969).

290. Studies on the Syntheses of Heterocyclic Compounds. CCCVII. A Synthesis of 3-Pheny 1-1,5-trimethylenepyrazole: T. Kametani, K. Yamaki, and K. Ogasawara, Yakugaku Zasshi, $89,583-585$ (1969).

291. Studies on the Syntheses of Heterocyclic Compounds. CCCVIII. Synthesis of 1 - (m-Ch1 oropheny 1propy 1$)-1,2,3,4$ - te trahydro-6,7-dimethoxy isoquinoline: T. Kametani, T. Terui, and K. Fukumoto, Yakugaku Zasshi, 89, 586 - 588 (1969).

292. Studies on the Syntheses of Heterocyclic Compounds. CCCX. Syntheses of 1,2,3,4-Tetrahydro-8-hydroxy-1-(3-hydroxy-4-methoxybenzy 1)-6, 7-dime thoxyisoqunoline and Diphenolic l-Phenethylisoquinoline Derivatives and Trial of Its Phenolic Oxidation: T. Kametani, T. Sugahara, and K. Fukumoto, Yakugaku Zasshi, $\underline{89}, 610-616$ (1969).

293. Studres on the Syntheses of Heterocyclic Compounds. CCCXI. The Formation of Diveratryl Ether in Crossed Cannizzaro Reaction of Veratraldehyde and Trial of Its Cyclization: T. Kametani, K. Yamaki, and K. Ogasawara, Yakugaku Zasshi, $\underline{89}, 638-640$ (1969).

294. Syntheses of $( \pm)-0$-Dimethylstepharotine and $( \pm)$-0-Methylstepharotine (Studies on the Syntheses of Heterocyclic Comnounds. CCCXII): T. Kametani and I. Noguchi, Yakugaku Zasshi, 89, 721 - 725 (1969).

295. Syntheses of 1-Substituted Isoquinoline and 1,4-Benzoxazepine Derivatives by Pomeranz-Fritsch Reaction (Studies on the Syntheses of Heterocyclic Compounds. $\operatorname{CCCXX):~T.~Kametani,~K.~Ohkubo,~and~S.~Takano,~Yakugaku~Zasshi,~}$ $\underline{89}, 1048-1055$ (1969).

296. Syntheses of Cyanomethy Derivatives by Benzyne Reaction between Halogenobenzene and Nitrile, and Application to Isoquinoline Syntheses (Studies on the Syntheses of Heterocyclic Compounds. CCCXXIII): T. Kametani, K. Kigasawa, M. Hiiragi, 0. Kusama, and K. Wakisaka, Yakugaku Zasshi, 89, 1212 $1217(1969)$. 
297. Syntheses of 1-Spiro-isoquinoline Derivatives by Phenolic Cyclization (Studies on the Syntheses of Heterocyclic Compounds. CCCXxxv): T. Kametani, K. Kigasawa, M. Hiiragi, H. Ishimaru, and S. Saito, Yakugaku Zasshi, $\underline{89}$, $1482-1487(1969)$.

298. Studies on Hypertensive Agents. II. Modified Synthesis of 2-Aminomethyl1,1-dipheny1-1-butene and Syntheses of Related Compounds: T. Kametani, S. Kaneda, I. Noguchi, K. Nakai, and K. Saito, Yakugaku Zasshi, 89, 1613 $1616(1969)$.

299. Dienone-Phenol Rearrangement of "Procularine-type Comnounds" and Synthesis of Its Rearranged Cularine-type Compound (Studies on the Syntheses of Heterocyclic Compounds. CCCVI): T. Kametani, H. Iida, T. Kikuchi, M. Mizushima, and K. Fukumoto, Chem. and Pharm. Bu11. (Janan), 17, $709-713$ (1969).

300. Dienone Synthesis by Phenolic Oxidation of Dihydroxy-1-phenethy1-1,2,3,4tetrahydroisoquinoline and Sodium Borohydride Reduction: T. Kametani and F. Satoh, Chem. and Pharm. Bul1. (Javan), 17, 814 - 818 (1969).

301. Capaurimine and Related Compounds. II. Syntheses of Position Isomers of Capaurimine and Capauridine (Studies on the Syntheses of Heterocyclic Compounds. CCCXIII): T. Kametani, H. Iida, T. Kikuchi, K. Ohkubo, and K. Fukumoto, Chem. and Pharm. Bu1l. (Japan), 17, 1051 - 1054 (1969).

302. Azamorphinan and Related Compounds. II. Synthesis of 3-Methoxy-9-azamorphinan Derivatives (Studies on the Syntheses of Heterocyclic Compounds. CCCXIX): T. Kametani, K. Kigasawa, K. Wakisaka, and N. Wagatsuma, Chem, and Pharm. Bull. (Japan), 17, 1096 - 1103 (1969).

303. Studies on the Syntheses of Heterocyclic Compounds. CCCXXI. Synthesis of Isoquinoline Derivatives Having Twenty-four Membered Ring System by U11mann Reaction: T. Kametani, H. Iida, and S. Tanaka, Chem. and Pharm. Bull. (Japan), $\underline{17}, 1729-1733(1969)$.

304. The Synthesis of C-nor-Androcymbine (Studies on the Syntheses of Heterocyclic Compounds. CCCXXIV): T. Kametani, M. Koizumi, and K. Fukumoto, Chem. and Pharm. Bu11. (Japan), 17, $1809-1814$ (1969).

305. Dimerization of Diphenolic Benzylisoquinolines by Phenolic Oxidative Coupling (Studies on the Syntheses of Heterocyclic Compounds. CXXVIII): T. Kametani and I. Noguchi, Chem. and Pharm. Bull. (Japan), 17, 1977 - 1982 (1969).

306. Novel Synthesis of Quinoline Derivatives with Triethyl Phosnhite: T. Kametani, K. Nyu, T. Yamanaka, H. Yagi, and K. Ogasawara, Chem. and Pharm. Bul1. (Japan), 17, $2093-2096$ (1969). 
307. The Nuclear Magnetic Resonance Spectra and Optical Rotatory Dispersion of Berbamunine, Magnoline and Two Diastereoisomers: T. Kametani, H, Iida, K. Sakurai, S. Kano, and M. Ihara, Chem. and Pharm. Bull. (Japan), 17, 2120 2125 (1969).

308. Modified Synthesis of Isosalutaridine (Studies on the Syntheses of Heterocyclic Compounds. CCCXXXVI): T. Kametani, M. Koizumi, and K. Fukumoto, Chem. and Pharm. Bull. (Japan), 17, 2245 - 2249 (1969).

309. Phenol1c Cyclization. IV. The Mechanism of the Isoquinoline Formation (Studies on the Syntheses of Heterocyclic Compounds. CCCXxxVII): T. Kametani, K. Kigasawa, M. Hiiragi, and H. Ishimaru, Chem. and Pharm. Bul1. (Japan), 17, $2353-2357$ (1969).

310. Synthesis of Isoquinoline Alkaloids and Related Compounds Having a SpiroRing: T. Kametani and H. Yagi, Kagaku no Ryoiki Zokan, 87, $99-130$ (1969).

311. Formation of Morphinandienone-type Compound through Methylenedioxy Cleavage by Pschorr Cyclisation: T. Kametani, T. Sugahara, and K. Fukumoto, Chem. and Ind., $1969,833-834$.

312. Ortho-Dienone Synthesis by the Phenolic Oxidation of Dihydroxy-1-phenethy11,2,3,4-tetrahydroisoquinoline: T. Kametani, K. Fukumoto, T. Hayasaka, F. Satoh, and K. Kigasawa, J. Chem. Soc. (C), 1969, 4 - 9.

313. Head-to-tail Coupling of 1,2,3,4-Tetrahydro-7-hydroxy-1-(4-hydroxyphenethy1)6-methoxy-2-methylisoquinoline by Enzymic Phenolic oxidation: T. Kametani, S. Takano, and T. Kobari, J. Chem. Soc. (C), 1969, $9-12$.

314. Nitrenes. Part III. The Reaction of 4-(2-Nitropheny1)pyridine Derivatives with Triethyl Phosphite: T. Kametani, K. Ogasawara, and T. Yamanaka, J. Chem. Soc. (C), 1969, $138-140$.

315. A Total Synthesis of Isoliensinine: T. Kametani, S. Takano, H. Iida, and M. Shinbo, J. Chem. Soc. (C), 1969, $298-300$.

316. Nitrenes. Part IV. Synthesis of Oxazo1o[5,4-b] quinoline through a Nitrene Intermediate: T. Kametani, T. Yamanaka, and K. Ogasawara, J. Chem. Soc. (C), $1969,385-387$.

317. A Total Synthesis of Magnoline: T. Kametani, H. Iida, and K, Sakurai, J. Chem. Soc. (C), 1969, $500-501$.

318. An Alternative Tota1 Synthesis of N-Methylcaaverine through Phenolic Oxidation: T. Kametani and I. Noguchi, J. Chem. Soc. (C), 1969, 502 - 505. 
319. Total Synthesis of O-Methylflavinantine: T. Kametani, K. Fukumoto, F. Satoh, and H. Yagi, J. Chem. Soc. (C), 1969, $520-523$.

320. Total Synthesis of ( \pm )-Amurine: T. Kametani, K. Fukumoto, and T. Sugahara, J. Chem. Soc. (C) $, \underline{1969}, 801-804$.

321. Studies on the Syntheses of Heterocyclic Compounds. Part CCLXXXI. Synthesis of Homoprotoberberine-type Compounds by Phenolic Cyclisation: T. Kametani, T. Terui, T. Ogino, and K. Fukumoto, J. Chem. Soc. (C), 1969, $874-878$.

322. Total Synthesis of ( \pm )-Flavinantine: T. Kametani, T. Sugahara, H. Yagi, and K. Fukumoto, J. Chem. Soc. (C), 1969, 1063-1065.

323. Biogenetic Synthesis of an Androcymbine-type Compound: T. Kametani, K. Fukumoto, M. Koizumi, and A. Kozuka, J. Chem. Soc. (C), 1969, $1295-1297$.

324. Nitrene. Part V. Reaction of 4-(2-Nitropheny1)-1,4-dihydropyridine Derivatives with Triethyl Phosphite: T. Kametani, T. Yamanaka, and K. Ogasawara, J. Chem. Soc. (C), 1969, $1616-1619$.

325. Studies on the Syntheses of Heterocyclic Compounds. Part CCC. Syntheses of Salutaridine, Sinoacutine, and Thebaine. Formal Total Syntheses of Morphine and Sinomenine: T. Kametani, M. Ihara, K. Fukumoto, and H. Yagi, J. Chem. Soc. (C) $, \underline{1969}, 2030-2033$.

326. Studies on the Syntheses of Heterocyc1ic Compounds. Part CCCI. Biogenetic Syntheses of the Morphinandienone-type Compounds, Isosalutaridine and 0Methylflavinantine: T. Kametani, K. Fukumoto, A. Kozuka, H. Yagi, and M. Koizumi, J. Chem. Soc. (C), 1969, $2034-2036$.

327. Studies on the Syntheses of Heterocyclic Compounds. Part CCCII. Alternative Total Syntheses of ( \pm )-Nandinine, ( \pm )-Canadine, and Berberine Iodide: T. Kametani, I. Noguchi, K. Saito, and S. Kaneda, J. Chem. Soc. (C), 1969, 2036 -2038 .

328. Studies on the Syntheses of Heterocyclic Compounds. Part CCCXV. Modified Total Synthesis of $( \pm)$-Galanthamine through Phenol Oxidation: T. Kametani, K. Yamaki, H. Yagi, and K. Fukumoto, J. Chem. Soc. (C), 1969, $2602-2605$.

329. Enzymic Phenol oxidation. Part III. Head-to-head Counling of 1,2,3,4Tetrahydro-7-hydroxy-1-(4-hydroxyphenethy1)-6-methoxy-2-methylisoquinoline with Homogenised Wasabia japonica: T. Kametani, S. Takano, and T. Kobari, J. Chem, Soc. (C), 1969, $2770-2773$.

330. An Alternative Synthesis of ( \pm )-Dihydrogriseofulvin by Enzymic Phenolic 0x1dation by Homogenised Potato Peelings: T. Kametani, S. Hibino, and S. Takano, 
J. C. S. Chem. Comm., 1969, 131 .

331. Modified Total Synthesis of ( \pm )-Galanthamine through Phenol Oxidation: T. Kametani, K. Yamaki, H. Yagi, and K. Fukumoto, J. C. S. Chem. Comm., 1969, $425-426$.

332. Two New Alkaloids; Kikemanine and the Morphinandienone-type Alkaloids, Pallidine, from Coryda1is Species: T. Kametani, M. Ihara, and T. Honda, J. C. S. Chem. Comm., 1969, 1301.

333. Biogenetic Type Syntheses of Aporphine Alkaloids, Isoboldine and Glaucine: T. Kametan 1 , T. Sugahara, H. Yagi, and K. Fukumoto, Tetrahedron, 25, 3667 3673 (1969).

334. Crystal Structure of One of the Position Isomer of Capaurimine by X-ray Analysis: T. Kametani, K. Wakisaka, T. Kikuchi, M. Ihara, H. Shimanouchi, and $Y$. Sasada, Tetrahedron Letters, 1969, $627-630$.

335. Nove1 Debenzylation of Quaternary Ammonium Salts with Thiopheno1: T. Kametani, K. Kigasawa, M. Hiiragi, N. Wagatsuma, and K. Wakisaka, Tetrahedron Letters, $1969,635-638$.

336. Novel Synthesis of Quinoline Derivatives with Triethyl Phosphite: T. Kametani, K. Nyu, T. Yamanaka, H. Yagi, and K. Ogasawara, Tetrahedron Letters, $1969,1027-1030$.

337. Syntheses of Benzomorphan and Related Compounds. Part I. Synthesis of NSubstituted $1,2,3,4,5,6$-Hexahydro-8-hydroxy-2,6-methano-6,11-dimethy 1-3benzazocine [Studies on the Syntheses of Heterocyclic Compounds. Part CCLXXXII]. T. Kametani, K. Kigasawa, M. Hiiragi, T. Hayasaka, N. Wagatsuma, and K. Wakisaka, J. Heterocyclic Chem., 6 , 43 - 48 (1969).

338. Ochotensine and Related Compounds. II. A Synthesis of Isoochotensine (Studies on the Syntheses of Heterocyclic Compounds. CCLXXV): T. Kametani, S. Takano, S. Hibino, and T. Terui, J. Heterocyclic Chem., 6, $49-51$ (1969).

339. Studies on the Syntheses of Heterocyclic Compounds. Part CCLXXIX. Synthesis of O-Isobutylcularidine: T. Kametani, H. Iida, and C. Kibayashi, J. Heterocyc1ic Chem., 6, 61 - 71 (1969).

340, Studies on the Syntheses of Heterocyclic Compounds. Part CCCXV. Erythrinan and Related Compounds. II. An Alternative Synthesis of cis-16-Hydroxy-15methoxyerythrinan-8-one and Its Mass Spectrum: T. Kametani, H. Agui, K. Saito, and K. Fukumoto, J. Heterocyclic Chem., 6, 453 - 457 (1969).

341. Mannich and Eshweiler-Clarke Reaction of 1-Benzy1-1,2,3,4-tetrahydroiso- 
quinolines. Studies on the Syntheses of Heterocyclic Compounds. Part CCCXVIII: T. Kametani, I. Noguchi, and K. Saito, J. Heterocyclic Chem., 6 , $869-873(1969)$.

342. Studies on the Syntheses of Heterocyclic Compounds. Part CCCXVII. The Benzyne Reaction of 3-Bromoquinoline with Alkyl Cyanides: $T$. Kametani, $K$. Kigasawa, M. Hiiragi, and 0 . Kusama, J. Heterocyclic Chem., 6, $933-935$ (1969).

343. Syntheses of Benzomorphan and Related Compounds. II. The Debenzylation of Quaternary Ammonium Salts with Thiophenol: T. Kametani, K. Kigasawa, M. Hiiragi, N. Wagatsuma, K. Wakisaka, and O. Kusama, J. Medicin. Chem., 12, $694-696(1969)$.

344. The Crystal Structure of Capaurine Hydrobromide: H. Shimanouchi, Y. Sasada, M. Ihara, and T. Kametani, Acta Cryst., B25, 1310 - 1319 (1969).

345. The Color Reaction in Non-Aqueous Solvents. I. Structural Changes and Bond for Reaction of Bromopheno1 Blue with Amines: K. Kigasawa, H. Shimizu, M. Fujino, and T. Kametani, Yakugaku Zasshi, 90, $182-187$ (1970).

346. Studies on the Syntheses of Heterocyc1ic Comnounds. CCCXXXVIII. On the Intermolecular U1lmann Reaction Products of 1-(4-Benzyloxy-3-bromobenzyl)1,2,3,4-tetrahydro-7-hydroxy-6-methoxy-2-methylisoquinoline: T. Kametani, H. Iida, and S. Tanaka, Yakugaku Zasshi, 90, $209-213$ (1970).

347. Reaction Mechanism in Drug Analysis. III. Reaction of 5-Allylbarbituric Acids with Hydrogen Peroxide and Hydrochloric Acid: K. Kigasawa, H. Shimizu, T. Iwata, H. Tanaka, H. Nakaguro, F. Satoh, and T. Kametani, Yakugaku Zasshi, 90, $532-536(1970)$.

348. Synthesis of Homoproaporphine by Phenol Oxidation (Studies on the Syntheses of Heterocyclic Compounds. CCCL): T. Kametani and M. Mizushima, Yakugaku Zasshi, 90, $696-698(1970)$.

349. The Dimerisation of Indole in the Presence of Acidic Catalyst (Studies on the Syntheses of Heterocyclic Compounds. CCCLI): T. Kametani and T. Suzuki, Yakugaku Zasshi, 90, $771-773$ (1970).

350. Abnormal products of 1-(2-Amino-3-benzyloxy-4-methoxyphenethy1)-1,2,3,4tetrahydro-6,7-dimethoxy-2-methylisoquinoline by Modified Pschorr Reaction (Studies on the Syntheses of Heterocyclic Compounds. CCCLXX): T. Kametani, M. Koizumi, and K. Fukumoto, Yakugaku Zasshi, 90, 1331-1338 (1970).

351. Streptonigrin and Related Compounds. IX. Syntheses of 4-Pheny1-2,3-dimethylpyridone Derivatives (Studies on the Syntheses of Heterocyclic Compounds. 
CCCLXIII): T. Kametani, A. Kozuka, and S. Tanaka, Yakugaku Zasshi, $\underline{90}$, $1574-1578(1970)$.

352. Synthesis of 1-Benzyloxindole Derivatives for the Study of Phenolc Oxidative Coupling (Studies on the Syntheses of Heterocyclic Compounds. CCCXLVII): T. Kametani, H. Yagi, K. Kawamura, and T. Kohno, Chem. and Pharm. Bull. (Japan), 18, $645-650(1970)$.

353. Application of Norphenylephrine Derivatives to the Isoquinoline Syntheses (Studies on the Syntheses of Heterocyc1ic Compounds. CCCLII): T. Kametani, F. Satoh, H. Agui, K. Ueki, K. Kigasawa, M. Hiiragi, H. Ishimaru, and S. Horie, Chem. and Pharm. Bull. (Japan), 18, 1161 - 1167 (1970).

354. An Alternative Syntheses of ( \pm )-Dehydrogriseofulvin by Enzymic Phenolic Oxidation by Homogenized Potato Peelings (Studies on the Syntheses of Heterocyclic Compounds. CCCLIII): T. Kametani, S. Hibino, and S. Takano, Chem. and Pharm. Bu1l. (Japan), 18, $1482-1484$ (1970).

355. Syntheses of Homotaurine Related Compounds (Studies on the Syntheses of Heterocyclic Compounds. Part CCCLV): T. Kametani, K. Takahashi, H. Sugi, S. Hirata, T. Kameyama, K. Sasaki, and 0. Umezawa, Oyo Yakuri, 4, $713-720$ (1970).

356. A Synthetic Approach to Camptothecin: T. Kametani, H. Nemoto, H. Takeda, and S. Takano, Chem. and Ind., 1970, 1323 - 1324.

357. Syntheses of Morphinandienone and Aporphine by Photolysis: T. Kametani, K. Fukumoto, and K. Shishido, Chem. and Ind., 1970, 1566 - 1567.

358. Nitrene. Part VI. Reaction of $6^{\prime}$-Nitropapaverine and Its Analogue with Triethyl Phosphite: T. Kametani, T. Yamanaka, K. Ogasawara, and K. Fukumoto, J. Chem. Soc. (C) $, 1970,380-381$.

359. Configuration and Rearrangements of Homoproaporphines: T. Kametani, F. Satoh, H. Yagi, and K. Fukumoto, J. Chem. Soc. (C), 1970, $382-385$.

360. An Approach to the Synthesis of Sinomenine: T. Kametani, T. Sugahara, H. Yagi, K. Fukumoto, B. R, Pai, and R. Charuba1a, J. Chem. Soc. (C), 1970, 624 - 626.

361. Studies on the Syntheses of Heterocyclic Compounds. Part CCXIII. Phenolic Oxidative Coupling of a Dihydroxy-1-phenethy 1-1,2,3,4-tetrahydroisoquinoline: T. Kametani, K. Fukumoto, M. Kawatsu, and M. Fujihara, J. Chem. Soc. (C), $1970,922-927$.

362. Alkaloids of Corydalis Pallida var. tenuis (Yatabe) and the Structures of 
Pallidine and Kikemanine: T. Kametani, M. Ihara, and T. Honda, J. Chem. Soc. (C), $1970,1060-1064$.

363. Abnormal Products of the Pschorr Reaction of 8-Amino-1,2,3,4-tetrahydro-1phenethylisoquinoline: T. Kametani, K. Fukumoto, M. Kawatsu, and M. Fujihara, J. Chem. Soc. (C), 1970, $2209-2213$.

364. Synthesis and Stereochemistry of 1,2,3,4-Tetrahdyro-6-methoxy-2-methy1-1phenylisoquinoline and Related Compounds: T. Kametani, H. Sugai, H. Yagi, K. Fukumoto, and S. Shibuya, J. Chem. Soc. (C), 1970, $2213-2217$.

365. Elucidation of the Structure of Capaurimine: T. Kametani, M. Thara, and T. Honda, J. Chem. Soc. (C), 1970, $2342-2346$.

366. Total Synthesis of ( \pm -Obaberine: T. Kametani, K. Wakisaka, and K. Kigasawa, J. C. S. Chem. Comm., 1970, $277-278$.

367. Total Synthesis of O-Methylandrocymbine by Photolysis of Diazotised Isoquinoline: T. Kametani, M. Koizumi, and K. Fukumoto, J. C. S. Chem. Comm., 1970, 1157 .

368. X-ray Determination of the Structure of Capaurimine: T. Kametani, M. Thara, Y. Kitahara, C. Kabuto, H. Shimanouchi, and Y. Sasada, J. C. S. Chem. Comm., $\underline{1970}, 1241-1242$.

369. A Total Synthesis of the Alkaloid ( \pm )-Kikemanine: T. Kametani, T. Honda, and M. Ihara, J.C. S. Chem. Comm., 1970, 1253 - 1254.

370. Studies on the Syntheses of Heterocyclic Compounds. CCCLXX1. Synthetic Approach to Camptothecin: T. Kametani, H. Nemoto, H. Takeda, and S. Takano, Tetrahedron, 26, $5753 \cdot 5755$ (1970).

371. A Novel Formation of the Indole Derivatives by Phenolic Oxidative Coupling: T. Kametani, I. Noguchi, K. Nyu, and S. Takano, Tetrahedron Letters, 1970 , $723-726$.

372. Studies on the Syntheses of Heterocyclic Compounds. Part CCCXXIX. Syntheses of 1-Spiroisoquinoline Derivatives by Phenolic Cyclization: T. Kametani, K. Kigasawa, M. Hiiragi, and H. Ishimaru, J. Heterocyc1ic Chem., 7, 51 - 54 (1970).

373. Studzes on the Syntheses of Heterocyclic Compounds. Part CCcxxx. Synthesis of a Homocularine Type Compounds: T. Kametani and T. Terui, J. Heterocyclic Chèm., 7, $55-58(1970)$.

374. Enzymic Phenol Oxidation of N-Methylcoclaurine. Studies on the Syntheses of Heterocyclic Compounds. Part CCCXXXII: T. Kametani, H. Nemoto, T. Kobari, and 
S. Takano, J. Heterocyclic Chem., 2, $181-186$ (1970).

375. A Synthesis of 0-Ethylcularidine (Studies on the Syntheses of Heterocyc1ic Compounds. Part CCCXXXIII): T. Kametani, H. Iida, and C. Kibayashi, J. Heterocyclic Chem., $7,339-343$ (1970).

376. The Total Synthesis of ( \pm )-Capaurine [Studies on the Syntheses of Heterocyclic Compounds. CCCXLVIII]: T. Kametani, H. Iida, T. Kikuchi, T. Honda, and M. Ihara, J. Heterocyc1ic Chem., 7, $491-493$ (1970).

377. Total Synthesis of ( \pm )-Obaberine [Studies on the Syntheses of Heterocyclic Compounds. Part CCCXLIX]: T. Kametani, K. Wakisaka, and K. Kigasawa, J. Heterocyclic Chem., 7, 509 - 510 (1970).

378. Studies on the Syntheses of Azole Derivatives. Part I. Formation of 1Substrtuted 3-Hydroxy-1H-indazole and 1-Substituted Benzimidazolin-2-one Derivatives by Thermal Reaction: T. Kametani, K. Sota, and M. Shio, J. Heterocyclic Chem., $\underline{7}, 807-813$ (1970).

379. Studies on the Syntheses of Azole Derivatives. Part II. Syntheses of N-(1or 2-Substituted)indazolone via Diazotization: T. Kametani, K. Sota, and M. Shio, J. Heterocyc1ic Chem., 7,815 - 820 (1970).

380. Studies on the Syntheses of Azole Derivatives. Part III. Syntheses of 1 Pheny $1-\Delta^{2}-1,2,4$-triazolin-5-one and 4-Phenyl- $\Delta^{2}-1,3,4$-oxadiazolin-5-one Derivatives by Fusion of I-Phenyl-2-acylhydrazine with Urea: T. Kametani, K. Sota, and M. Shio, J. Heterocyclic Chem., 7, $821-829$ (1970).

381. Studies on the Syntheses of Azole Derivatives. Part IV. Novel Syntheses of 1-Benzylbenzimidazolines by Photolys is of N-Aryl-N-benzylcarbamoy 1 Azides [Studies on the Syntheses of Heterocyclic Compounds. Part CCCLXXVIII]: T. Kametani and M. Shio, J. Heterocyclic Chem., 7, 831 - 834 (1970).

382. Azamorphinan and Related Compounds. III. Syntheses of 3-Hydroxy-N-substituted 9-Azamorphinans: T. Kametani, K. Kigasawa, M. Hiiragi, N. Wagatsuma, K. Wakisaka, F. Satoh, and S. Saito, J. Medicin. Chem., 13, $1064-1067$ (1970).

383. Studies on the Syntheses of Azole Derivatives. VI. The Mass Spectra of Benzimidazolines and Indazoline (Studies on the Syntheses of Heterocyclic Compounds. CCCLXXVIII): T. Kametani, S. Hirata, S. Shibuya, and M. Shio, Org. Mass Spectrometry, $\underline{4}, 395-404$ (1970).

384. The Crysta1 Structure of cis-5,6,13,13a-Tetrahdyro-3,9-dihydroxy-1,2,10-trimethoxy-8H-dibenzo[a,g]quinolizine Hydrobromide Monohydrate: H. Shimanouchi, Y. Sasada, K. Wakisaka, T. Kametani, and M. Ihara, Acta Cryst., B26, 607 $616(1970)$. 
385. Synthesis of 1-Benzylindole Derivatives (Studies on the Syntheses of Heterocyclic Compounds. CDXIX): T. Kametani, S. Shibuya, and T. Kohno, Yakugaku Zasshi, $\underline{91}, 818-821$ (1971).

386. Studies on the Syntheses of Heterocyclic Compounds. CDXXX. Synthesis of Camptothecin and Related Compounds. II. A Synthesis of 4-Ethy1-4-hydroxy-5methoxy-6-methy 1-3-oxo-1,2,3,4-tetrahydro-2,7-naphthyridine: T. Kametani, S. Takano, H. Nemoto, and H. Takeda, Yakugaku Zashsi, $\underline{91}, 966-971$ (1971).

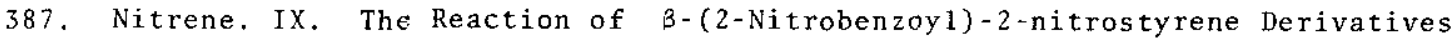
with Triethyl Phosphite (Studies on the Syntheses of Heterocyclic Compounds. CDXXV): T. Kametani, T. Yamanaka, K. Nyu, and S. Takano, Yakugaku Zasshi, $\underline{91}$, $1033-1036(1971)$.

388. Studies on the Syntheses of Heterocyclic Compounds. CDXLII. Syntheses of Streptonigrin and Related Compounds. X. A Synthesis of Methy1 3-Acetamido1,2 -dihydro-2-(2,3,4-trimethoxypheny 1)-5-methyl-2-oxo-6-pyridinecarboxy 1 ate : T. Kametani, S. Tanaka, and A. Kozuka, Yakugaku Zasshi, 91, 1068 - 1072 (1971).

389. Chemical and Enzymic Pheno1 Oxidation of (R) (-)-N-Methylcoclaurine and (S) (+)Reticuline (Studies on the Syntheses of Heterocyclic Compounds. CDII): T. Kametani, K. Fukumoto, K. Kigasawa, and K. Wakisaka, Chem. and Pharm. Bul1. (Japan), 19, $714-717$ (1971).

390. Phenolic Cyclization. IX. Syntheses of Benz[c] phenanthridine and Related Compounds (Studies on the Syntheses of Heterocyclic Compounds. CDIX): T. Kametani, K. Kigasawa, M. Hiiragi, O. Kusama, E. Hayashi, and H. Ishimaru, Chem. and Pharm. Bu1l. (Japan), 19, $1150-1157$ (1971).

391. Nitrenes. VIII. A Nove1 Synthesis of 3-Cyano-2-ethoxy-6,7-disubstituted Quinolines with Triethyl Phosphite (Studies on the Syntheses of Heterocyclic Compounds. CDXVI): T. Kametani, K. Nyu, and T. Yamanaka, Chem. and Pharm. Bu11. (Japan), 19, $1321-1324$ (1971).

392. Studies on the Syntheses of Heterocyclic Compounds. CDXVII. Syntheses of 1,2Benzoxazepine, Oxindole and Furanoquinolone Derivatives by Cyclization of Hydroxamic Acid with Polyphosphoric Acid: T. Kametani and H. Nemoto, Chem. and Pharm. Bull. (Japan), 19, 1325 - 1328 (1971).

393. Total Syntheses of ( \pm )-N-Nordasycarpidone and $( \pm$ )-Dasycarpidone (Studies on the Syntheses of Heterocyclic Compounds. CDXVIII): T. Kametani and T. Suzuki, Chem. and Pharm. Bu11. (Japan), 19, $1424-1425$ (1971).

394. Total Synthesis of Flavinantine and Bracteoline by a Photo-Pschorr Reaction: T. Kametani, H. Sugi, S. Shibuya, and K. Fukumoto, Chem, and Pharm. Bul1. (Japan), 19, $1513-1514$ (1971). 
395. Studies on the Syntheses of Heterocycic Compounds. CDXXIV. The Abnorma1 Formation of 3-(4-Methoxyphenethy1)-6,7-methylenedioxy-1,2,3-benzotriazin4-one in Case of Pschorr Reaction: T. Kametani, C. Seino, and T. Nakano, Chem. and Pharm. Bull. (Japan), 19, 1959 - 1962 (1971).

396. Synthesis of $1,2,3,4,5,6,7,8$-Octahydro-1-(4-methoxybenzy 1 )-2-methylphthalazine Derivaitve (Studies on the Syntheses of Heterocyclic Compounds. CDXXXI): T. Kametani, T. Kohno, K. Kigasawa, M. Hiiragi, K. Wakisaka, and T. Uryu, Chem. and Pharm. Bull. (Japan), 19, 1794 - 1799 (1971).

397. Synthesis of Erythrinadienone by Phenol Oxidation of Bisphenethylamine (Studies on the Syntheses of Heterocyclic Compounds. CDXLV): T. Kametani and T. Kohno, Chem. and Pharm. Bu11. (Japan), 19, 2102 - 2105 (1971).

398. Studies on the Syntheses of Heterocyclic Compounds. CDLII. An Alternative Total Synthesis of Corydalactam: T. Kametani and M. Ihara, Chem. and Pharm. Bu11. (Japan), 19, $2256-2258$ (1971).

399. The Synthesis of Morphinandienone-type Alkaloids: K. Fukumoto (T. Kametani), Kagaku no Ryoiki Zokan, 94, 133 - 178 (1971).

400. Syntheses of Pentazocine: T. Kametani and K. Kigasawa, J. Synth. Org. Chem. Japan, 29, 227 - 236 (1971).

401. Total Synthesis of Salutaridine by Photolysis: T. Kametani, H. Nemoto, T. Nakano, S. Shibuya, and K. Fukumoto, Chem, and Ind., 1971, 788.

402. An Alternative Total Synthesis of Glaziovine by Photolysis: T. Kametani,H. Sugi, S. Shibuya, and K. Fukumoto, Chem. and Ind, 1971, 818.

403. Studies on the Syntheses of Heterocyclic Compounds. Part CCCLXXXI. A Nove1 Conversion of Galanthamine into Nivalidine under Non-acidic Conditions: $T$. Kametani, K. Yamaki, S. Shibuya, and K. Fukumoto, J. Chem. Soc. (C), 1971, 590 - 592.

404. Synthesis of Corydalactam: T. Kametani and M. Ihara, J. Chem. Soc. (C), 1971, $999-1000$.

405. Studies on the Syntheses of Heterocyclic Compounds. Part CCCLXXX1I. Phenolic Oxidative Coupling of Reticuline by Use of Various Reagents: T. Kametani, A. Kozuka, and K. Fukumoto, J. Chem. Soc. (C), 1971, 1021 - 1024.

406. Studies on the Syntheses of Heterocyclic Compounds. Part CCCLXXXIII. A Total Synthesis of (-)(-)-00-Dimethylcurine: T. Kametani, H. Iida, and K. Sakurai, J. Chem. Soc. (C), 1971, $1024-1029$. 
407. Studies on the Syntheses of Heterocyclic Compounds. Part CCCLxxxv. Pschorr Reaction of 1-(2-Aminobenzy 1)- and 1-(2-Aminophenethy 1)-1,2,3,4-tetrahydroisoquinolines (Total Synthesis of Tha1icsimidine): T. Kametani, K. Takahashi, T. Sugahara, M. Koizumi, and K. Fukumoto, J. Chem. Soc. (C), 1971, 1032 1043 .

408. Studies on the Syntheses of Heterocyclic Compounds. Part CCCLXXXVI. Alternative Total Syntheses of Galanthamine and $\mathrm{N}$-Benzylgalanthamine lodide: $\mathrm{T}$. Kametani, C. Seino, K. Yamaki, S. Shibuya, K. Fukumoto, K. Kigasawa, S. Satoh, M. Hiiragi, and T. Hayasaka, J. Chem. Soc. (C), 1971, $1043-1047$.

409. Benzyne Reaction. Part X. The Benzyne Reaction of ortho-Substituted Ha10genobenzenes with Cyclohexanone in Secondary Cyclic Amines or in Organic Solvents: T. Kametani, S. Noguchi, I. Agata, T. Aono, K. Kigasawa, M. Hiiragi, T. Hayasaka, and O. Kusama, J. Chem. Soc. (C), 1971, $1047-1050$.

410. Benzyne Reaction. Part XI. Nove1 Syntheses of 2-(3-Substituted Phenyl)cycloalkanones by the Benzyne Reaction: T. Kametani, K. Kigasawa, M. Hiiragi, T. Hayasaka, and O. Kusama, J. Chem. Soc. (C), 1971, $1051-1052$.

411. Studies on the Syntheses of Heterocyclic Compounds. Part CCCLXxxix. An Alternative Synthesis of De-ethyldasycarpidone: T. Kametani and T. Suzuki, J. Chem. Soc. (C), 1971, 1053 - 1054 .

412. Tota1 Synthesis of O-Methylandrocymbine by a Photo-Pschorr Reaction and Synthes is of Thalifoline: T. Kametani, M. Koizumi, and K. Fukumoto, J. Chem. Soc. (C) , 1971, $1792-1796$.

413. Studies on the Syntheses of Heterocyc1ic Compounds. Part CCCXCII. An Alternative Total Synthesis of Petaline: T. Kametani, T. Kobari, K. Fukumoto, and M. Fujihara, J. Chem. Soc. (C), 1971, 1796 - 1800 .

414. Studies on the Syntheses of Heterocyclic Compounds. Part CCCXCIII. Synthesis of Norerythrinadienone by Phenolic Oxidative Coupling: T. Kametani, K. Takahashi, S. Shibuya, and K. Fukumoto, J. Chem. Soc. (C), 1971, $1800-1803$.

415. Formation of Indole Derivaitves by Phenolic Oxidative Counling: T. Kametani, C. Seino, I. Noguchi, S. Shibuya, K. Fukumoto, T. Kohno, and S. Takano, J. Chem. Soc. (C) $1971,1803-1805$.

416. Cyclized Products in the Synthesis of 6-Substituted Phenanthridines by Phenolic Cyclisation: T. Kametani, K. Fukumoto, K. Kigasawa, M. Hiiragi, H. Ishimaru, and K. Wakisaka, J.Chem. SoC. (C), 1971, 1805 - 1808.

417. Studies on the Syntheses of Heterocyclic Comnounds. Part CD. Total Syntheses of NO(10)-Dimethylhernovine and Kreysigine by Photolysis of Diazotised Iso- 
quinolines: T. Kametani, M. Koizumi, K. Shishido, and K. Fukumoto, J. Chem. Soc. (C), 1971, $1923-1927$.

418. Studies on the Syntheses of Heterocyclic Compounds. Part CDI. Rearrangement of B-Hydroxylaudanosine: T. Kametani, S. Hirata, S. Shibuya, and K. Fukumoto, J. Chem. Soc. (C), 1971, $1927-1928$.

419. A Total Synthesis of $( \pm)$-Capaurimine: T. Kametani, T. Honda, and M. Ihara, J. Chem. Soc. (C), 1971, $2396-2398$.

420. Studies on Total Photolytic Syntheses of Alkaloids. Part V. Total Syntheses of Flavinantine, Amurine, Bracteoline, and Domesticine by Photolysis of the Appropriate 1-(2-Bromobenzyl)isoquinolines: T. Kametani, S. Shibuva, H. Sugi, O. Kusama, and K. Fukumoto, J. Chem. Soc. (C), 1971, $2446-2448$.

421. Studies on the Syntheses of Heterocyclic Compounds. Part CDVIII. Crystal Structure of Capaurimine Mono-p-bromobenzoate: T. Kametani, M. Ihara, T. Honda, H. Sh1manouchi, and Y. Sasada, J. Chem. Soc. (C), 1971, 2541 - 2545.

422. Phenolic Cyclisation. Part X. Isoquinoline Cyclisation under Baisc Conditions: T. Kametani, K. Kigasawa, M. Hiiragi, and H. Ishimaru, J. Chem. Soc. (C), 1971, 2632 - 2634.

423. Studies on the Syntheses of Heterocyclic Compounds. Part CDXII. Total Synthesis of Canadine: T. Kametani, K. Fukumoto, T. Terui, K. Yamaki, and E. Taguchi, J. Chem. Soc. (C), 1971, $2709-2711$.

424. Benzyne Reaction. Part XII. Syntheses of Amurine and Domesticine by the Benzyne Reaction: T. Kametani, S. Shibuya, K. Kigasawa, M. Hiirag1, and 0. Kusama, J. Chem. Soc. (C), 1971, 2712 - 2714 .

425. Syntheses of a Proerythrinadienone by Phenolic Oxidation and a Morphinandienone System by a Photo-Pschorr Reaction: T. Kametani, R. Charubala, M. Ihara, M. Koizumi, K. Takahashi, and K. Fukumoto, J. Chem. Soc. (C), 1971, 3315 - 3318.

426. A Total Synthesis of ( \pm -Kikemanine: T. Kametani, T. Honda, and M. Ihara, J. Chem. Soc. (C), 1971, $3318-3321$.

427. Studies on the Syntheses of Heterocyc1ic Compounds. Part CDXXI. General Synthesis of 7,8-Dioxygenated 1-Benzyl-1,2,3,4-tetrahydroisoquinolines and Elucidation of the Structure of Caseadine: T. Kametani, T. Nakano, K. Shishido, and K. Fukumoto, J. Chem. Soc. (C) , 1971, 3350 - 3354 .

428. Studies on the Syntheses of Heterocyc1ic Compounds. Part CDXLIII. An Alternative Synthesis of $\{ \pm\}$-Glaziovine by Photolysis and Phenolic oxidation: $T$. Kametani, S. Shibuya, T. Nakano, and K. Fukumoto, J. Chem. Soc. (C), 1971, 
$3818-3821$.

429. Studies on the Syntheses of Heterocyclic Compounds. Part CDXLVI. Total Phatolytic Synthesis of ( \pm )-Androcymbine and ( \pm )-Multifloramine: T. Kametani and M. Koizumi, J. Chem. Soc. (C), 1971, $3976-3979$.

430. Synthesis of a Proerythrinadienone System by Phenol Oxidation: T. Kametani, R. Charuba1a, M. Ihara, M. Koizumi, and K. Fukumoto, J. C. S. Chem. Comm., $\underline{1971}, 289$.

431. Biosynthesis of Cularine: T. Kametani, K. Fukumoto, and M. Fujihara, J. C. S. Chem. Commm., 1971, 352 - 353 .

432. Total Photolytic Synthesis of ( \pm )-Pronuciferine, ( \pm )-0-Methylorientalinone, and ( \pm )-O-Methylkreysiginone: T. Kametani, T. Sugahara, H. Sugi, S. Shibuya, and K. Fukumoto, J. C. S. Chem. Comm., 1971, 724 .

433. Photochemical Synthesis of the Crinine Ring System: Formal Total Synthesis of ( $\ddagger$ )-Maritidine: T. Kametani, T. Kohno, S. Shibuya, and K. Fukumoto, J. C. S. Chem. Comm., 1971, $774-775$.

434. Stereospecific Total Synthesis of ( \pm )-Ochrobirine: T. Kametani, S. Hibino, and S. Takano, J. C. S. Chem. Comm., 1971, $925-926$.

435. The Absolute Configuration of Cryptostyline-III. Studies on the Syntheses of Heterocyclic Compounds. CCCXCVII: T. Kametani, H. Sugi, and S. Shibuya, Tetrahedron, 27, $2409-2414$ (1971).

436. Studies on Total Photolytic Synthesis of Alkaloids. III. The Products of Photo-Pschorr Reaction - Total Synthesis of Isocorydine: T. Kametani, T. Sugahara, and K. Fukumoto, Tetrahedron, 27, $5367-5374$ (1971).

437. Studies on Total Photolytic Syntheses of Alkaloids. IV. Modified Total Syntheses of Flavinantine, Bracteoline, Isoboldine and Mecambrine by Photolysis: T. Kametani, H. Sugi, S. Shibuaya, and K. Fukumoto, Tetrahedron, 27, 5375 $5379(1971)$.

438. Studies on the Synthesis of Heterocyclic Compounds. CDXXXVI. Photolytic Synthesis of the Crinine Ring System -- Formal Total Synthesis of ( \pm )-Marit1dine: T. Kametani, T. Kohno, S. Shibuya, and K. Fukumoto, Tetrahedron, 27, $5441-5444(1971)$.

439. Tota1 Syntheses of ( \pm )-Pronuciferine, ( \pm )-0-Methylorientalinone, and ( \pm )-0Methylkreysiginone: T. Kametani, T. Sugahara, H. Sugi, S. Shibuya, and K. Fukumoto, Tetrahedron, 27, 5993 - 5998 (1971). 
440. Total Synthesis of ( \pm )-Epicrinine by Photolysis; T. Kametani and T. Kohno, Tetrahedron Letters, 1971, 3155 - 3156.

441. Morphinandienone Alkaloids from Corydalis Incisa: T. Kametani, M. Ihara, and T. Honda, Phytochemistry, 10, $1881-1883$ (1971).

442. Benzyne Reaction. IX. Benzyne Reaction of o-Halobenzenes with Acetonitrile or Phenylacetonitrile in Organic Solvents: T. Kametani, K. Kigasawa, M. Hiiragi, T. Aoyama, and O. Kusama, J. Org. Chem., 36, 327 - 330 (1971).

443. Studies on the Syntheses of Heterocyclic Compounds. CCCXciv. Total Syntheses of $( \pm)$-Dasycarpidone and ( \pm )-3-Epidasycarpidone. Formal Total Syntheses of $( \pm)$-Uleine and $( \pm)$-3-Epiuleine: T. Kametani and T. Suzuki, J.Org. Chem., $\underline{36}, 1291-1293(1971)$.

444. Studies on the Syntheses of Heterocyclic Compounds. CCCXCV. The Synthesis of Homopetaline-Type Compounds: T. Kametani, K. Fukumoto, and M, Fujihara, J. Org. Chem., 36, 1293 - 1295 (1971).

445. Studies on the Syntheses of Heterocyclic Compounds. CCCXCVI. An Alternative Total Synthesis of ( \pm )-Galanthamine: T. Kametani, K. Shishido, E. Hayashi, C. Seino, T. Kohno, S. Shibuya, and K. Fukumoto, J. Org. Chem., 36, 1295 1297 (1971).

446. Studies on the Syntheses of Heterocyclic Compounds. CDL. Total Synthesis of Androcymbine: T. Kametani, M. Koizumi, and K. Fukumoto, J. Org. Chem., $\underline{36}, 3729-3733(1971)$.

447. Studies on the Syntheses of Heterocyclic Compounds. CDLI. Alternative Photolytic Total Syntheses of O-Methylandrocymbine and Kreysigine: T. Kametani, Y. Satoh, S. Shibuya, M. Koizumi, and K. Fukumoto, J. Org. Chem., 36 , $3733-3736(1971)$.

448. Synthesis of Morphinandienone Alkaloids by Phenol oxidation and the Pschorr Reaction: T. Kametani and K. Fukumoto, J. Heterocyclic Chem., $8,341-356$ (1971).

449. Studies on the Syntheses of Azole Derivatives. Part VI. Syntheses of IPhenyl- $\Delta^{2}-1,2,4-t r i z o l i n-5-o n e ~ D e r i v a t i v e s$ (Studies on the Syntheses of Heterocyclic Compounds. CDXI): T. Kametani, S. Shibuya, and M. Shio, J.Heterocyclic Chem., 8 , 541 - 544 (1971).

450. Studies on the Syntheses of Azole Derivatives. Part VIII. Photolysis of NAryl-N-benzylcarbamoyl Azides (Studies on the Syntheses of Heterocyclic Compounds. Part CDXV): T. Kametani and M. Shio, J. Heterocyclic Chem., $\underline{8}, 545$ - 549 (1971). 
451. Syntheses of Benzomorphan and Related Compounds. Part III. An Alternate Synthesis of 3 -Substituted $1,2,3,4,5,6$-Hexahydro-8-hydroxy-2,6-methano-6,11dimethyl-3-benzazocine: T. Kametani, K. Kıgasawa, M. Hayasaka, K. Wakisaka, F. Satoh, A. Aoyama, and H. Ishimaru, J. Heterocyclic Chem., 8, $769-771$ (1971).

452. Studies on the Syntheses of Azole Derivatives. Part IX. Formation of 2,4Disubstituted $\Delta^{2}-1,3,4$-oxadiazolin-5-one and 4-Substituted 1,2,4-Triazolidin3,5-dione Derivatives by Thermal Reaction of N-Ary1-N-benzylcarbamoy1 Azides: T. Kametani, S. Shibuya, and M. Shio, J. Heterocyclic Chem., 8, $889-897$ (1971).

453. A Novel Synthesis of Quinazoline Derivatives with Triethyl Phosphite:

T. Kametani, K. Nyu, T. Yamanaka, and S. Takano, J. Heterocyclic Chem., $\underline{8}$, $1071-1073(1971\}$.

454. Antispasmodic Agents. I, Syntheses and Pharmacological Activity: T. Kametani, K. Kigasawa, M. Hiiragi, T. Aoyama, and 0. Kusama, J. Medicin. Chem. $\underline{14}, 72-75(1971)$.

455. Antispasmodic Agents. 2. Syntheses and Pharmacological Acitivity of Ethyl 2-( $\omega$-Aminoa1ky1)-2-(3-methoxyphenyl)phenylacetates: T. Kametani, K. Klgasawa, M. Hiiragi, and T. Aoyama, J. Medicin. Chem., 14, $1235-1237$ (1971).

456. Biogenetic-type Synthesis of Cularine: T. Kametan1, K. Fukumoto, and M. Fujihara, Bioorg. Chem., 1, 40 - 50 (1971).

457. Studies on the Syntheses of Azole Derivatives. V: The Mass Spectra of 1,2, 4-Triazoles and Oxadiazoles (Studies on the Syntheses of Heterocyclic Compounds. CCCLXXIV): T. Kametani, S. Hirata, and S. Shibuya, Org. Mass. Spectrometry, $\underline{4}, 117-122$ (1971).

458. On the Alkaloids from Litsea Xylanica: Occurrence of (+)-Reticuline, (+) Isoboldine and (+)-N-Norisoboldine: T. Kametani, Y. Satoh, K. Fukumoto, and B. R. Pai, Indian J. Chem., 9 , $770-771$ (1971).

459. A Synthesis of 10,11-Dihydro-2,3,7,8-tetramethoxy-10,5-(N-methyliminomethano)5매, 12 -dibenzo[a, d]cyclooctene (Homoisopavine) (Studies on the Syntheses of Heterocyclic Compounds. CDLVI): T. Kametani, M. Mizushima, and S. Takano: Yakugaku Zasshi, $\underline{92}, 204-206$ (1972).

460. Synthesis of Protoberberine Derivatives as Hypotensives (Studies on the Syntheses of Heterocyclic Compounds. CDLVIII): T. Kametani, K. Nyu, I. Noguchi, and M. Ihara, 住ugaku Zasshi, 92, $238-240$ (1972).

461. Syntheses of Analgesics. XXVII1. Syntheses of 4-Amino-3-methy1-1,2-dipheny1- 
2npropionyloxybutane Derivatives: T, Kametani, K. Kigasawa, M. Hiiragi, K. Wakisaka, T. Uryu, and H. Hayashi, Yakugaku Zasshi, 92, $421-430$ (1972).

462. Syntheses of Anaigesics. XXIX. Synthesis and Pharmacological Activity of N-(2-Aminoethy 1)-2-indanamine Derivatives: T. Kametani, K. Kigasawa, M. HIiragi, H. Ishimaru, and S. Saito, Yakugaku Zasshi, 92, $431-436$ (1972).

463. Studies on the Syntheses of Heterocyclic Compounds. CDLXXIV. Syntheses of Camptothecin and Related Compounds. III. A Synthesis of 12-Ethyl-6,7,10,12, 13,13a-hexahydro-12-hydroxy- $1 \underline{\mathrm{H}}, 9 \underline{\mathrm{H}}$-furano [3,4-g $]$ indolo [3,2- $\underline{\mathrm{d}}$ ] quinolizine:

T. Kametani, S. Takano, and H, Takeda, Yakugaku Zassh1, 92, $743-746$ (1972).

464. Studies on the Syntheses of Heterocyclic Compounds. CDLXXVI. Syntheses of Camptothecin and Related Compounds. IV. A Synthesis of 8-Cyano-7-ethoxycarbony 1-9,11-dihydro-9,11-dioxoindo1izino[1,2-b b quinoline: T. Kametani, S. Takano, H. Terasawa, and H. Takeda, Yakugaku Zasshi, 92, $868-870$ (1972).

465. Studies on the Syntheses of Heterocyclic Compounds. CDXC. Synthetic Approach to Seven-membered Ring System by Pschorr Reaction: T. Kametani, S. Hirata, and S. Shibuya, Yakugaku Zasshi, 92, 1108 - 1110 (1972).

466. Nitrene. XI. The Reactions of Ethyl $\alpha$-Pheny1-2-nitrocinnamate Derivatives with Triethyl Phosphite (Studies on the Syntheses of Heterocyclic Compounds. CDXCIV): T. Kametani, K. Nyu, and T. Yamanaka, Yakugaku Zasshi, 92, 1180 $1183(1972)$.

467. Nitrene. XII. Synthesis of 1-Keto-3-dioxyvasicine (Studies on the Syntheses of Heterocyclic Compounds. CDXCV): T. Kametani, K. Nyu, and T. Yamanaka, Yakugaku Zasshi, 92, 1184 - 1186 (1972).

468. Benzyne Reaction. XV. Syntheses of Mefenamic Acid and Its Related Compounds by Benzyne Reaction between Halogenobenzoic Acid Derivatives and 2,3-Xylidine: T. Kametani, K. Kigasawa, M. Hirragi, K. Wakisaka, and S. Saito, Yakugaku Lasshi, 92, 1547 - 1551 (1972).

469. Studies on the Syntheses of Heterocyclic Compounds. CDLVII. Synthesis of 0 -Benzylhomosalutaridine by Photolysis of Diazotized 1-(2-Aminophenethy 1)1,2,3,4-tetrahydroisoquinoline: T. Kametani, M. Koizumi, C. Seino, and T. Nakano, Chem. and Pharm. Bull. (Japan), 20, 295 - 299 (1972).

470. Studies on the Syntheses of Heterocyclic Compounds. CDLXxxil. Total Photolytic Synthesis of ( \pm )-Epicrinine: T. Kametani, T. Kohno, R. Charubala, S. Shibuya, and K. Fukumoto, Chem. and Pharm. Bull. (Japan), 20, 1488 1491 (1972). 
471. Studies on the Syntheses of Heterocyclic Compounds. CDLXxxVII. Photolytic Synthesis and Rearrangement of Proerythrinadienones: T. Kametani, K. Takahashi, T. Honda, M. Ihara, and K. Fukumoto, Chem. and Pharm. Bu11. (Japan), 20, $1793-1799$ (1972).

472. Studies on the Syntheses of Heterocyclic Compounds. CDLXXXIII. Synthesis of Homoaporphine and Attempts to Synthesize C-Noraporphine by Pschorr Reaction: T. Kametani, T. Nakano, C. Seino, S. Shibuya, K. Fukumoto, T. R. Govindachari, K. Nagarajan, B. R. Pai, and P. S. Subramanian, Chem. and Pharm. Bull. (Japan), 20, $1507-1512$ (1972).

473. Biotransformation of $( \pm)$-Reticuline in Rat: T. Kametani, M. Ihara, and K. Takahashi, Chem. and Pharm. Bull. (Japan), 20, 1587 - 1588 (1972).

474. Studies on the Syntheses of Heterocyclic Compounds. CDLXxxVI. Behavior of the Erythrinadienone and Its Relatives in Acidic Medium: T. Kametani, T. Kohno, and K. Fukumoto, Chem. and Pharm. Bull. (Japan), 20, $1678-1680$ (1972).

475. Studies on the Syntheses of Heterocyclic Compounds. CDLxxxvili. An Alternative Synthesis of "Isocularine" by an Intramolecular Ullmann Reaction: T. Kametani, K. Fukumoto, and M. Fujihara, Chem. and Pharm. Bu11. (Japan), $\underline{20}, 1800-1804(1972)$.

476. Studies on the Syntheses of Heterocyclic Compounds. CDXCIII. Reaction of N-Ethoxycarbonyl-5-methoxytryptamine with Methyl Fluorosulfonate ("Magic Methy 1"): T. Kametani, T. Suzuki, and K. Ogasawara, Chem. and Pharm. Bu11. (Japan), 20, $2057-2059$ (1972).

477. Studies on the Syntheses of Analgesics. XXXIII. Synthesis of N-Methy1-N[2-(3-methoxypheny 1)-2-pheny1]propylhydrazine (Studies on the Syntheses of Heterocyclic Compounds. CDXCVI): T. Kametani, K. Kigasawa, M. Hiiragi, T. Aoyama, K. Araki, and S. Saito, Chem. and Pharm. Bull. (Japan), 20, 2483 2487 (1972).

478. Studies on the Syntheses of Heterocyclic Compounds. D. Novel Cleavage of Tetrahydroprotoberberines with Trifluoroacetic Anhydride: T. Kametani, S. Shibuya, S. Hirata, and K. Fukumoto, Chem. and Pharm. Bu11. (Japan), 20, 2570 - 2574 (1972).

479. Photolytic Synthesis of Proerythrinadienones: T. Kametani, T, Honda, M. Ihara, and K. Fukumoto, Chem. and Ind., 1972, 119 - 120.

430. Total Synthesis of ( \pm )-Cepharamine: T. Kametani, H. Nemoto, T. Kobari, K. Shishido, and K. Fukumoto, Chem. and Ind., 1972, $538-540$. 
481. Studies on the Syntheses of Heterocyclic Compounds. Part CDLIII. Total Synthesis of ( \pm )-Ochorobirine: T. Kametani, S. Hibino, and S. Takano, J. C. S. Perkin I, 1972, $391-393$.

482. Studies on the Syntheses of Heterocyclic Compounds. Part CDLIV. Abnormal - Dienone-Phenol Rearrangement of Procularine: T. Kametani, K. Fukumoto, and M. Fujihara, J. C. S. Perkin I, 1972, $394-396$.

483. Studies on the Syntheses of Heterocyclic Compounds. Part CDLXII. Total Photolytic Syntheses of Aporvhine $[( \pm)-N-M e t h y l 1 a u r o t e t a n i n e,( \pm)-C a s s y-$ thicine, and ( \pm )-Pukateine], Proaporphine [( \pm )-Orientalinone], and Morphinandienone $[( \pm)$-Pallidine and $( \pm)$-Salutaridine] Alkaloids: $T$. Kametani, K. Fukumoto, S. Shibuya, H. Nemoto, T. Nakano, T. Sugahara, T. Takahashi, Y. Aizawa, and M. Toriyama, J. C. S. Perkin_I, 1972, 1435 - 1441 .

484. Studies on the Syntheses of Heterocyclic Compounds. Part CDLXVI. Synthesis of Narwedine-type Enones by Photochemical Cyc1isation: T. Kametani, K. Yamaki, T. Terui, S. Shibuya, and K. Fukumoto, J. C. S. Perkin I, 1972, $1513-1516$.

485. Total Syntheses of (-)-O-Methylandrocymbine, (-)-Kreysigine, and Alkaloid CC-10 Methyl Ether: T. Kametani, Y. Satoh, and K. Fukumoto, J. C. S. Perkin I, $1972,2160-2162$.

486. Total Synthesis of (-)-Discretine $(2,10,11-$ Trimethoxy-13aa-berbin-3-o1): T. Kametani, M. Takeshita, and S. Takano, J. S. C. Perkin I, 1972, $2834-$ 2837 .

487. Synthesis of the Hasubanan Ring System from the Alkaloid Reticuline: T. Kametani, T. Kobari, and K. Fukumoto, J.C. S. Chem. Comm., 1972, 288 289 .

488. Total Synthesis of the Isoquinoline Alkaloid $( \pm)$-Xylopinine by Thermolysis: T. Kametani, K. Ogasawara, and T. Takahashi, J. C. S. Chem, Comm, , 1972, $675-676$.

489. Absolute Configuration of the Alkaloid Cularine: an X-ray Structure Determination: T. Kametani, T. Honda, H. Shimanouchi, and Y. Sasada, J. C. S. Chem. Comm., 1972, $1072-1073$.

490. Studies on the Syntheses of Heterocyclic Compounds. CDLXVII. Photolytic Synthesis of Kreysiginine-type Compounds: T. Kametani, T. Kohno, R. Charubala, and K. Fukumoto, Tetrahedron, 28, 3227-3231 (1972).

491. Studies on the Syntheses of Heterocyclic Comnounds. CDLXXXIV. One-step Synthesis of Dibenzoindolizinium Salt and Phenolic Aporphine by Benzyne Re- 
action: T. Kametani, K. Fukumoto, and T. Nakano: Tetrahedron, 28, $4667-$ 4672 (1972).

492. Crystal Structure of Corynoline p-Bromobenzoate: T. Kametani, T. Honda, M. Ihara, H. Shimanouchi, and Y. Sasada, Tetrahedron Letters, 1972, 3729 - 3730.

493. A Novel Synthesis of Ochotensine-type Isoquinolines by Thermolysis: T. Kametani, T. Takahashi, and K. Ogasawara, Tetrahedron Letters, 1972,4847 4850 .

494. Studies on the Syntheses of Heterocyclic Compounds. CDLX. Benzyne Reaction XIII. Benzyne Reaction of Halogenobenzenes with N-Alky1mornholines: T. Kametani, K. Kigasawa, M. Hiiragi, and T. Aoyama, J. Org. Chem., 27, $1450-$ 1453 (1972).

495. Studies on the Syntheses of Heterocyclic Compounds. Part CDLV. The Mass Spectral Investigation and Synthesis of the Ochotensinan Skeleton: $T$. Kametani, S. Hibino, S. Shibuya, and S. Takano, J. Heterocyclic Chem., 9 , $47-52(1971)$.

496. Pyrimidine Derivative. IV. Synthesis of $N^{1}-(2-$ Methoxy-4-nyrimidy 1$)$ sulfanilamide: K. Okui, K. Ito, and T. Kametani: J. Heterocyclic Chem., 9 , 821 $825(1972)$.

497. Synthesis of a 2-Methyl-4-sulfanilamido-s-triazine Derivative: T. Kametani, K. Okui, and M. Koizumi, J. Heterocyclic Chem., 9, 1013 - 1016 (1972).

498. Syntheses of Analgesics. Part Xxx. Conformational Studies of Diastereoisomeric Quaternary Ammonium Salts of 1,2,3,4,5,6-Hexahydro-2,6-methano-3benzazocines: T. Kametani, K. Kigasawa, M. Hiiragi, F. Satoh, S. Saito, H. Sugai, and T. Uryu, J. Heterocyclic_Chem., 9, 1057 - 1059 (1972).

499. Studies on the Syntheses of Analgesics. Fart XXXI. Synthesis of $1,2,3,4,5,6-$ Hexahydro-3-methy 1-6-pheny 1-2,6-methano-2,3-benzo[g]diazocine [Studies on the Syntheses of Heterocyclic Compounds. Part CDLXXIX]: T. Kametani, K. Kigasawa, M. Hiiragi, and T. Aoyama, J. Heterocyclic Chem., 9, 1061 - 1064 (1972).

500. Studies on the Syntheses of Analgesics. Part XXXII. An Alternative Synthesis of $1,2,3,4,5,6$-Hexahydro-3-hydroxy-6,11-dimethy 1-3-(3-methy1-2-buteny 1 )2,6-methano-3-benzazocine (Studies on the Syntheses of Heterocyclic Compounds. Part CDLXXX): T. Kametani, K. Kigasawa, M. Hi iragi, F. Satoh, H. Sugi, and T. Uryu, J. Heterocyclic Chem., 9, 1065 - 1069 (1972).

501. The Synthesis of Pseudorutecarpine with Triethyl Phosphite: T, Kametani, T. Yamanaka, and K. Nyu, J. Heterocyc1ic Chem., 9, $1281-1282$ (1972). 
502. Studies on the Syntheses of Heterocyclic Compounds. CDXCI. Pyrimidine Derivatives. V. Abnormal Condensation Products of 4-Amino-6-chloro-2methoxypyrimidine with $\underline{p}$-Nitrobenzenesulfonyl Chloride: K. Okui, K. Ito, M. Koizumi, K. Fukumoto, and T. Kametani, J. Heterocyclic Chem., 9, 1283 $1288(1972)$.

503. Studies on the Syntheses of Heterocyclic Comnounds. Part CDXCVII. Total Syntheses of $( \pm)$-Cryptaustoline and $( \pm)$-Thaliporphine by the Benzyne Reaction: T. Kametani, K. Fukumoto, and T. Nakano, J. Heterocyclic Chem., $\underline{9}$, 1363 - $1366(1972)$.

504. Biochemical Studies on Drugs and the Central Nervous System. 1. Synthesis and Actuvity of Pyridoxal Derivatives (Studies on the Syntheses of Heterocyclic Compounds. 438): T. Kametani, M. Koizumi, K. Okui, Y. Nishii, and M. Ono, J. Medicin. Chem., 15, 203 - 204 (1972).

505. Studies on the Syntheses of Heterocyclic Compounds. 459. Synthesis of Rescinnamine-1ike Compounds as Antihypertensive Agents: T. Kametani, M. Ihara, T. Suzuki, T. Takahashi, R. Iwaki, H. Takei, N. Miyake, M. Yoshida, Y. Hasegawa, and H. Kitagawa, J. Medicin. Chem., 15, 686-687 (1972).

506. Photochemical Synthesis of Isoquinoline Alkaloids : T. Kametani and K. Fukumoto: Accounts Chem. Res., 5, 212 - 219 (1972).

507. A Nove1 Methylsulfonation of Hydroxy or Alkoxy Aromatics with Methyl Fluorosulfonate: T. Kametani, K. Takahashi, and K. Ogasawara, Synthesis, 1972, $473-474$.

508. Studies on the Syntheses of Heterocyclic Compounds. Part CDLXXXI. A Simple Preparation of Tryptamine: T. Kametani, S. Takano, S. Hibino, and M. Takeshita, Synthesis, 1972, $475-476$.

509. Application of Phenolic Oxidation to the Total Syntheses of the Isoquinoline and Related Alkaloids; Biogenetic Type Synthesis: T. Kametani and K. Fukumoto, Synthesis, 1972, $657-674$.

510. Photo-Pschorr Reaction of 1-(2-Amino-4,5-dimethoxybenzy1)-2-benzy1-6-benzy1oxy-7-methoxy-1,2,3,4-tetrahydroisoquinoline: T. Kametani, Y. Aizawa, S. Sugahara, S. Shibuya, M. S. Premila, and B. R. Pai, Indian J. Chem., 10, 987 - $988(1972)$.

511. Studies on the Syntheses of Heterocyclic Compounds. DXV. Syntheses of Streptonigrin and Related Compounds. XI. Synthesis of 2-Chloro-5,6,8-trimethoxyquinoline: T. Kametani, A. Kozuka, and T. Terui, Yakugaku Zasshi, 93, $406 * 408(1973)$. 
512. Studies on the Syntheses of Heterocyclic Compounds. DXVII. Syntheses of Berberine and Related Compounds. II. The Mannich Reaction of 1-Benzylisoquinoline under Various Conditions: T. Kametani, E. Taguchi, K. Yamaki, A. Kozuka, and T. Terui, Yakugaku Zasshi, 93, 529 - 531 (1973).

513. Synthesis of Protoberberine Derivatives as Hypotensives. II. Synthesis of 11-Amino-5,6,13,13a-tetrahydro-2,3,10-trimethoxy-8ㅂ-dibenzo[a, g]quinolizine Derivatives (Studies on the Syntheses of Heterocyclic Compounds. DXXVIII): T. Kametani, K. Nyu, S. Ikeda, and R. Iwaki, Yakugaku Zasshi, 93, $899-901$ (1973).

514. Studies on the Syntheses of Heterocyclic Compounds. DXXIX. Dehydrogenation of Cularine Type Compound: T. Kametani, K. Fukumoto, Y. Kato, and M. Fujihara, Yakugaku Zasshi, 93, 1094 - 1099 (1973).

515. Synthesis of Protoberberine Derivatives as Hypotensives. III. Synthesis of 10-Acyloxy-5,6,13,13a-tetrahydro-2,3,11-trimethoxy-8H-dibenzo [a-g]quinolizine (Studies on the Syntheses of Heterocyclic Compounds. DXXX): T. Kametani, K. Nyu, S. Ikeda, T. Tominaga, and R. Iwaki, Yakugaku Zasshi, 93, $1116-1119$ $(1973)$.

516. Synthesis of Protoberberine Derivatives as Hypotensives. IV. Synthesis of 11-0-Deme thy 1 xylopinine (11-Hydroxy-5,6,13,13a-tetrahydro-2,3,10-tr1methoxy-8ㅂ-dibenzo[a,g]quinolizine) and Its Acyl Derivatives, and Optical Resolution of $( \pm)$-Xylopinine (Studies on the Syntheses of Heterocyclic Compounds. DXXXI): T. Kametani, K. Nyu, S. Ikeda, T. Tominaga, and R. Iwaki, Yakugaku Zasshi, 93, $1120-1126$ (1973).

517. Syntheses of Analgesics. XXXVIII. Reaction of 2-(3-Substituted Phenyl)cyclohexanone with Ethyl $\alpha$-Haloacetate (Studies on the Syntheses of Heterocyclic Compounds. DXXXII): T. Kametani, K. Kigasawa. M. Hiiragi, N. Wagatsuma, and T. Uryu, Yakugaku Zasshi, 93, 1162 - 1164 (1973).

518. Studies on the Syntheses of Heterocyclic Compounds. DX. A Novel Rearrangement of Proerythrinadienol with Methyl Fluorosulfonate: T. Kametani, K. Takahashi, K. Ogasawara, and K. Fukumoto, Chem. and Pharm. Bull. (Japan), 21, $662-664 \cdot(1973)$.

519. Studies on the Syntheses of Heterocyclic Compounds. DXVI. Total Syntheses of the Aporphine, Morphinandienone and Tetrahydrodibenzopyrrocoline Alkaloids by Benzyne Reaction: T. Kametani, A. Ujiie, K. Takahashi, T. Nakano, T. Suzuki, and K. Fukumoto, Chem. and Pharm. Bul1. (Janan), 21, $766-769$ (1973).

520. A Nove1 Synthes is of Isopavine Ring System: T. Kametani and K. Ogasawara, Chem. and Pharm. Bull. (Japan), 21, 893 - 894 (1973). 
521. Studies on the Syntheses of Heterocyclic Compounds. DXIX. A Total Synthesis of ( \pm )-Discretine by Thermolysis: T. Kametani, Y. Hirai, F. Satoh, K. Oga* sawara, and K. Fukumoto, Chem. and Pharm, Bull. (Japan), 21, 907 - 911 (1973).

522. Studies on the Syntheses of Heterocyclic Compounds. DXXV. Syntheses of Berberine and Related Compounds. III. Dealkylation of N-Substituted Protoberberinium Salts: T. Kametani, E. Taguchi, K. Yamaki, A. Kozuka, and T. Terui, Chem. and Pharm. Bull. (Japan), 21, $1124-1126$ (1973).

523. Catalytic Hydrogenation of ( \pm )-Kreysiginone: T. Kametani, F. Satoh, K. Fukumoto, H. Sugi, and K. Kigasawa: Heterocycles, 1, $47-52$ (1973).

524. Syntheses of Isoquinoline Alkaloids by a Systematic Design: T. Kametani and K. Fukumoto, Heterocycles, $\underline{1}, 129$ - 163 (1973).

525. Synthesis of Corgoine: T. Kametani, K. Takahashi, C. V. Loc, and S. Hirata, Heterocycles, $1,247-250$ (1973).

526. Synthesis of Androcymbine and Related Homomorphinandienones: T. Kametani, K. Fukumoto, and M. Koizumi, Heterocycles, $1,327-377$ (1973).

527. Syntheses of Hexadehydro-17-methoxyyohimbane: T. Kametani, M. Kajiwara, and K. Fukumoto: Chem. and Ind., 1973, $1165-1166$.

528. Studies on the Syntheses of Heterocyclic Compounds. Part DII. Synthesis of 1-Substituted 1,2,3,4-Tetrahydrophthalazines by a Pictet-Spengler-type Reaction of 3-Hydroxybenzylhydrazine with Carbonyl Compounds: T. Kametani, K. Kigasawa, M. Hiiragi, H. Ishimaru, T. Uryu, and S. Haga, J. C. S. Perkin I, $1973,471-472$.

529. Studies on the Syntheses of Heterocyclic Compounds. Part DXIV. Synthesis of 6a,7-Didehydroaporphine and Indolo[2,1-a]isoquinoline Systems by Benzyne Reactions: T. Kametani, S. Shibuya, and S. Kano, J. C. S. Perkin I, 1973, $1212-1214$.

530. Crystal and Molecular Structure and Absolute Stereochemistry of Cularine Methiodide: H. Shimanouchi, Y. Sasada, T. Honda, and T. Kametani, J. C. S. Perkin II, 1973, $1226-1230$.

531. A Novel Synthesis of an ochotensine-type Isoquinoline by Thermolysis: T. Kametani, T. Takahashi, and K. Ogasawara, J. C. S. Perkin I, 1973, $1464-$ 1466.

532. Studies on the Syntheses of Heterocyclic Compounds. Part DXXVI. A Novel Synthesis of Isopavine-type Alkaloids. Total Synthesis of ( \pm )-Reframidine: T. Kametani, S. Hirata, and K. Ogasawara, J. C. S. Perkin I, 1973, $1466-1470$. 
533. Crystal Structure of Corynoline p-Bromobenzoate: T. Kametani, T. Honda, M. Ihara, H. Shimanouchi, and Y. Sasada, J. C. S. Perkin II, 1973, $1605-1608$.

534. Studies on the Syntheses of Heterocyclic Compounds. - -- CDXCIV. A Tota1

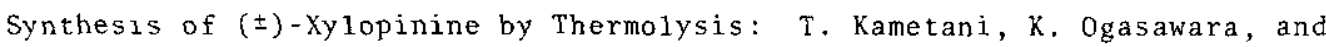
T. Takahashi, Tetrahedron, $29,73-76$ (1973).

535. Studies on the Syntheses of Heterocycilic Compounds. DXXII. Photolytic Synthesis of 1,12-Dihydroxy-2,10,11-trimethoxyhomoaporphine: T. Kametani, Y. Satoh, and K. Fukumoto, Tetrahedron, 29, $2027-2030$ (1973).

536. Studies on the Syntheses of Heterocyclic Compounds. -- DXXIII. Enzymic Oxidation of Homoorientaline with Homogenised Potato Peelings: T. Kametani, M. Mızushima, S. Takano, and K. Fukumoto, Tetrahedron, 29, 2031 - 2033 (1973).

537. A Nove1 Formation of ( \pm )-Glaziovine Through Nitrenium Intermediate: T. Kametanı, K. Takahashi, K. Ogasawara, and K. Fukumoto, Tetrahedron Letters, 1973 , $4219-4220$.

538. Novel Conversion of Butyrolactones Containing the ortho-Nitrophenyl Moiety to Indoles with Triethyl Phosphite: T. Kametani, F. F. Ebetino, and K. Fukumoto, Tetrahedron Letters, 1973, $5229-5230$.

539. Studies on the Syntheses of Heterocyclic Compounds. Part DV. Cyclization Products of 1-Substituted 2-Benzy1-1,2,5,6-tetrahydropyridines [Syntheses of Analgesics. Part XXXV]: T. Kametani, K. Kigasawa, M. Hiiragi, N. Wagatsuma, T. Uryu, and H. Sugi, J. Heterocyclic Chem., 10, $27-29$ (1973).

540. Studies on the Syntheses of Heterocyclic Compounds. Part DVI. Synthesis of Oxynitidine and Nitidine: T. Kametani, K. Kigasawa, M. Hiiragi, and 0. Kusama, J. Heterocyclic Chem., 10, $31-33$ (1973).

541. Studies on the Syntheses of Heterocyclic Compounds. Part DVII. A Synthesis of ( \pm )-N-Norgalanthamine: T. Kametani, K. Yamaki, and T. Terui, J. Heterocyclic Chem., 10, $35-37$ (1973).

542. Synthesis of a Potenital Camptothecin Intermediate: T. Kametani, H. Takeda, F. Satoh, and S. Takano, J. Heterocyclic Chem., 10, $77-78$ (1973).

543. Studies on the Syntheses of Analgesics. Part XXXVI. Synthesis of 1,2,3,4,5, 6-Hexahydro-2,6-methano-6-pheny 1-2-benzazocine [Studies on the Syntheses of Heterocyclic Compounds. Part DXI]: T. Kametani and T. Aoyama, J. Heterocyclic Chem., 10, 291 - 295 (1973).

544. Syntheses of Analgesics. Part XXXVII. An Alternative Synthesis of 1,2,3,4, 
5,6-Hexahydro-8-hydroxy-2,6-me thano-6,11-dime thy 1-3-phenethy 1-3-benzazocine [Studies on the Syntheses of Heterocyclic Compounds. Part DXXI]: T. Kametani, K. Kigasawa, M. Hiiragi, N. Wagatsuma, S. Saitoh, and H. Sugi, J. Heterocyclic Chem., 10, 313 - 315 (1973).

545. Studies on the Syntheses of Heterocyclic Compounds. Part DXXVII. The Absolute Configuration of $1,2,3,4$-Tetrahydro-1-phenylisoquinoline: T. Kametani, S. Shibuya, H. Sugi, and K. Fukumoto, J. Heterocyclic Chem., 10, $451-453$ (1973).

546. Studies on the Syntheses of Analgesics. Part XXXIV. Synthesis of $1,2,3,4,5$, 6-Hexahydro-8-hydroxy-2,6-methano-3,6,11-trimethyl-2,3-benzo[g]diazocine and $1,2,3,4,5,10,11,12$-octahydro-7-hydroxy-1,5-dimethy 1 pyridazino [2,3-b ] isoquinoline [Studies on the Syntheses of Heterocyclic Compounds. Part LIX]: T. Kametani, K. Kigasawa, M. Hi iragi, K. Wakisaka, N. Wagatsuma, O. Kusama, and T. Uryu, J. Heterocyclic Chem., 10, 999 - 1005 (1973).

547. Syntheses of Ana1gesics. 34. Synthesis of 3-Hydroxy-N-cyclopropylmethy1-9azamorphinan (Studies on the Syntheses of Heterocyclic Compounds. 509):

T. Kametani, K. Kigasawa, M. Hiiragi, N. Wagatsuma, T. Uryu, and K. Araki, J. Medicin. Chem., 16, $301-303$ (1973).

548. The Total Synthesis of Natural Products by the Intermolecular Coupling Reaction: T. Kametani, Lectures in Heterocyclic Chemistry, 2, S57 - S70 (1973).

549. Phenethylisoquinoline Alkaloids: T. Kametani and M. Koizumi, The Alkaloids, $14,265-323(1973)$.

550. Benzylisoquinoline and Homobenzylisoquinoline Alkaloids: T. Kametani and K. Fukumoto, MTP. International Review of Science, Alkaloids, Organic Chemistry Series one, 9, $181-234$ (1973).

551. Syntheses of 1-Benzyl-1,2,3,4-tetrahydro-B-carboline and Hexadehydroyohimbine Derivatives under the Conditions of Pictet-Spengler Reaction (Studies on the Syntheses of Heterocyclic Compounds. DLI): T. Kametani, M. Takeshita, and F. Satoh, Yakugaku Zasshi, 94, $261-264$ (1974).

552. Studies on the Syntheses of Heterocyclic Compounds. DLV. A Synthesis of Protoberberine Derivatives by Vilsmeier-Haack Reaction: T. Kametani, M. Takeshita, F. Satoh, and K. Nyu, Yakugaku Zasshi, 94, $478-480$ (1974).

553. Studies on the Syntheses of Heterocyclic Compounds. DLXXXIV. Studies on the Syntheses of Analgesics. XL. Synthesis of 1-Substituted 3-(3-Hydroxypheny1)3-pheny1piperidines: T. Kametani and T. Aoyama, Yakugaku Zasshi, $94,1489-$ $1490(1974)$. 
554. The Direction of the Ring Closure of N-Furoyltryptophan (Studies on the Syntheses of Heterocyclic Compounds. DLXXXVI): T. Kametani, K. Takahashi, T. Suzuki, and K. Fukumoto, Yakugaku Zasshi, 94, $1520-1523$ (1974).

555. Formation of Morphinandienone-type Compound through Methylenedioxy Cleavage by pschorr Cyclization: T. Kametani, T. Sugahara, and K. Fukumoto, Chem. and Pharm. Bull. (Japan), 22, $966-969$ (1974).

556. Studies on the Syntheses of Heterocyclic Compounds. DLxVIII. Catalytic Hydrogenation of $( \pm)$-Kreysiginone: T. Kametani, F. Satoh, K. Fukumoto, H. Sugi, and K. Kigasawa, Chem, and Pharm. Bull. (Japan), 22, 1835 - 1838 (1974).

557. Studies on the Syntheses of Tetracycline Derivatives. I. Thermolytic Cycloaddition of o-Quinodimethanes with Naphthoquinone: T. Kametani, T. Takahashi, M. Kajiwara, Y. Hirai, C. Ohtsuka, F. Satoh, and K. Fukumóto, Chem. and Pharm. Bu11. (Japan), 22, 2159-2163 (1974).

558. A Synthesis of Benzocarbazole Derivatives by Thermolysis: T. Kametani, T. Suzukı, K. Takahashi, and K. Fukumoto, Heterocycles, $\underline{2}, 9-14$ (1974).

559. Total Synthesis of ( \pm )-Mecambridine: T. Kanetani, A. Ujiie, and K. Fukumoto, Heterocycles, 2, 55 - 59 (1974).

560. Synthesis of Pentazocine: T. Kametani, K. Kigasawa, M. Hiiragi, and N. Wagatsuma, Heterocycles, $2,79-103$ (1974).

561. Synthetic Approach to Pakistanamine by Phenolic Oxidative Coupling: T. Kametan1, H. Terasawa, and F. Satoh, Heterocycles, 2, $159-162$ (1974).

562. One-Step Synthesis of Dihydropyridocarbazole Derivatives: T. Kametan1, Y. Ichikawa, T. Suzuk1, and K. Fukunoto, Heterocycles, 2, $171-176$ (1974).

563. Synthesis of Heterocycles through Nitrenes: T. Kametani, F. F. Ebetino, T. Yamanaka, and K. Nyu, Heterocycles, 2, $209-226$ (1974).

564. Reductive Cyclization of $\alpha$-(6-Nitroveratrylidene)- $\beta$-butyrolactone with Triethyl Phosphite: F. F. Ebetino, K. Fukumoto', and T. Kametani, Heterocycles, 2, $303-307(1974)$.

565. A Facile Synthesis of the Spirobenzylisoquinolines and the Spirobenzylcarbolines: T. Kametani, Y. Hirai, H. Takeda, M. Kajiwara, T. Takahashi, F. Satoh, and K. Fukumoto, Heterocycles, 22, $339-344$ (1974).

566. Syntheses of Benzodiazocines: T. Kametani, K. Kigasawa, M. Hiiragi, and K. Wakisaka, Heterocycles, $2,349-390$ (1974). 
567. Abnorma1 Hofmann Degradation of Tetrahydroprotoberberinium Salts: T. Kametani, M. Takemura, K. Fukumoto, T. Terui, and A. Kozuka, Heterocycles, 2 , $433-437$ (1974).

568. A Nove1 Formation of 1-Hydroxymethy1-4,5-dimethoxy-7--azirıno[1,2-a ] indole8a-carboxylic Acid $\gamma$-Lactone: T. Kametani, F. F. Ebetino, K. Fukumoto, and A. I. Meyers, Heterocycles, $2,559-563$ (1974).

569. Asymmetric Synthesis of Salsolidine: T. Okawara and T. Kametani, Heterocyc1es, $\underline{2}, 571-574(1974)$.

570. The Nove1 Formation of a Dibenzocyclohepta[b] pyridune by an Abnormal Degradation of a Diphenolic Tetrahydroprotoberberinium Salt: $T$. Kametani, $M$. Takemura, K. Takahashi, M. Takeshita, M. Ihara, and K. Fukumoto, Heterocycles, 2, $653-657$ (1974).

571. A New Synthetic Method for the Key Intermediate of the Eudesmane Class of Sesquiterpenes through Furan Derivatives: T. Kametani, H. Nemoto, and K. Fukumoto, Heterocycles, 2, $639-641$ (1974).

572. Cel1 Production from $\mathrm{n}$-Paraffin by Candida kofuensis $\mathrm{MT}-\mathrm{Y}-8$ at $37^{\circ} \mathrm{C}$ and $\mathrm{pH}$ 3.5: K. Ueno, Y. Asai, M. Shimada, and T. Kametani, J. Fermetation Tech., 52, $867-872(1974)$.

573. Nitrene. Part XIII. Novel Conversion of 2-Nitrophenyl Substituted Butyrolactones into Indoles with Triethyl Phosphite: T. Kametani, F. F. Ebetino, and K. Fukumoto, J.C.S. Perkin I, 1974, $861-863$.

574. Regioselectivity in the Thermal 1,2-Cycloaddition of Benzocyclobutenes to 3,4-Dihdyroisoquinolines: T. Kametani, Y. Katoh, and K. Fukumoto, J.C.S. Perkin I, 1974, $1712-1714$.

575. Total Synthesis of $( \pm)$-Mecambridine $(1,10,11$-Trimethoxy-2,3-methylenedioxyberbin-12-ylmethanol): T. Kametani, A. Ujiie, and K. Fukumoto, J.C. S. Perkin I, $1974,1954-1957$.

576. A Simple Route to Spiro[indene-2,1'-isoquinoline]s, a Spiro[indene-2,1'-Bcarbolıne], and Hexadehydroyohimbane: T. Kametani, H. Takeda, Y. Hırai, F. Satoh, and K. Fukumoto, J.C. S. Perkin I, 1974, 2141-2145]

577. Synthetic Approach to Rhoeadine-type Alkalo1ds: T. Kametani, S. Hirata, F. Satoh, and K. Fukumoto, J.C.S. Perkin I, 1974, $2509-2510$.

578. Studies on the Syntheses of Heterocyclic Compounds. Part DLXxVII. Synthesis of 2,3,4,5-Tetrahydro-1-benzazepine Derivaitves by Phenolic Cyclisation: T. Kametani, K. Kigasawa, M. Hiiragi, H. Ishimaru, and S. Haga, J. C. 
S. Perkın I, $1974,2602-2604$.

579. Studies on the Syntheses of Heterocyclic Compounds. Part DLxxVI. An Abnormal Hofmann Degradation of Phenolic Berbinium Salts: T. Kametani, M. Takemura, K. Fukumoto, T. Terui, and A. Kozuka, J. C. S. Perkin I, 1974, $2678-2681$.

580. Studies on the Syntheses of Heterocycic Compounds. DXLV. An Alternative Synthesis of the Protoberberine Ring System: T. Kametani, T. Kato, and $K$. Fukumoto, Tetrahedron, 30, 1043 - 1046 (1974).

581. Studies on the Syntheses of Heterocyclic Compounds. --- DXLVI. Regiospecific Cycloaddition of a Benzocyclobutene Derivative with Schiff Bases by Thermolysis - A New Method for Isoquinoline Synthesis: T. Kametani, T. Takahashi, K. Ogasawara, and K. Fukumoto, Tetrahedron, 30, $1047-1051$ (1974).

582. Studies on the Syntheses of Heterocyclic Compounds - DXLVII. Synthesis of a Yohimbane Derivative by Thermolysis: T. Kametani, M. Kajiwara, and $K$. Fukumoto, Tetrahedron, 30, 1053 - 1058 (1974).

583. Studies on the Syntheses of Heterocyclic Compounds. DXLVIII. Synthesis of a Hasubanan Ring System from the Benzylisoquinoline Reticuline: T. Kametani, T. Kobari, K. Shishido, and K. Fukumoto, Tetrahedron, 30, 1059 - 1064 (1974).

584. Studies on the Syntheses of Heterocyclic Compounds. DLIX. A Synthesis of Benzocarbazole Derivatives by Thermolysis: T. Kametani, T. Suzuki, K. Takahashi, and K. Fukumoto, Tetrahedron, 30, $2207-2210$ (1974).

585. Nitrenes - XIV. Triethyl Phosphite Deoxygenation of $\alpha$-(6-Nitroveratry1-

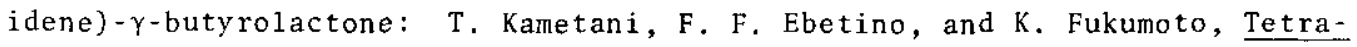
hedron, $30,2713-2716(1974)$.

586. A Nove1 Regioselective Protoberberine Synthesis by Thermolysis: T. Kametani, T. Takahashi, T. Honda, K. Ogasawara, and K. Fukumoto, J. Org. Chem., $\underline{39}, 447$ - $450(1974)$.

587. Studies on the Syntheses of Heterocyclic Compounds. Part DLIV. A Total Synthesis of $( \pm)$-Coreximine by Thermolysis: T. Kametani, M. Takemura, K. Ogasawara, and K. Fukumoto, J. Heterocyclic Chem., 11, $179-182$ (1974).

588. Studies on the Syntheses of Heterocyclic Compounds. Part DLxxxII. Synthesis of Benzo[a]quinolizine Derivatives and Pyrrolo[2,1-a ] isoquinoline Derivatives by Phenolic Cyclization: T. Kametani, K. Kigasawa, M. Hiiragi, H. Ishimaru, and S. Haga, J. Heterocyclic Chem., 11, 1023 - 1025 (1974).

589. Studies on the Syntheses of Heterocyc1ic Compounds. Part DLXXXI. Syntheses of 3-Carboxy-1,2,3,4-tetrahydroisoquinoline Derivatives by Phenolic Cyclizat- 
ion: T. Kametani, K. Kigasawa, M. Hiiragi, H. Ishimaru, and S. Haga, J. Heterocyclic Chem., 11, 1063 - 1064 (1974).

590. The Syntheses of Isoquinoline Alkaloids and Related Compounds by Biogenetic Type Reaction: T. Kametani, K. Fukumoto, and F. Satoh, Bioorg. Chem., $\underline{3}$, $430-497$ (1974).

591. Studies on the Syntheses of Heterocyclic Compounds. DXLIII. An Alternative and Simple Preparation of Tryptamine from L-Tryptophan by Catalytic Decarboxylation with Metal Ion: T. Kametani, T. Suzuki, K. Takahashi, and K. Fukumoto, Synthesis, 1974, $131-132$.

592. Studies on the Syntheses of Heterocyclic Compounds. Part DLXXVIII. The Synthesis of the Yohimbane Ring System by an Electrocyclic Reaction of $\underline{o}^{-}$ Quinodimethane: T. Kametani, T. Takahashi, M. Kajiwara, and K. Fukumoto, Anales de Quim., 70, 1000 - 1003 (1974).

593. Decarboxylation of Tryptophan and a Synthesis of Harman (Studies on the Syntheses of Heterocyclic Compounds. DCVI): T. Kametani, T. Suzuki, C. Otsuka, K. Takahashi, and K. Fukumoto, Yakugaku Zasshi, 95, 363 - 366 (1975).

594. Synthesis of 4-Carboxy-1,2,3,4-tetrahydrozsoquinoline Derivatives by Phenolic Cyclization (Studies on the Syntheses of Heterocyclic Compounds. DCXLIII): T. Kametani, K. Kigasawa, M. Hiiragi, H. Ishimaru, and S. Haga, Yakugaku Zasshi, 95, $1298-1301(1975)$.

595. Studies on the Syntheses of Heterocyclic Compounds. DCXXVI. A Modified Synthesis of Pentazocine: T. Kametani, S.-P. Huang, M. Ihara, and K. Fukumoto, Chem. and Pharm. Bull. (Japan), 23, 2010 - 2014 (1975).

596. Studies on the Syntheses of Heterocylcic Compounds. DCXXVII. The Formation of $2,3,9,10$-Tetramethoxybenz[] ] acridine by Treatment of $6,7-$ Dimethoxy-1- $(4,5-$ dumethoxy-2-nitrophenethyl)-2-methylisoquinoline with Triethyl Phosphite:

T. Kametani, Y. Fujimoto, and M. Mizushima, Chem. and Pharm. Bull. (Japan), $\underline{23}, 2025-2028(1975)$.

597. Studies on the Syntheses of Heterocyclic Compounds. DCXLI. A Convenient Synthesis of Hexadehydroyohimbine and a Total Synthesis of Yohimbine: $T$. Kametani, Y. Hirai, M. Kajiwara, T. Takahashi, and K. Fukumoto, Chem. and Pharm. Bu11. (Japan), 23, $2634-2642$ (1975).

598. Total Synthesis of Certain Isoquinoline and Indole Alkaloids by Thermolysis: T. Kametani and K. Fukumoto: Hleterocycles, $\underline{3}, 29$ - 56 (1975).

599. Biotransformation of $( \pm)$-Reticuline into $( \pm)$-Coreximine with Rat Liver: $T$. Kametani, M. Takemura, K. Takahashi, M. Ihara, and K. Fukumoto, Heterocycles, 
3, $139-142(1975)$.

600. Total Synthesis of $( \pm)$-Orientalidine: T. Kametani, A. Ujiie, M. Ihara, and K. Fukumoto, Heterocycles, 3, $143-146$ (1975).

601. Transformation of the Spiroisoquinoline to the Benzindanoazepine: T. Kametani, S. Hirata, H. Nemoto, M. Ihara, and K. Fukumoto, Heterocycles, $\underline{3}$, $151-154(1975)$.

602. The Toal Synthesis of ( \pm )-Mappicine: T. Kametani, H. Takeda, H. Nemoto, and K. Fukumoto, Heterocycles, $\underline{3}, 167-170$ (1975).

603. A Total Synthesis of ( \pm )-Yohimbine: T. Kametani, M. Kajiwara, T. Takahash1, and K. Fukumoto, Heterocycles, 3, $179-182$ (1975).

604. Structural Elucidation of Two New Spirobenzylisoquinoline Alkaloids, Yenhusomine and Yenhusomidıne: S.-T. Lu, T.-L. Su, T. Kametani, amd M. Ihara, Heterocycles, $\underline{3}, 301-305$ (1975).

605. Synthesis of the 1,2,3,4-Tetrahydroisoquinolines and Related Compounds by Phenolic Cyclisation: T. Kametani, K. Fukumoto, K. Kigasawa, M. Hiiragi, and H. Ishimaru: Heterocycles, $\underline{3}, 311$ - 341 (1975).

606. Conformational Analys is of Tetrahydroprotoberberines by Carbon-13 NMR Spectroscopy: T. Kametani, A. Ujiie, M. Ihara, K. Fukumoto, and H. Koizumi, Heterocycles, $\underline{3}, 371-377(1975)$.

607. A Fascinating Synthesis of Olivacine: T. Kametani, Y. Ichikawa, T. Suzuki, and K. Fukumoto, Heterocycles, 3 , $401-494$ (1975).

608. A Nove1 Phthalideisoquinoline Synthesis from the Benz[d]]indeno[1,2-b] azepine: T. Kametani, S. Hirata, M. Ihara, and K. Fukumoto, Heterocycles, $\underline{3}, 405$ $411(1975)$.

609. Pschorr Reaction of 1-(2-Aminopheny1)-1,2,3,4-tetrahydro-2-methylisoquinoline: T. Kametani, S. Shibuya, R. Charubala, M. S. Premila, and B. R. Pai, Heterocycles, $\underline{3}, 439-443(1975)$.

610. Structure Elucidation of Two New Tetrahydroprotoberberine Alkaloids, Corytenchine and Corytenchirine: S. -T. Lu, T.-L. Su, T. Kametani, A. Ujiie, M. Ihara, and K. Fukumoto, Heterocycles, $\underline{3}, 459-465$ (1975).

611. A Simple Synthesis of Benzonyrans: T. Kametani, K. Kigasawa, M. Hiirag1, H. Ishimaru, and N. Wagatsuma, Heterocyc1es, $\underline{3}, 521-527$ (1975).

612. Novel Formation of the Benzimidazo[2,1-a $]$ ] isoqumoline and Benz[c]acridine 
from the 1,2,3,4-Tetrahydro-1-(2-nitrophenethy 1) isoquinoline with Triethy1 Phosphite: T. Kametanı, Y. Fujimoto, and M. Mizushima, Heterocycles, $\underline{3}$, $619-626(1975)$.

613. A Tota1 Synthesis of Angustine: T. Kametani, M. Takeshita, M. Ihara, and K. Fukumoto, Heterocycles, 3, 627-631 (1975).

614. A Facile Synthesis of 2,3-Dihydro-1H-pyrrolo[1,2,-a]indoles: T. Kametani, K. Takahashi, M. Ihara, and K. Fukumoto, Heterocycles, 3 , $691-695$ (1975).

615. Formation of Protoberberines by Debenzylation and Photolysis of Tetrahydroisoquinolines: T. Kametani, K. Fukumoto, M. Ihara, M. Takemura, H. Matsumoto, B. R. Pai, K. N. Nagarajan, M. S. Premila, and H. Suguna, Heterocycles, $\underline{3}$, $811-820(1975)$.

616. Syntheszs of Oxaporphine by Photolysis: A Total Synthesis of Atheroline: T. Kametani, R. Nitadori, H. Terasawa, K. Takahashi, and M. Ihara, Heterocycles, $\underline{3}, 821-825$ (1975).

617. Synthesis of Homoproaporphine Related Compounds: T. Kametani, K. Fukumoto, F. Satoh, K. Kigasawa, and H. Sugi, Heterocycles, 3, 921 - 926 (1975).

618. Synthesis of Benzazepine Alkaloids and Related Compounds: T. Kametani and K. Fukumoto, Heterocycles, 3, 931 - 1004 (1975).

619. A One Step Synthesis of the Phthalideisoquinoline Alkaloid Cordrastine: T. Kametani, T. Honda, H. Inoue, and K. Fukumoto, Heterocycles, 3, $1091-1098$ $(1975)$.

620. Sekiyukagaku to Iyakuhın: T. Kametani and K. Fukumoto, Journal of the Japan Petroleum Institute, $\underline{18}, 363-370$ (1975).

621. Studies on the Syntheses of Heterocyclic Compounds. Part DLXXXIX. A Simple Route to Pyridocarbazoles: T. Kametani, T. Suzuki, K. Takahashi, Y. Ichikawa, and K. Fukumoto, J.C. S. Perkin I, 1975, $413-415$.

622. Tetra- and Hexa-dehydroyohimbane Synthesis by an Intermolecular Cycloaddition of o-Quinodimethane: T. Kametani, M. Kajiwara, T. Takahashi, and K. Fukumoto, J.C.S. Perkin I, 1975, 737 - 740 .

623. Methyl Transfer: the Mass Spectra of Reserpine Derivatives: T. Kametani, Y. Fujimoto, Y. Suzukı, Y. Tanaka, K. Nyu, T. Yamanaka, and S. Ikeda, J. C. S. Perin I, 1975, $932-934$.

624. Studies on the Syntheses of Heterocyclic Compounds. Part DXCVII. Nove 1 Formation of Benzo[5,6]cyclohept $[1,2,3$-ij] isoquinolines from Berbinium 
Salts: T. Kametanı, M. Takemura, K. Takahashi, M. Takeshita, M. Ihara, and K. Fukumoto, J.C. S. Perkin I, 1975, 1012 - 1015.

625. Studies on the Syntheses of Heterocyclic Compounds. Part DCxx. Total Syntheses of $( \pm)$-Orientalidine and a Positional Isomer: T. Kametani, A. Ujile, M. Thara, and K. Fukumoto, J.C. S. Perkin I, 1975, $1822-1825$.

626. Studies on the Syntheses of Heterocyclic Compounds. Part DCXXI. Total Synthesis of ( \pm )-Mappicine [7-(1-Hydroxypropy 1$)-8$-methylindolizino[1,2-b ]quino1ine-9(11ㅂ)-one]: T. Kametani, H. Takeda, H. Nemoto, and K. Fukumoto, J. C. S. Perkin I, 1975, $1825-1828$.

627. Reaction of 1,2-Dihydrobenzocyclobutene-1-carbonitriles with Methyl Acrylate as an Unsymmetric Dienophile: T. Kametani, Y. Kato, $\vec{T}$. Honda, and K. Fukumoto, J.C.S. Perkin I, 1975, $2001-2004$.

628. Studies on the Syntheses of Heterocyclic Compounds. Part DCXXIX. A Ready Synthesis of Indeno[2,1-a $][3]$ benzazepines: T. Kametani, S. Hirata, H. Nemoto, M. Ihara, S. Hibino, and K. Fukumoto, J.C. S. Perkin I, 1975, 2028 2030 .

629. Studies on the Syntheses of Heterocyclic Compounds. Part CDXXIV. A Nove1 Total Synthesis of Olivacine (1,5-Dimethyl-6H-pyrido[4,3-b]carbazole): T. Kametani, T. Suzuki, Y. Ichikawa, and K. Fukumoto, J.C. S. Perkin I, $\underline{1975}, 2102-2104$.

630. Studies on the Syntheses of Heterocyclic Compounds. DXCI. Total Synthesis of $( \pm)$-Cheryl1ine and Corgoine through Quinonoid Intermediates: T. Kametani, K. Takahashi, and C. V. Loc, Tetrahedron, 31, $235-238$ (1975).

631. Relationship between Activity and ${ }^{13} \mathrm{C}$ Chemical Shifts of Benzocyclobutenes: T. Kametani, M. Kajiwara, T. Takahashi, and K. Fukumoto, Tetrahedron, 31, $949-951(1975)$.

632. Nitrenes --.. XV. 1-Hydroxymethy 1-4,5-dimethoxy-7H-azirino[1,2-a ] indole7a-carboxylic Acid $\gamma$-Lactone, and Nitrene Addition Compound: T. Kametani, F. F. Ebetino, and K. Fukumoto, Tetrahedron, 31, 1241 - 1243 (1975)

633. Conformational Analysis of the Dibenzo[a,g]quinolizidines by Spectroscopic Methods: T. Kametani, K. Fukumoto, M. Ihara, A. Ujiie, and H. Koizumi, J. Org. Chem., 40, $3280-3283$ (1975).

634. Studies on the Syntheses of Heterocyclic Compounds. Part DLxxxvil. A Modified Synthesis of the Spirobenzylisoquinolines: T. Kametani, Y. Hirai, H. Nemoto, and K. Fukumoto, J. Heterocyclic Chem., 12, $185-186$ (1975). 
635. Studies on the Syntheses of Heterocyclic Compounds. Part DxCV. The Stereochemistry of Methyl 0-(4-Hydroxy-3-methoxycinnamoyl) reserpate: T. Kametani, T. Hıga, M. Ihara, K. Fukumoto, and M. Kajiwara, J. Heterocyclic Chem., 12, $259-262(1975)$.

636. Studies on the Syntheses of Heterocyclic Compounds. Part DXCVII. A Synthesis of Dienone Analogs by Elecrolytic Oxidation: T. Kametani, K. Shishido, and S. Takano, J. Heterocyc11c Chem., 12, $305-307$ (1975).

637. Studies on the Syntheses of Heterocyclic Compounds. Part DCXII. A Simple Synthesis of Benzopyran and Dibenzopyran Derivatives: T. Kametani, K. Kigasawa, M. Hiiragi, H. Ishimaru, N. Wagatsuma, S. Haga, and O. Kusama, J. Heterocyclic Chem., $12,851-854$ (1975).

638. Studies on the Syntheses of Heterocyclic Compounds. Part DCXxxII. The Formation of the Benzimidazo[2,1-a] ] isoquinoline By Reaction of the 1,2,3,4Tetrahydro-1-(2-nitrophenethyl) isoquinoline with Triethy1 Phosphite: T. Kametani, Y. Fujimoto, and M. Mizushima, J. Heterocyclic Chem., 12, 1271 $1273(1975)$.

639. Studies on the Syntheses of Heterocyclic Compounds. Part DCXXXVI. An A1ternatıve Synthesis of Pentazocine: T. Kametani, T. Honda, S.-P. Huang, and K. Fukumoto, Canad. J. Chem., 53, $3820-3823$ (1975).

640. Studies on the Syntheses of Heterocyclic Compounds. Part DCXXXVIII. Simple Synthesis of Benz[d] indeno[1,2-b] ]azepine from 1-Benzoyl-3,4-dihydroisoquinoline: T. Kametani, M. S. Premila, S. Hirata, H. Seto, H. Nemoto, and K. Fukumoto, Canad. J. Chem., $\underline{53}, 3824$ - 3830 (1975).

641. Synthesis of $( \pm)$-Glaziovine, a Proaporphine Alka1oids, thorugh Nitrenium Intermediate: T. Kametani, K. Takahashi, K. Ogasawara, C. V. Loc, and K. Fukumoto, Coll. Czech.Chem. Comm., 40, 712 - 718 (1975).

642. Synthesis of $1,2,3,4,4 \mathrm{a}, 10 \mathrm{~b}-$ Hexahydro-6ㅂ-dibenzo[b, d]pyran Derivatives (Studies on the Syntheses of Heterocyclic Compounds. DCLII): T. Kametani, K. Kigasawa, M. Hiiragi, N. Wagatsuma, O. Kusama, T. Uryu, T. Nakamura, T. Kohagizawa, and S. Haga, Yakugaku Zasshi, 96, 550 - 556 (1976).

643. Studies on the Synthesis of Antispasmodic Agent. II. Configuration of Diastereoisomers of 1-Diethylamino-3-hydroxy-2-methylbutane: T. Kametani, K. Kigasawa, M. Hiiragi, N. Wagatsuma, T. Kohagizawa, and T. Nakamura, Yakugaku Zasshi, 96, 995 - 999 (1976).

644. Syntheses of 1-Carboxy-1,2,3,4-tetrahydroisoquinoline Derivatives and 6Carboxydibenzo[ $\underline{b}, \underline{d}]$ pyran Derlvatives by Phenolic Cyciization (Studies on the Syntheses of Heterocyclic Compounds. DCLXIV): T. Kametani, K. Kigasawa, 
M, Hi iragı, H. Ishimaru, and K. Shiroyama, Yakugaku Zasshi, 96, $1031-1035$ (1976).

645. Studies on the Syntheses of Analgesics. XLVI. An Abnormal Hofmann Degradation of $\mathrm{N}$-(4-Hydroxybenzyl)-3-benzazocinium Halides (Studies on the Syntheses of Heterocyclic Compounds. DCLXVIII): T. Kametani, K. Kigasawa, M. Hiiragi, K. Wakısaka, T. Uryu, H. Sugi, S. Saitoh, H. Ishimaru, and S. Haga, Chem. and Pharm. Bul1. (Japan), 24, $1246-1253$ (1976).

646. Synthetic Approach to the Synthesis of Eudesmane Tyep of Sesquiterpenes by Using Furan Derivatives as a Starting Material: T. Kametani, H. Nemoto, M. Takeuchi, S. Hibino, and K. Fukumoto, Chem. and Pharm. Bul1. (Japan), 26, 1354 - 1361 (1976).

647. Studies on the Syntheses of Heterocyclic Compounds. DCLXIII. The Reaction of Pyridone Derivatives with Diazoalkane: T. Kametani, Y. Kigawa, T. Takahashi, H. Nemoto, and K. Fukumoto, Chem. and Pharm. Bull. (Japan), 24, 1870 $-1878(1976)$.

648. Studies on the Syntheses of Heterocyclic Compounds. DCLXXI: An Alternative Total Synthesis of Yohimbine: T. Kametani, Y. Hirai, and K. Fukumoto: Chem. and Pharm. Bu11. (Japan), 24, $2500-2503$ (1976).

649. Studies on the Syntheses of Heterocyclic Compounds. DCLXXI1. A Synthesis of Coralydine and O-Methylcorytenchirine by Thermolys is of Benzocyclobutene: T. Kametani, C. Ohtsuka, H. Nemoto, and K. Fukumoto, Chem. and Pharm. Bull. (Japan), 24, $2525-2531$ (1976).

650. Studies on the Syntheses of Analgesics. XLI. Optical Resolution of ( \pm ) N-Cyclopropylmethyl-3-hydroxy-9-azamorphinan (Studies on the Syntheses of Heterocyclic Compounds. Part DCLXXIX): T. Kametani, K. Kigasawa, M. Hiiragi, N. Wagatsuma, O. Kusama, and T. Uryu, Chem. and Pharm. Bu11. (Japan), 24, $2563-2566(1976)$.

651. A One-step Synthesis of Evodiamine and Rutecarpine: T. Kametani, T. Higa, K. Fukumoto, and M. Koizumi, Heterocycles, 4 , $23-28$ (1976).

652. An Alternative Syntheses of ( \pm )-Yohimbine: T. Kametani, Y.Hirai, and K. Fukumoto, Heterocycles, 4, 29 - 33 (1976).

653. Synthesis of a Fantastic Anlgesic 'N-Cyclopropylmethyl-3-hydroxy-9-azamorphinan: T. Kametani, K. Kigasawa, M. Hiiragi, N. Wagatsuma, 0 . Kusana, and $T$. Uryu, Heterocycles, $\underline{4}, 41-45$ (1976).

654. A Simple and Stereospecific Synthesis of Diterpene Alkaloid Intermediate:

T. Kametani, Y. Kato, T. Honda, and K. Fukumoto, Heterocycles, 4, $241-246$ 
(1976).

655. A Total Synthesıs of Naucléfine: T. Kametani, M. Takeshita, and M. Ihara, Heterocycles, $4,247-250$ (1976).

656. Recent Chemical Progress in Berberine Alkaloids: T. Kametani, M. Ihara, and T. Honda, Heterocycles, 4, $483-526$ (1976).

657. Structure Elucidation of Six New Non-phenolic Alkaloids Isolated from Corydalis ochotensis var. Raddeana: T. Kametani, M. Takemura, M. Ihara, and K. Fukumoto, Heterocycles, 4, 723 - 728 (1976).

658. A New Alkylating Method at the 4-Position of Isoquinoline Derivatives: T. Kametani, H. Nemoto, M. Takeuchi, M. Takeshita, and K. Fukumoto, Heterocyc1es, 4, $921-926(1976)$.

659. Alternative Synthesis of Protoberberine Alkaloid $( \pm)$-Xyloninine: T. Kame$\operatorname{tani}$, T. Honda, T. Suga1, and K. Fukumoto, Heterocycles, 4, $927-932$ (1976).

660. Stevens Rearrangement of Berberine Methıdides by Sodium Bis(2-methoxyethoxy)aluminium Hydride: T. Kametani, S.-P. Huang, A. Ujiie, M. Ihara, and K. Fukumoto, Heterocycles, $4,1223-1228$ (1976).

661. The Mechanism in the Colorimetry of Caffeine and Theobromine by Hypoch1orous Acid-Pyridine Method: K. Kigasawa, K. Ohkubo, T. Kohagisawa, H. Shimizu, S. Saitoh, and T. Kametan1, Heterocycles, 4, $1257-1262$ (1976).

662. Simple Synthesis of Quinazolone Alkaloids Arborine and Rutecarpine Through Iminoketene: T. Kametani, C. V. Loc. T. Higa, M. Koizumi, M. Ihara, and K. Fukumoto, Heterocycles, $4,1487-1492$ (1976).

663. Photooxygenation of 9-Keto-7-methoxy-6-methy1-9--pyrrolo[1,2-a ]indole as a Synthetic Approach to the Mitomycins: T. Kametani, T. Ohsawa, K. Takahashi, M. Ihara, and K. Fukumoto, Heterocycles, 4, 1637 - 1644 (1976).

664. Phenol Oxidation of Isoquinoline Alkaloids with Cuprous Chloride and Oxygen in Pyridine as an Enzymatic Mode1. Biomimetic Total Synthesis of Corytuberine, Isoboldines, Pallidine, Orientalinone and Kreysiginone: T. Kametani, Y. Satoh, M. Takemura, Y. Ohta, M. Ihara, and K. Fukumoto, Heterocycles, $\underline{5}, 175-182(1976)$.

665. Racemisation and Epimerisation in Isoquinoline and Indole A1kaloids: T. Kametani and M. Ihara, Heterocycles, $\underline{5}, 649$ - 668 (1976).

666. Total Synthesis of Natural Products by Retro Mass Spectral Synthesis: T. Kametani and K. Fukumoto, J. Synth. Org. Chem. Japan, 34, 934 - 947 (1976). 
667. Studies on the Alkaloids of Formosan Corydalis Species. Part VI. Elucidation of the Structure of Two Spirobenzylisoquinoline Alkaloids, Yenhusomine and Yenhusomidine, and Two Berbine Alkaloid, Corytenchine and Corytenchirine, from Corydalis Ochotensis (Turcz.): S.-T. Lu, T.-L. Su, T. Kametani, A. Ujije, M. Ihara, and K. Fukumoto, J. C. S. Perkin I, 1976, $63-68$.

668. Synthesis of 2,3-Dihydro-1H-pyrrolo[1,2-a]indoles by Intramolecular Nucleophilic Aromatic Substitution: T. Kametani, K. Takahashi, M. Ihara, and K. Fukumoto, J.C. S. Perkin I, 1976, $389-393$.

669. Studies on the Syntheses of Heterocyclic Compounds. Part DCL. Total Synthesis of Corytenchirine: T. Kametani, A. Ujiie, M. Ihara, K. Fukumoto, and S.-T. Lu, J.C.S. Perkin I, 1976, $1218-1221$.

670. A One-Step Synthesis of the Phthalideisoquinoline Alkaloids, Cordrastine and Hydrastine: T. Kametani, T. Honda, H. Inoue, and K. Fukumoto, J. C. S. Perkin I, $1976,1221-1225$.

671. Studies on the Syntheses of Heterocyclic Compounds. Part 673. New Routes to Benzo [a]quinolizines: T. Kametani, H. Terasawa, and M. Ihara, J. C. S. Perkin $1,1976,2547-2550$.

672. Novel Stereospecific Synthesis of a Potential Intermediate for Preparation of Tetracyclic Diterpenes from Dihydrobenzocyclobutene Derivatives: T. Kametani, H. Nemoto, and K. Fukumoto, J. C. S. Chem. Comm, 1976, $400-401$.

673. (+)-Corytuberine from Corydalis Pallida var. Tenuis: T. Kametani, M. Takemura, and M. Ihara, Phytochemistry, $15,2017-2018(1976)$.

674. Biotransformation of 1-Benzy1-1,2,3,4-tetrahydro-2-methylisoquinolines into Tetrahydroprotoberberines with Rat Liver Enzymes:T. Kametani, M. Takemura, M. Ihara, K. Takahashi, and K. Fukumoto, J.Amer. Chem. Soc., 98, $1956-1959$ (1976).

675. A Formal Regio- and Stereoselective Total Synthesis of Estrone. A Convenient Synthesis of D-Homoestrone: T. Kametani, H. Nemoto, H. Ishikawa, K. Shiroyama, and K. Fukumoto, J. Amer. Chem. Soc., 98, 3378 - 3379 (1976).

676. Iminoketene Cycloaddition. I. A Facile Synthesis of Quinazolone System by Condensation of Iminoketene with Imines - - A Total Synthesis of Evodiamine and Rutecarpine by Retro Mass Spectral Synthesis: T. Kametani, T. Higa, C. V. Loc, M. Ihara, M. Koizumi, and K. Fukumoto, J. Amer. Chem. Soc., 98,6186 - $6188(1976)$.

677. Studies on the Syntheses of Heterocyclic Compounds. 675. A Facile Regiospecific and Stereocontrolled Synthesis of a Diterpene Alkaloid Intermediate 
from Benzocyclobutenes: T. Kametani, Y. Kato, T. Honda, and K. Fukumoto, J. Amer. Chem. Soc., 98, 8185 - 8190 (1976).

678. Studies on the Syntheses of Heterocyclic Compounds. 657. Total Synthesis of Angustine, Naucléfine, and Gentianine: T. Kametani, M. Takeshita, M. Ihara, and K. Fukumoto, J. Org. Chem., 41, 2542 - 2545 (1976).

679. A Novel Cleavage of Aryl Benzyl Ether and Allyl Aryl Ethers by Sodium Bis(2methoxyethoxy)aluminum Hydride. An Alternative Synthesis of Pentazocine:

T. Kametani, S.-P. Huang, M. Ihara, and K. Fukumoto, J. Org. Chem., 41, 2545 - 2548 (1976).

680. A New Synthetic Approach to the 3-Benzazepine Skeleton through Pinacol-Pinacolone Rearrangement: T. Kametani, H. Nemoto, K. Suzuki, and $K$. Fukumoto, J. Org. Chem., 41, $2988-2990$ (1976).

681. Studies on the Syntheses of Heterocyclic Compounds. Part DCXLIV. Catalytic Reduction of Homoproaporphine Related Compounds: T. Kametani, K. Fukumoto, F. Satoh, K. Kıgasawa, and H. Sugi, J. Heterocyc1ic Chem., 13, $29-31$ (1976).

682. Studies on the Syntheses of Heterocyclic Compounds. Part DCLV. Two Stereoisomers of 1-Benzy 1-5-hydroxy-6-(4-methoxybenzy1)-4,5-dimethylpiperidin-2-one: T. Kametani, S.-P. Huang, M. Ihara, and K. Fukumoto, J. Heterocyclic Chem., $13,779-780(1976)$.

683. Total Synthesis of Natura1 Products by Retro Mass Spectral Synthesis: T. Kametani and K. Fukumoto, Accounts Chem. Res,, 9, $319-325$ (1976).

684. Reaction Mechanism in Drug Analysis. V. Color Reaction of Caffeine by Hypochlorous Acid-Pyridine Method: K. Kigasawa, K. Ohkubo, T. Kohagisawa, H, Shımizu, S. Saito, and T. Kametani, Yakugaku Zasshi, 97, $18-23$ (1977).

685. Studies on the Synthesis of Analgesics. XLVII. Syntheses of Galanthamine Analogues and Cyclization Reaction of Amidoalcohol (Studies on the Syntheses of Heterocyclic Compounds. DCCVIII): T. Kametani, K. Kigasawa, N. Hiiragi, N. Wagatsuma, T. Kohagizawa, and T. Nakamura, Yakugaku Zasshi, 97, $519-527$ (1977).

686. Studies on the Syntheses of Heterocyclic Compounds. DCCXII. Attempts to the Ring-Closure of Piperidone Derivatives by Grewe Cyclization: T. Kametani, K. Fukumoto, H. Nemoto, and H. Seto, Yakugaku Zasshi, 97, 615-622 (1977).

687. Studies on the Syntheses of Heterocyclic Compounds. DCcxvil. The Reaction of Methylenomycin A Methyl Ester with Several Amines as a Nucleophile: T. Kametani, H. Seto, H. Nemoto, and K. Fukumoto, Yakugaku Zasshi, 97, $944-947$ (1977). 
688. Studies on the Synthesis of Analgesics. XLVIII. New Synthetic Method of Tetrahydro-2-benzazepine Derivatives and Syntheses of Galanthamine Analogues (Studied on the Syntheses of Heterocyclic Compounds. DCCXXIV): T. Kametani, K, Kigasawa, M. Hiiragi, N. Wagatsuma, T. Kohagisawa, and T. Nakamura, Yakugaku Zasshi, $\underline{97}, 1353$ - 1358 (1977).

689. Studies on the Syntheses of Heterocyc1ic Compounds. DCXCII. A Nove1 Synthetac Route to Phthalideisoquinoline and Spirobenzylisoquinoline Type Alkaloids: T. Kametani, T. Ohsawa, S. Hirata, M. S. Premila, M. Ihara, and K. Fukumoto, Chem. and Pharm. Bull. (Japan), 25, 321 - 326 (1977).

690. Studies on the Syntheses of Heterocyclic Compounds. DCCIX. A Synthetic Approach to Kesselringine: T. Kametani, Y. Satoh, and K. Fukumoto, Chem. and Pharm. Bull. (Japan), 25, 922 - 925 (1977).

691. An Abnormal Formation of Indane from $N$-Phenethylphenylpropionanide under Bischler-Napieralski Reaction Conditions: T. Kametani, Y. Satoh, and K. Fukumoto, Chem. and Pharm. Bu11. (Japan), 25, $1129-1134$ (1977).

692. Studies on the Syntheses of Heterocyclic Compounds. DCCXXVIII. A Simple Synthesis of 1,3-Benzoxazin-4-ones from Salicylic Acid: T. Kametani, T. Higa, C. V. Loc, M. Ihara, and K. Fukumoto, Chem. and Pharm. Bul1. (Japan), $\underline{25}, 2735-2738(1977)$.

693. A Facile Formation of Benzo[a]quinolizin-4-ones: T. Kametani, H. Terasawa, M. Ihara, and K. Fukumoto, Heterocycles, 6, $37-41$ (1977).

694. A Biomimetic Approach to Benzophenanthridine Alkaloid from Protoberberine Alkaloid: T. Kametani, M. Takemura, M. Ihara, K. Fukumoto, and K. Takahashi, Heterocyc1es, 6, $99-105$ (1977).

695. A Novel and Simple Synthesis of 1,3-Benzoxazin-4mone Derivatives: T. Kametani, T. Higa, C. V. LoC, M. Thara, and K. Fukumoto, Heterocycles, 6, 255 260 (1977).

696. The Cyclisation Reaction of $\gamma$-Amido-alcohols and Synthesis of 2-Benzazepin3-one Derivatives by Acid Catalysed Rearrangement of 1,3-Oxazepin-4-one Derivatives: T. Kametani, K. Kigasawa, M. Hiiragi, N. Wagatsuma, T. Kohagisawa, and T. Nakamura, Heterocycles, 6, $305-312$ (1977).

697. Biotransformation of Reticuline into Morphinandienone, Aporphine and Protoberberine Alkaloids with Rat Liver Enzyme: T. Kametani, Y. Ohta, M. Takemura, M. Ihara, and K. Fukumoto, Heterocycles, 6, 415 - 421 (1977).

698. A Facile Synthesis of 1-(2-Tetrahydrofury 1)-5-fluorouracil (Ftorafur): $T$. Kametani, K. Kigasawa, M. Hiiragi, K. Wakisaka, 0. Kusama, H. Sugi, and 
K. Kawasaki, Heterocycles, 6 , $529-533$ (1977).

699. A Novel Method for Acetalization of Formyl Group at the $\mathrm{C}_{3}$-Position of 2,3 -

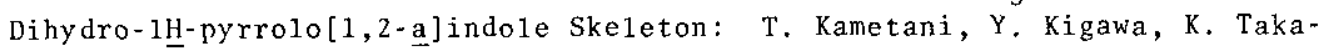
hashi, H. Nemoto, and K. Fukumoto, Heterocycles, 6, $887-893$ (1977).

700. Thermolysis of $\mathrm{N}$-Substituted Benzazocine Hydrochlorides: T. Kametani, K. Kigasawa, M. Hi iragi, T. Iwata, and K. Ohkubo, Heterocycles, 6, $1183-1187$ (1977).

701. A New Method for an Epoxidation of olefins and Its Application to a Biomimetic Synthesis of Monoterpenes, Linalyloxides: T. Kametani, H. Nemoto, and $K$. Fukumoto, Heterocycles, 6, $1365-1370$ (1977).

702. Interconversion between Pyrrolo[1,2-a] indoles and 2,3-Benzazocin-5-ones A Synthetic Approach to Mitomycins: T. Kametani, K. Takahashi, M. Ihara, and K. Fukumoto, Heterocycles, 6, 1371 - 1375 (1977).

703. Therma1 Rearrangement of Aminomethy1 Cyclopropy1 Ketones: H. Nemoto, H. Seto, and T. Kametani, Heterocycles, 6, 1569 - 1574 (1977).

704. Synthetic Approaches to Mitomycins: M. Ihara, K. Takahashi, Y. Kigawa, T. Ohsawa, K. Fukumoto, and T. Kametani, Heterocycles, 6, 1658 - 1665 (1977).

705. A New Synthesis of Quinazolone Alkaloids by an Intermolecular Cycloaddition of Iminoketenes: T. Kametani, K. Fukumoto, M. Ihara, and C. V. Loc, Heterocycles, $6,1741-1746$ (1977).

706. Synthesis of a Diterpene Alkaloid Intermediate from Benzocyclobutene: F. Satoh, T. Kamétani, Y. Kato, T. Honda, and K. Fukumoto, Heterocycles, $\underline{6}, 1757$ - $1764(1977)$.

707. Synthesis of Quinazolone Alkaloids and Benzoxazinones by Retro Mass Spectral Synthesis and Related Analysis: T. Kametani and K. Fukumoto, Heterocycles, 7, $615-635$ (1977).

708. A Simple Synthesis of 4-0xazolidinones, 1,3-oxazin-4-ones and 1,3-0xazepin4-ones from Amido-alcohols: T. Kametani, K. Kigasawa, M. Hiiragi, N. Wagatsuna, T. Kohagisawa, and H. Inoue, Heterocycles, 7, $919-925$ (1977).

709. A Stereoselective Formal Total Synthesis of Emetine: T, Kametani, Y, Suzuki, H. Terasawa, M. Ihara, and K. Fukumoto, Heterocycles, $\underline{8}, 119-124$ (1977).

710. Newer Method in the Total Syntheses of Natural Products: T. Kametani and K. Fukumoto, Heterocycles, $\underline{8}, 465$ - 562 (1977)." 
711. Annelation --- Synthesis of Natura1 Products: T. Kametani, H. Nemoto, and K. Fukumoto, J. Synth. Org. Chem. Japan, 35, 1009 - 1028 (1977).

712. Studies on the Syntheses of Heterocyclic Comnounds.. Part 676. Synthesis of 1-Subst1tuted 7-Methoxymitosenes: T. Kametani, K. Takahashi, Y. Kigawa, M. Jhara, and K. Fukumoto, J. C. S. Perkin I, 1977, $28-31$.

713. Studies on the Syntheses of Heterocyclic Compounds. Part 678. Photoracem1sation and Photoepimerisation of the Phthalidylisoquinoline Alkaloids (-)- $\alpha-$ Narcotine and (-)-B-Hydrastine: T. Kametani, H. Inoue, T. Honda, T. Sugahara, and K. Fukumoto, J. C.S. Perkin I, 1977, $374-376$.

714. Studies on the Syntheses of Heterocyclic Compounds. Part 679. A Stereoselective Total Synthesis of ( \pm )-Ophiocarpine; a Simple Route to 13-Hydroxyberbines: T. Kametani, H. Matsumoto, Y. Satoh, H. Nemoto, and K. Fukumoto, J.C. S. Perkin I, $1977,376^{\circ}-382$.

715. Studies on the Syntheses of Heterocyclic Compounds. Part 680. Abnormal Formation of Aporphine Derivatives by Grewe Cyclisation: T. Kametani, T. Uryu, and K. Fukumoto, J.C. S. Perkin I, 1977, $383-386$.

716. Studies on the Syntheses of Heterocyc1ic Compounds. Part 681. A Novel Alky1ation in the 4-Position of Isoquinoline Derivatives: T. Kametani, H. Nemoto, M. Takeuchi, M. Takeshita, and K. Fukumoto, J. C. S. Perkin I, 1977, $386-390$.

717. Studies on the Syntheses of Heterocyclic Compounds. Part 682. Six New Isoquinoline Alkaloids from Corydalis Ochotensis var. Raddeana: T. Kametani, M. Takemura, M. Ihara, and K. Fukumoto, J. C. S. Perkin I, 1977, $390-393$.

718. Studies on the Syntheses of Heterocyclic Compounds. Part 683. Stevens Rearrangement of Berbine Methiodides by Sodium Bis-(2-methoxyethoxy)aluminium Hydride: T. Kametani, A. Ujiie, S. - P. Huang, M. Ihara, and K. Fukumoto, J. C. S. Perkin I, 1977, $394-397$.

719. Studies on the Syntheses of Heterocyclic Compounds. Part 687. Asymmetric Synthesis of Salsolidine: T. Kametani and T. Okawara, J. C. S. Perkin I, $\underline{1977}, 579-581$.

720. Studies on the Syntheses of Heterocyclic Compounds. Part 698. An Alternative Protoberberine Synthesis; Total Synthesis of $( \pm)$-Xylopinine, $( \pm)$-Schefferine, $( \pm)$-Nandinine, $( \pm)$-Corydaline, and $( \pm)$-Thalictricavine: T. Kametani, T. Sugai, Y. Shoji, T. Honda, F. Satoh, and K. Fukumoto, J.C. S. Perkin I, 1977, $1151-1155$.

721. Studies on the Syntheses of Heterocyclic Compounds. Part 724. Total Syntheses of the Quinazolinone Alkaloids Glycorine, Glomerine, Homoglomerine, 
Crysogine, and Euxylophorıcines A and C: T. Kametani, C. V. Loc, T. Higa, M. Ihara, and K. Fukumoto, J. C. S. Perkin I, 1977, $2347-2349$.

722. Short and Stereoselective Construction of a Key Intermediate for Synthesis of Unsymetrical Pentacyclic Triterpenes: T. Kametani, Y. Hirai, F. Satoh, and K. Fukumoto, J. C. S. Chem. Comm., 1977, $16-18$.

723. Studies on the Syntheses of Heterocyclic Comnounds. DCXCIII. A Total Synthesis of Atheroline by Photolysis: T. Kametani, R. Nitadori, H. Terasawa, K. Takahashi, M. Ihara, and K. Fukumoto, Tetrahedron, 33, 1069 - 1077 (1977).

724. Iminoketene Cycloaddition. 2. Total Syntheses of Arborine, Glycosminine, and Rutecrapine by Condensation of Iminoketene with Amides: T. Kametani, C. V. Loc, T. Higa, M. Koizumi, M. Ihara, and K. Fukumoto, J. Amer. Chem. Soc., $\underline{99}, 2306-2309(1977)$.

725. A Stereoselective Total Synthesis of Estrone by an Intramolecular Cycloaddition Reaction of Olefinic o-Quinodimethane: T. Kametani, H. Nemoto, H. Ishikawa, K. Shiroyama, H. Matsumoto, and K. Fukumoto, J. Amer. Chem. Soc., 99, $3461-3466(1977)$.

726. Studies on the Syntheses of Heterocyclic Compounds. 700. Syntheses of Isoquinoline Alkaloids with Cuprous Chloride and Oxygen in Pyridine as an Enzymic Model: T. Kametani, M. Ihara, M. Takemura, Y. Satoh, H. Terasawa, Y. Ohta, K. Fukumoto, and K. Takahashi, J.Amer. Chem. Soc., 99, $3805-3808$ (1977).

727. Studies on the Syntheses of Heterocyc1ic Compounds. 696. Stereochemistry of Four Isomeric $4 a-C y a n o-1,2,3,4,4 a, 9,10,10 a-o c t a h y d r o-7-m e$ thoxy-1-methoxycarbonyl-1-methylphenanthrenes: T. Kametani, Y. Kato, F. Satoh, and K. Fukumoto, J. Org. Chem., 42, $1177-1180$ (1977).

728. Competitive Reactions between Sigmatropic Reaction and Cycloaddition Affected by the Geometry of o-Quinodimethanes: T. Kametani, M. Tsubuki, Y. Shiratori, Y. Kato, H. Nemoto, M. Ihara, and K. Fukumoto, J. Org. Chem., 42, $2672-2676$ (1977).

729. Studies on the Syntheses of Heterocyclic Compounds. 726. Therma1 Rearrangement of Aminomethyl Cyclopropyl Ketones and a Novel Synthesis of Pentazocine: T. Kametani, H. Seto, H. Nemoto, and K. Fukumoto, J. Org. Chem., 42, 3605 3608 (1977).

730. Studies on the Syntheses of Heterocyclic Compounds. 715. Stevens Rearrangement of cis- and trans-Berbine Methiodides by Sodium Bis-(2-methoxyethoxy)aluminum Hydride: T. Kametani, S.-P. Huang, C. Koseki, M. Ihara, and K. Fukumoto, J. Org. Chem., 42, 3040 - 3046 (1977). 
731. Studies on the Synthesis of Chemotherapeutics. I. Synthesis of 1-(2-Tetrahydrofury1)-5-fluorouracil [Ftoraful] (Studies on the Syntheses of Heterocyclic Compounds. Part 703): T. Kametani, K. Kigasawa, M. Hiiragi, K. Wakisaka, O. Kusama, K. Kawasaki, and H. Sugi, J. Heterocyclic Chem., 4, 473 475 (1977).

732. Synthetic Studies on Chemotherapeutics. II. Synthesis of Phenylsubstituted 1,4-Dihydro-4-oxonicotinic Acid Derivatives [Studies on the Syntheses of Heterocyclic Compounds. Part 704]: T. Kametani, K. Kigasawa, M. Hiiragi, K. Wakisaka, O. Kusama, H. Sugi, and K. Kawasaki, J. Heterocyclic Chem., 14, $477-482$ (1977).

733. Synthetic Studies on Chemotherapeutics. III. Synthesis of the 6,9-Dihydro-

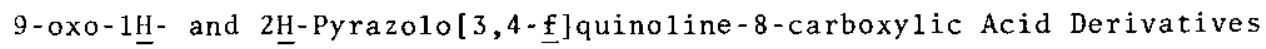
[Studies on the Syntheses of Heterocyclic Compounds. Part 718]: T. Kametani, K. Kigasawa, M. Hiiragi, K. Wakisaka, O. Kusama, H. Sugi, and K. Kawasaki, J. Heterocyc1ic Chem., 14, 1175 - 1182 (1977) .

734. Biotransformation of Reticuline into Coreximine, Scoulerine, Pallidine, and Isoboldine with Rat Liver Enzyme: T. Kametani, Y. Ohta, M. Takemura, M. Ihara, and K. Fukumoto, Bioorg. Chem., 6, $249-256$ (1977).

735. Conformational Analysis of the Dibenzo[a,g]quinolizidines by Spectroscopic Means II - The Use of High Resolution $270 \mathrm{MHz}$ Proton Magnetic Resonance: D. Tourwé, G. Van Binst, and T. Kametani, Org. Magnetic Resonance, 9 , 341 346 (1977).

736. Oxidation of Amines to Nitriles or Aldehydes Using Copper (I): T. Kametani, K. Takahashi, T. Ohsawa, and M. Ihara, Synthesis, 1977, $245-246$.

737. A Biomimetic Synthesis of Benzo[들 phenanthridine Alkaloid Nitidine: T. Kametani, M. Takemura, M. Ihara, K. Fukumoto, and K. Takahashi, Israel J. Chem., $\underline{16}, 4-6(1977)$.

738. The Total Syntheses of Isoquinoline Alkaloids: T. Kametani, The Total Synthesis of Natural Products, edited by J. ApSimon, Vol. 13, pp. 1-272, John Wiley \& Sons, 1977.

739. Alkaloids: T. Kametani, Y. Hirata, and M. Ihara, Methodicum Chimicum, Vol. 11, Part 3, edited by F. Korte and M. Goto, pp. 102-132, 1977.

740. Studies on the Syntheses of Analgesics. XLIX. Synthesis of 2-(6-Methoxy-2naphthyl)propanoic Acid (Studies on the Syntheses of Heterocyclic Compounds. DCCXL): T. Kametani, K. Kigasawa, M. Hiiragi, H. Ishimaru, S. Haga, and K. Shirayama, Yakugaku Zasshi, 98, $146-152$ (1978).

741. Studies on the Syntheses of Heterocyclic Compounds. DCCLII. Cyclization 
Reaction of Amldo-alcohols: T. Kametani, K. Kigasawa, M. Hiiragi, N. Wagatsuma, T. Kohagızawa, and H. Inoue, Yakugaku Zasshi, 98, $817-821$ (1978).

742. Studies on the Syntheses of Chemotherapeutics. V. Synthesis of the Pyrazolo[4,3-f]- and [3,4-f]quinoline-8-carboxylic Acid Derivatives (Studies on the Syntheses of Heterocyclic Compounds. CDDLVI): T. Kametani, K. Kigasawa, M. Hiiragi, K. Wakisaka, S. Haga, O. Kusama, H. Sugi, and K. Tanigawa, Yakugaku Zasshí, $\underline{98}, 1063-1071$ (1978).

743. Studies on the Synthesis of Chemotheraneutics. IV. Synthesis of Pyrazolo[4,3-g] quinoline-6-carboxylic Acid Derivatives (Studies on the Syntheses of Heterocyc1ic Compounds. DCCLIX): T. Kametani, K. Kigasawa, M. Hiiragi, K. Wakisaka, O. Kusama, S. Haga, H. Sugi, and K. Tanigawa, Yakugaku Zasshi, 98, 1158 - $1166(1978)$.

744. Studies on the Synthesis of Chemotherapeutics. VI. Synthesis of 6- and 7Carbamoy 1-1,4-dihydro-4-oxoquinoline-3-carboxylic Acid Derivatives (Studies on the Syntheses of Heterocyclic Compounds. DCCLXI): T. Kametani, K. Kigasawa, M. Hiiragi, K. Wakisaka, S. Haga, O. Kusama, H. Sugi, K. Kawasaki, and K. Tanigawa, Yakugaku Zasshi, 98, 1291 - 1296 (1978).

745. Studies on the Syntheses of Tetracycline Derivatives. II. Thermolytic Cycloaddition of $\underline{o}$-Quinodimethanes with Tetrahydronaphthoquinone and Naphthoquinone: T. Kametani, M. Takeshita, H. Nemoto, and K. Fukumoto, Chem. and Pharm. Bu11. (Japan), 26, $556-562$ (1978).

746. Studies on the Syntheses of Heterocyclic Compounds. DCCLIV. A Novel Method for Acetalisation of Formy 1 Group at the $C_{3}$-Position of 2,3-Dihydro- 1 Hpyrro1o[1,2-a $]$ indole Skeleton: T. Kametani, Y. Kigawa, K. Takahashi, H. Nemoto, and K. Fukumoto, Chem. and Pharm. Bu11. (Japan), 26, $1918-1922$ (1978).

747. Studies on the Syntheses of Heterocyclic Compounds. DCCLX. Iminoketene Cycloaddition. (4). A1ternative Syntheses of 5,6,7,8-Tetrahydro-2,3-dimethoxy-8oxoisoquinolo[1,2-b]quinazole and Rutecarpine: T. Kametani, T. Ohsawa, M. Ihara, and K. Fukumoto, Chem. and Pharm. Bull. (Japan), 26, 1922 - 1926 (1978).

748. Studies on the Syntheses of Heterocyclic Compounds. DCCLXVIII. Reaction of Pyrrolo[1,2-a $]$ indole Derivatives with $N$-Bromosuccinimide in Protic Solvents: T. Kametani, K. Takahashi, M. Ihara, and K. Fukumoto, Chem. and Pharm. Bul1. (Japan), 26, $3815-3819$ (1978).

749. Studies on the Syntheses of Tetracycline Derivatives. III. Synthetic Approach to Adriamycin --- Synthesis of the Linear Tetracyclic Skeleton Having the Same BC Rıng System with Adriamycin: T. Kametani, M. Chihiro, M. Takeshita, K. Takahashi, K. Fukumoto, and S. Takano, Chem. and Pharm. Bull. (Japan), 26, 
750. Synthesis of Pyrrolo[1,2-a] indoles and Related Systems: T. Kametani and K. Takahashi, Heterocycles, 9 , $293-351$ (1978).

751. Alternative Syntheses of 2,3-Benzazocin-5-one Derivatives via Pyrrolo[1,2-a] indoles: T. Kametani, K. Takahashi, M. Ihara, and K. Fukumoto, Heterocycles, g, $435-438(1978)$.

752. Reaction of Pyrrolo[1,2-a $]$ indole-5,8-dione Derivatives with N-Bromosuccinimide in Protic Solvents: T. Kametani, K. Takahashi, M. Ihara, and K. Fukumoto, Heterocycles, $9,439-442$ (1978).

753. A Simple Synthesis of 1,3-Benzoxazin-4-one Derivatives: T. Kametani, C. V. Loc, M. Ihara, and K. Fukumoto, Heterocycles, 9, 673 - 676 (1978).

754. A Simple Synthesis of 2-Substituted 4-0xazolidinones and 1,3-Oxazin-4-ones from Amide-alcohols (Studies on the Syntheses of Heterocyclic Comnounds. 748): T. Kametani, K, Kigasawa, M. Hiiragi, N. Wagatsuma, T. Kohagizawa, and H. Inoue, Heterocycles, $9, .819-830(1978)$.

755. A Simple Synthesis of 4-Thiazolidinones, Tetrahydro-1,3-thiazin-4-ones and Hexahydro-1,3-thiazepin-4-ones from Amide-thiols (Studies on the Syntheses of Heterocyclic Compounds. 749): T. Kametani, K. Kigasawa, M. Hiiragi, N. Wagatsuma', T. Kohagizawa, and H. Inoue, Heterocycles, 9, $831-840$ (1978).

756. NMR Spectral Assignment of 6,13-Dihydro-5-oxo-5ㅂ-isoquinolino[1,2-b $][1,3]$ benzoxazine: R. J. Bass, M. Kinns, T. Kametani, C. V. Loc, M. Ihara, and K. Fukumoto, Heterocycles, $\underline{9}, 863$ - 864 (1978).

757. Cyclisation Reaction of N-Substituted Mandelhydrazide with Formaldehyde: T. Kametani, K. Kigasawa, M. Hirragi, N. Wagatsuna, T. Kohagizawa, and H. Inoue Heterocycles, 9, $1031-1040$ (1978).

758. An Approach to the Skeleton of Rauwolfia Alkaloids. A General Synthesis of 3,8-Enoxy-7-keto-6-oxabicyclo[3.2.1]octane Derivatives: T. Suzuki, A. Tomino, S. Kagaya, K. Unno, and T. Kametani, Heterocycles, 9, 1263 - 1269 (1978).

759. Modified Total Synthesis of Arborine, Glycosminine, and Glomerine by Condensation of Sulfinamide Anhydride with Thioamides: T. Kametani, C. V. Loc, M. Ihara, and K. Fukumoto, Heterocycles, 9 , 1585 - 1591 (1978).

760. An Approach to the Skeleton of Rauwolfia Alkaloids: A General Synthesis of 3,8-Epoxy-7-keto-6-oxabicyc1o[3.2.1]octane Derivatives: T. Suzuki, S. Kagaya, A. Tomino, K. Unno, T. Kametani, T. Takahashi, and Y. Tanaka, Heterocycles, 9, $1749-1757$ (1978). 
761. The Correction of the Structure of Die1s-A1der Reaction Products of Furan Derivatives with Maleic Anhydride: T. Suzuki, A. Tomino, S. Kagaya, K. Unno, T. Kametani, M. Ihara, and T. Takahashi, Heterocycles, $\underline{9}, 1759-1762$ (1978).

762. Annelation Reaction by Using Heterocyclic Compounds: T. Kametani and'H. Nemoto, Heterocycles, $10,349-390$ (1978).

763. Total Syntheses of Natural Products from Five-membered Heterocyclic Compounds as Starting Materials: T. Kametani and K. Fukumoto, Heterocycles, $10,469-$ $553(1978)$.

764. Total Synthesis of $( \pm)$-Tubulosine and $( \pm)$-Deoxytubulosine: T. Kametani, Y. Suzuki, and M. Ihara, Heterocycles, 11 , 415 - 418 (1978).

765. ESR Spectra of Various Natura1 Fungi with an Anti-cancer Effect: T. Ogata, K. Oikawa, T. Fujisawa, Y. Suzukı, N. Tanaka, and T. Kametani, Oyo Yakuri, $\underline{15}, 133-135$ (1978).

766. Studies on the Syntheses of Heterocyclic Compounds. Part 738. Photo-oxygenation of 9-0xo-9ㅂ-pyrrolo[1,2-a ]indoles: T. Kametani, T. Ohsawa, M. Ihara, and K. Fukumoto, J. C. S. Perkin I, 1978, $460-464$.

767. Studies on the Syntheses of Heterocyclic Compounds. Part 744. A Synthesis of 1-Benzazocin-5-ones from 2,3-Dihydro-1ㅁ-pyrrolo[1,2-a ] indoles; a Synthetic Approach to the Mitomycins: T. Kametanı, K. Takahashi, M. Ihara, and K. Fukumoto, J.C.S. Perkin I, 1978, $662-666$.

768. The Asymetric Total Synthesis of Estradiol by an Intramolecular Cycloaddition Reaction of o-Quinodimethane: T. Kametani, H. Matsumoto, H. Nemoto, and K. Fukumoto, Tetrahedron Letters, 1978, $2425-2428$.

769. Convenient and Stereoselective Route to Basic Frameworks for Synthesis of Unsymetrical Pentacyclic Triterpenes: T. Kametani, Y. Hirai, Y. Shiratori, K. Fukumoto, and F. Satoh, J. Amer. Chem. Soc., 100, 554 - 560 (1978).

770. Asymmetric Total Synthesis of Estradiol by an Intramolecular Cycloaddition of Benzocyclobutene Derivative: T. Kametanx, H. Matsumoto, H. Nemoto, and K. Fukumoto, J. Amer. Chem. Soc., 100,6218-6220 (1978).

771. Studies on the Syntheses of Analgesics. Part 50. Synthesis of Optical1y Active 2-[4-(1-0xo-2-isoindolyny1)phenyl]propanoic Acid [Studies on the Syntheses of Heterocyclic Compounds. Part 742]: T. Kametani, K. Kigasawa, M. Hiiragi, H. Ishimaru, S. Haga, and K. Shirayama, J. Heterocyclic Chem., 15, $369-375(1978)$.

772. A New Method for Selective Epoxidation and a Biogenetic-Type Synthesis of 
Linalyloxides: T. Kametani, H. Nemoto, and K. Fukumoto, Bioorg. Chem., 7 , $215-220(1978)$.

773. Bioformation and Biotransformation of Isoquinoline Alklaoids and Related Compounds: T. Kametani, K. Fukumoto, and M. Ihara, Bioorg. Chem., II, 153 $174(1978)$.

774. An Ene Reaction During Thermolysis of a Benzocyclobutene: T. Kametani, Y. Shiratori, H. Inoue, M. Thara, K. Fukumoto, and F. Satoh, J. Indian Chem. Soc., 55, $1219-1223$ (1978).

775. Studies on the Syntheses of Heterocyclic Compounds. DCCLXXVI. Cyclisation Reaction of $\mathrm{N}$-Substituted Mandelohydrazide with Formaldehyde: T. Kametani, K. Kigasawa, M. Hi iragi, N. Wagatsuma, T. Kohagizawa, and H. Inoue, Yakugaku Zasshi, $\underline{99}, 135-140(1979)$.

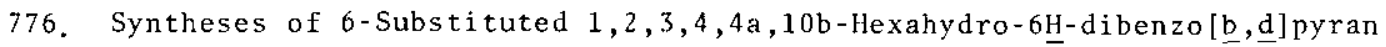
Derivatives (Studies on the Syntheses of Heterocyclic Compounds. DCCXCV): T. Kametani, K. Kigasawa, M. Hiiragai, H. Ishimaru, and T. Nakamura, Yakugaku Zasshi, 99, $752-756$ (1979).

777. Studies on the Syntheses of Chemotherapeutics. VII. Synthesis of 1,9b-Dihydro- $2 \underline{\mathrm{H}}, 4 \underline{\mathrm{H}}-2$-oxoazeto[1,2-c] [1,3]benzoxazine Derivatives (Studies on the Syntheses of Heterocyclic Compounds. DCCCXII): T. Kametani, K. Kigasawa, M. Hiiragi, K. Wakisaka, H. Sugi, and K. Tanigawa, Yakugaku Zas shi, 99, 1126 - $1131(1979)$.

778. Studies on the Synthesis of Chemotherapeutics. VIII. Stereoselective Synthesis of $1,9 \mathrm{~b}$-Dihydro- $2 \underline{\mathrm{H}}, 4 \underline{\mathrm{H}}-2$ - oxazeto $[1,2-\underline{\mathrm{c}}][1,3]$ benzoxazine- 4 -carboxyl $1 \mathrm{c}$ Acid Derivatives (Studies on the Syntheses of Heterocyclic Compounds. DCCCXCI): T. Kametani, K. Kigasawa, M. Hiiragi, K. Wakisaka, H. Sugi, and K. Tanigawa, Yakugaku Zasshi, 99, 1132 - 1140 (1979).

779. Synthetic Approach to the Grayanotoxins and Asebotoxines: A New Construction of $\mathrm{A}, \mathrm{B}$, and $\mathrm{C}$ Ring System of Grayanotoxan: T. Kametani, M. Tsubuki, H. Nemoto, and K. Fukumoto, Chem. and Pharm. Bu11. (Japan), 27, $152-157$ (1979).

780. Synthetic Studies on B-Lactam Antibiotics. II. Condensation of B-Lactams with Active Methylene Groups: T. Kametani, S. Hirata, H. Nemoto, M. Ihara, and $K$. Fukumoto, Heterocycles, $\underline{12}, 523-527$ (1979).

781. Synthetic Studies on B-Lactam Antibiotics. III. Synthesis of New Bicyclic B-Lactam Ring System 12-Oxo-4,8-dithia-1-azabicyclo[8.2.0]dodec-2-enes: T. Kametani, S. Yokohama, Y. Shiratori, F. Satoh, M. Ihara, and K. Fukumoto, Heterocycles, 12, $669-679$ (1979). 
782. The Synthesis of a Potential Intermediate to Apomitomycin: T. Kametani, Y. Kıgawa, H. Nemoto, M. Ihara, and K. Fukumoto, Heterocycles, 12, 685 $689(1970)$.

783. A Simpie and Facile Total Synthesis of Sesquiterpene Cuparene by Using Furan Derivatives: T. Kametani, M. Tsubuki, and H. Nemoto, Heterocycles, $\underline{12}$, $791-793(1979)$.

784. Studies on the Synthesis of Heterocyc1ic Compounds. 775. Synthesis of BLactams by Acid Chloride- and Phosphate Anhydride-Imine Methods: T. Kametani, S. Yokohama, Y. Shiratori, S. Aihara, and K. Fukumoto, Heterocycles, 12,405 - $414(1979)$.

785. Synthetic Studies on B-Lactam Antibiotics. IV. Synthesis of 1,9b-Dihydro$2 \underline{H}, 4 \underline{H}$-oxo-azeto[1,2-c] $[1,3]$ benzoxazine Derivatives: T. Kametani, K. Kigasawa, M. Hiiragi, K. Wakisaka, H. Sugi, and K. Tanigawa, Heterocycles, 12, $735-$ $740(1979)$.

786. Synthetic Studies on B-Lactam Antibiotics. VI. Synthesis of 7--Azeto[1,2a] thieno[2,3-c]pyridine Derivatives: T. Kametani, K. Fukumoto, K. Kigasawa, M. Hiiragaı, K. Wakisaka, K. Tanigawa, and H. Sugi, Heterocycles, 12, 741 744 (1979).

787. Synthetic Studies on B-Lactam Antibiotics, V. Stereoselective Synthesis of 1,9b-Dihydro-2ㅆ,4ㄱ-2-oxo-azeto[1,2-c] $\{1,3]$ benzoxazine-4-carboxylic Acid Derivatives: T. Kametani, K. Krgasawa, M. Hiiragi, K. Wakisaka, H. Sugi, and $K$. Tanigawa, Heterocycles, $12,795-800$ (1979).

788. Drug Interactions of Cephalosporin Derivatives with Gabexate Mesilate: K. Unno, T. Suzuki, K. Ataku, H. Nakata, A. Tomino, and T. Kametani, Heterocyc1es, $\underline{12}, 801-810$ (1979).

789. Studies on the Syntheses of Heterocyclic Compounds. 792. Biomimetic Synthesis of Protoberberien Alkalo1ds and Aporphine Alkaloids through $\underline{N}-0 x r d e$ Intermediate: T. Kametani and M. Ihara, Heterocycles, $12,893-896$ (1979).

790. Studies on the Syntheses of Heterocyclic Compounds. Part 791. A Synthesis of 1-Benzazocin-5-one Derivatives from a 1,2,3,4-Tetrahydrocyclopent[b]indole; a Synthetic Approach to Mrtomycins: T. Kametani, T. Ohsawa, and M. Ihara, Heterocyc1es, $\underline{12}, 913-916$ (1979).

791. Synthesis of Seco-mitosane Type compounds by Key Intermediates to Mitomycins: T. Kametani, K. Takahashi, M. Ihara, and K. Fukumoto, Heterocycles, 12, 933. $942(1979)$.

792. Regioselective Synthesis of Naphthacenequinones Using Sulfolene: S. Takano, 
S. Hatakeyama, K. Ogasawara, and T. Kametani, Heterocycles, 12, $1163-1169$ (1979).

793. The Fac1le Synthesis of an Important Key Intermediate for Synthesis of $( \pm)-8 S^{*}-$ Thienamycin - A Formal Total Synthesis of $( \pm)-8 \mathrm{~S}^{*}$-Thienamycin: $T$. Kametani, S.-P. Huang, and M. Ihara, Heterocycles, 12, $1183-1187$ (1979).

794. Total Synthesis of $( \pm)-8 S^{*}$-Descysteaminylthienamycin Protected with o-Nitrobenzy1 Groups: T. Kametani, S. - P. Huang, and M. Ihara, Heterocycles, 12 , $1189-1190(1979)$.

795. A Stereoselective Formal Total Synthesis of Thienamycin: T. Kametani, S,-P. Huang, Y. Suzuki, S. Yokohama, and M. Ihara, Heterocycles, 12, 1301 - 1303 (1979).

796. A Synthetic Approach to Reserpine and Related Compounds: T. Suzuki, A. Tomino, S. Kagaya, K. Unno, and T. Kametani, Heterocycles, 13, 203 - 208 (1979).

797. Studies on the Syntheses of Heterocyclic Compounds. Part 808. Total Synthesis of ( \pm ) - $\underline{0}$-Methyltubulosine: T. Kametani, Y. Suzuki, and M. Ihara, Heterocycles, $\underline{13}, 209-215$ (1979).

798. Stereoselective Synthesis of Yohimbane and Alloyohimbane: T. Suzuki, A. Tomino, K. Unno, and T. Kametani, Heterocycles, 13, $301-305$ (1979).

799. Synthetic Studies on Mitomycins and Related Compounds: K. Takahashi and T. Kametani, Heterocycles, 13, $411-467$ (1979).

800. Chemical and Biochemical Aspects of Isoquinoline Alka1oids: T. Kametani and M. Ihara, Heterocycles, $13,497-530$ (1979).

801. Syntheses of Natural Products by Ring Opening Reaction of Five-membered Heterocyclic Compounds: T. Kametani and K. Fukumoto, Kagaku no Ryoiki Zokan, $\underline{123}, 153-189(1979)$.

802. Syntheses of Physiologically Active Nitrogen compounds__ Syntheses of Analgesics Having 6,7-Benzomorphan System: T. Kametani and K. Fukumoto, Kagaku, 34, $105-113$ (1979).

803. Physiological Activity of Aza Organic Compounds _- Syntheses of Morphinetype Analgesics: T. Kametani and K. Fukumoto, Kagaku Zokan, 79, $77-97$ (1979).

804. Synthesis of Tetracyclic Antibiotics _- Tetracyclines and Anthracyclines:

T. Kametani and K. Fukumoto, Kagaku Kogyo, 30, 1023 - 1031 (1979). 
805. Studies on the Syntheses of Heterocyclic Compounds. Part 766. A Total Stereoselective Synthesis of Emetine and ( \pm )-Dihydroprotoemetine: T. Kametani, Y. Suzuki, H. Terasawa, and M. Ihara, J.C. S. Perkin I, 1979, $1211-1217$.

806. Studies on the Syntheses of Heterocyclic Compounds. Part 777. A Synthetic Approach to Seco-mitrosane Type of Compound Related to Mitomycins: T. Kametani, K. Takahashi, M. Ihara, and K. Fukumoto, J. C. S. Perkin 1, 1979, 1847 - 1851.

807. Total Synthesis of $14 \alpha$-Hydroxyestrone 3-Methyl Ether: T. Kametani, H. Nemoto, M. Tsubuki, G.-E. Purvaneckas, M. Aizawa, and M. Nishiuchi, J. C. S. Perkin I, $\underline{1979}, 2830-2835$.

808. Studies on the Syntheses of Heterocyclic Compounds. Part 796. A New Synthesis of Isochroman-3-ones from Benzocyclobutenes; An Application to a Total Synthesis of Sendaverine: T. Kametani, Y. Enomoto, K. Takahashi, and K. Fukumoto, J.C. S. Perkin I, 1979, 2836 - 2839.

809. An Asymmetric Total Synthesis of Steroid Hormones: An Efficient Route to

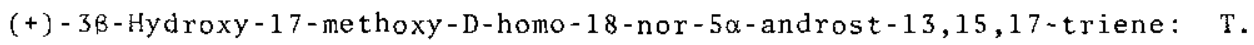
Kametani, K. Suzuki, and H. Nemoto, J. C. S. Chem. Comm., 1979, $1127-1128$.

810. A New Method for Carbon-Carbon Bond Formation: A Biogenetic-type Synthesis of Safranal: T. Kametani, K. Suzuki, H. Kurobe, and H. Nemoto, J. C. S. Chem. Comm., 1979, $1128-1129$.

811. Studies on the Syntheses of Heterocyclic Compounds. 762. Synthesis of 3Benzy1-6-methy1-2-oxo-3,6-diazabicyc1o[3.1.0]hexane as a Synthetic Intermediate of Mitomycins: T. Kametani, Y. Kigawa, and M. Ihara, Tetrahedron, $\underline{35}, 313-316(1979)$.

812. Nove1 Stereoselective Total Synthesis of $14 \alpha$-Hydroxyestrone Methyl Ether: T. Kametani, H. Nemoto, M. Tsubuki, and M. Nishiuchi, Tetrahedron Letters, $\underline{1979}, 27-30$.

813. Studies on the Syntheses of Heterocyclic Compounds. Part 803. Transformation of 1,2,3,4-Tetrahydrocyclopent [b] indole into a 2,3-Dihydro-1ㅂ-pyrrolo[1,2a] Indole through 1-Benzazocin-5-one Derivatives; A Synthetic Approach to Mitomycins: T. Kametani, T. Ohsawa, and M. Thara, J. Chem. Res., 1979, 364 - 365 .

814. Stereoselective Total Synthesis of the Tetracyclic Diterpenes Hibaol and Dihydrohibaene: T. Kametani, K. Suz̃uki, H. Nemoto, and K. Fukumoto, J. Org. Chem., 44, 1036 - 1043 (1979).

815. Studies on the Synthesis of Analgesics. Part 51. Synthesis of 4-(1-0xo-2- 
isoindolyl)phenyl Derivatives [Studies on the Syntheses of Heterocyclic Compounds. Part 779]: T. Kametani, K. Kigasawa, M. Hiiragi, H. Ishimaru, T. Nagakura, and K. Shirayama, J. Heterocyclic Chem., 16, 581 - 584 (1979).

816. Studies on the Syntheses of Heterocyclic Compounds. Part 782. Another Total Synthesis of $( \pm)$-Tubulosine and $( \pm$ )-Deoxytubulosine: T. Kametani, Y. Suzuki, and M. Ihara, Canad. J. Chem., 57, $1679-1681$ (1979).

817. Total Syntheses of Natural Products by Thermolysis: T. Kametani, Pure Appl. Chem., $51,747-768$ (1979).

818. Studies on the Syntheses of Drugs Acting on Circulatory System. 1. Synthesis of 1-Substituted 3,7-Dimethylxanthine (Studies on the Syntheses of Heterocyclic Compounds. Part DCCCXXIV): T. Kametani, K. Kigasawa, M. Hiiragi, N. Wagatsuma, T. Uryu, and H. Inoue, Yakugaku Zasshi, 100, 192 $199(1980)$.

819. Facile Synthesis of Indolo[2,3-a]quinolizine Derivatives (Studies on the Syntheses of Heterocyclic Compounds DCCCXXXV): T. Kametani, T. Nagahara, S. - P. Huang, and M. Ihara, Yakugaku Zasshi, 100, $530-534$ (1980).

820. Studies on the Syntheses of Antispasmodic Agnet. IV. Synthesis of 2-Cyclohexy1- $\gamma$-pheny1-c- and-t-4-piperidinomethyl-1,3-dioxolan Methiodide (Studies on the Syntheses of Heterocyclic Compounds. DCCCXLVI): T. Kametani, K. Kigasawa, M. Hiiragi, H. Ishimaru, T. Nakamura, K. Shirayama, Yakugaku Zasshi, $100,760-763(1980)$.

821. Studies on the Syntheses of Drugs Acting on Circulatory System. II. Stereoselective Reduction of $\alpha$-Aminopropiophenone Derivatives with Sodium Borohydride (Studies on the Syntheses of Heterocyclic Compounds. DCCCLIII): T. Kametani, K. Kigasawa, M. Hiiragi, N. Wagatsuma, T. Kohagizawa, and H. Inoue, Yakugaku Zasshi, $100,839-843(1980)$.

822. Studies on the Syntheses of Drugs Acting on Circulatory System. III. Synthesis of 2-(4-Benzylpiperidino)-1-(4-hydroxyphenyl)propanol and the Determination of the Related Configuration of These Diastereoisomers (Studies on the Syntheses of Heterocyclic Compounds. DCCCLIVI): T. Kametani, K. Kigasawa, M. Hiiragi, N. Wagatsuma, T. Kohagizawa, and H. Inoue, Yakugaku Zasshi, 100,844 - $854(1980)$.

823. Studies on the Syntheses of Analgesics. LII. Synthesis of 4a-(3-Substituted pheny1)-1,2-disubstituted Decahydrocinnoline Derivatives (Studies on the Syntheses of Heterocyclic Compounds. DCCCLIII): T. Kametani, K. Kigasawa, M. Hi iragi, H. Ishimaru, N. Wagatsuma, 'T. Kohagizawa, and T. Nakamura, Chem. and Pharm. Bull. (Japan), 100, 64! - 648 (1980). 
824. Studies on the Syntheses of Analgesics.lili. Synthesis of 3-(4-Substituted pheny 1)-2-oxo-butanamide Derivatives (Studies on the Syntheses of Heterocyclic Compounds. DCCCXLV): T. Kametani, K. Kigasawa, M. Hiiragi, H. Ishimaru, T. Nakamura, and K. Shirayama, Chem. and Pharm. Bu11. (Japan), 100, $649-656$

825. Synthetic Studies on B-Lactam Antibiotics. XIV. Synthesis of 7H-Azeto-[1,2a] thieno[2,3-c]pyridine Derivatives: T. Kametani, K. Kigasawa, M. Hiiragi, K. Wakisaka, H. Sugi, and K. Tanigawa, Chem. and Pharm. Bull. (Japan), 28, 1196 - 1199 (1980).

826. Synthetic Approach to the Quassinoid K1aineanone -- The Synthesis of a Potential Intermediate by Intramolecular Cycloaddition: T. Kametani, M. Chihiro, T. Honda, K. Fukumoto, Chem. and Pharm. Bull. (Japan), 28, 2468 2475 (1980).

827. A Novel Synthesis of Indole Derivatives: T. Kametani, T. Ohsawa, and M. Ihara, Heterocycles, 14, $277-280$ (1980).

828. The Total Stereoselective Retro Mass Spectral Synthesis of $( \pm)$-Emetine: T. Kametani, S. A. Surgenor, and K. Fukumoto, Heterocycles, 14, $303-310$ (1980).

829. An Improved Synthesis of an Intermediate for Thienamycin Synthesis: $T$. Kametani, T. Nagahara, Y. Suzuki, S. Yokohama, S.-P. Huang, and M. Ihara, Heterocycles, 14, $403-406$ (1980).

830. Facile Formation of the Basic Skeletons of Naturally Occurring Terpenoidal Lactones: T. Kametani, T. Honda, and K. Fukumoto, Heterocycles, 14, 419 $422(1980)$.

831. A Synthetic Approach to Ervitsine-A. General Synthesis of 2-Indolylnyridine Derivatives: T. Suzuki, E. Sato, K. Goto, K. Unno, and T. Kametani, Heterocycles, 14, $433-437$ (1980).

832. A Synthetic Approach to Important Intermediates of Reserpine and Yohimbine --- Synthesis of Non-tryptamine Components from Furfural: T. Suzuki, A. Tomino, K, Unno, and T. Kametani, Heterocycles, 14, $439-444$ (1980).

833. Novel Type of Analgesics - Synthesis of Analgesic Activity: T. Kametani, K. Kigasawa, M. Hirragi, H. Ishimaru, N. Wagatsuma, T. Kohagizawa, and T. Nakamura, Heterocycles, $14,449-451$ (1980).

834. A New Carbon-Carbon Bond Formation Reaction at the C-4 Position of a B-Lactam: T. Kametani, T. Honda, J. Sasaki, H. Terasawa, Y. Nakayama, and K. Fukumoto, Heterocycles, $14,575-578$ (1980).

835. The Stereoselective Reduction of $\alpha$-Aminopropiophenone Derivatives with Sodium 
Borohydride: T. Kametani, K. Kigasawa, M. Hiiragi, N. Wagatsuma, T. Kohagizawa, and $\mathrm{H}$. Inoue, Heterocycles, 14, 775 - 778 (1980).

836. Synthesis of a Potentical Intermediate to Apomitomycins: T. Kametani, Y. Kigawa, H. Nemoto, M. Ihara, and K. Fukumoto, Heterocycles, $14,799-807$ (1980).

837. Synthesis of $( \pm\}$-Kreysiginone, a Homoaporphine and homoprotoberberines via N-Oxide Intermediates: T. Kametani, M. Ihara, M. Takemura, and Y. Satoh, Heterocycles, $14,817-825(1980)$.

838. A Facile Synthesis of $( \pm)$-Camptothecin by Enamine Annelation: T. Kametani, T. Ohsawa, and H. Ihara, Heterocycles, 14, $951-953$ (1980).

839. Biotransformation of Isoquinoline Alkaloids with Rat Liver Microsomes: T. Kametani, N. Kanaya, Y. Ohta, and M. Ihara, Heterocycles, 14, $963-970$ (1980).

840. An A1ternative Total Synthesis of $( \pm)$-Thienamycin: T. Kametani, S. -P. Huang, T. Nagahara, and M. Ihara, Heterocycles, 14, 1305 - 1308 (1980).

841. A Novel Synthesis of 6-Azapurines by the Oxidative Cyclization of Azahexa trienes with Diethyl Azodicarboxylate: T. Kametani, M. Higuchi, M. Noguchi, Y. Hashiguchi, and F. Yoneda, Heterocycles, 14, $1295-1300$ (1980).

842. Pharmaceutical Industry in 1980: T. Kametani and K. Kigasawa, Kagaku Kogyo, $\underline{31}, 57-59(1980)$.

843. Total Synthesis of Natural Products via Intramolecular Diels-Alder Reactions: T. Kametani and K. Fukumoto, Farumashia, 16, $295-299$ (1980).

844. Synthesis of Natural Products: T. Kametani, Modern Chemistry (Gendai Kagaku), vo1.14, Chapter II. pp. 313 - 386, Iwanami Shoten, 1980.

845. Alka1oid Formation through $\mathrm{N}$-Oxide Intermediate; Regioselective Synthesis of $( \pm)$-Corytuberine by Redox Reaction: T. Kametani and M. Ihara, J. C. S. Perkin I, $1980,629-632$.

846. A Simple and Efficient Total Synthesis of the Sesquiterpenes Cuparene and Iso$\alpha$-curcumene from Furan Derivatives: T. Kametani, M. Tsubuki, and H. Nemoto, J. C. S. Perkin I, $1980,759-761$.

847. Total Synthesis of (+)-5 $\alpha$-Dihydropregnenolone via Acetylene-Cation Cyclization: T. Kametani, K. Suzuki, and H. Nemoto, Tetrahedron Letters, 1980, $1469-1470$.

848. Stereoselective Synthesis of the Basic Skeleton of Aphidicolan Diterpenes: 
Synthetic Approach to Aphidicolin: T. Kametani, T. Honda, Y. Shiratori, and K. Fukumoto, Tetrahedron Letters, 1980, 1665 - 1666.

849. Studies on the Syntheses of Heterocyclic Compounds 800 . A Formal Tota1 Synthesis of $( \pm)$-Thienamycin and a $( \pm)$-Descysteaminylthienamycin Derivative: $T$. Kametani, S.-P. Huang, S. Yokohama, Y. Suzuki, and M. Ihara, J. Amer. Chem. Soc., 102, $2060-2065$ (1980).

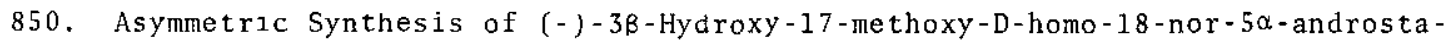
13,15,17-triene: T. Kametani, K. Suzuk1, and H. Nemoto, J. Org. Chem., $\underline{45}$, $2204-2207(1980)$. 